Portland State University

PDXScholar

Spring 9-1-2017

\title{
Sampling Fish: a Case Study from the Čixwicən Site, Northwest Washington
}

Laura Maye Syvertson

Portland State University

Follow this and additional works at: https://pdxscholar.library.pdx.edu/open_access_etds

Part of the Archaeological Anthropology Commons Let us know how access to this document benefits you.

\section{Recommended Citation}

Syvertson, Laura Maye, "Sampling Fish: a Case Study from the Cíxwicən Site, Northwest Washington" (2017). Dissertations and Theses. Paper 3941.

https://doi.org/10.15760/etd.5825

This Thesis is brought to you for free and open access. It has been accepted for inclusion in Dissertations and Theses by an authorized administrator of PDXScholar. Please contact us if we can make this document more accessible: pdxscholar@pdx.edu. 
Sampling Fish: A Case Study from the Číx ${ }^{\mathrm{W}}$ icən Site, Northwest

Washington

by

Laura Maye Syvertson

A thesis submitted in partial fulfillment of the requirements for the degree of

\author{
Master of Science \\ in \\ Anthropology
}

Thesis Committee:

Virginia L. Butler, Chair

Kenneth M. Ames

Shelby L. Anderson

Ian Dinwoodie

Portland State University

2017 


\begin{abstract}
Researchers on the Northwest Coast (NWC) are often interested in complex questions regarding social organization, resource intensification, resource control, and impacts of environmental change on resources and in turn human groups. However, the excavation strategies used on the NWC often do not provide the spatial and chronological control within a site that is necessary to document their variability and answer these research questions. The Čî́x ${ }^{\mathrm{w}}$ icon site has the potential to address some of the limitations of previous Northwest Coast village site excavations because of its unique and robust sampling strategy, the wide expanse of time that it was occupied, and the multiple house structures present. An on-going project is examining changing human ecodynamics over the breadth of site occupation, focusing on zooarchaeology and geoarchaeological records.
\end{abstract}

This site, located on the Strait of Juan de Fuca in Port Angeles, WA was excavated in 2004 as part of a Washington State Department of Transportation (WSDOT) undertaking to build parts for the Hood Canal Bridge Large scale excavation $\left(261.4 \mathrm{~m}^{3}\right.$ $528 \mathrm{~m}^{2}$ ) generated enormous quantities of faunal remains. Radiocarbon dates and historic records show occupation extends from 2750 cal. BP to the early $20^{\text {th }}$ century.

Statistical sampling methods provide an empirical way to maximize the amount of information obtained with the least amount of effort. My thesis addressed the utility of Sampling to Redundancy (STR) as a statistical sampling method for sampling faunal remains from large village sites. My project has documented the variability of fish family representation across time and space in one part of the Číi ${ }^{\mathrm{w}}$ icən village, while minimizing the time and effort required to do so. This thesis applies STR to "S" $(>1 / 4$ 
in.) 10 Liter bucket samples from eight excavation units and a total of 26 separate unique temporal and spatial contexts. I focused on 1/ 4 in. samples for my study for a particular reason. Previous fish faunal studies have focused on effects of mesh size on fish representation; and emphasized the need to use fine mesh (e.g., $1 / 8$ in. or finer) to document small-bodied fishes. This focus on fine mesh typically means that only limited volumes of matrix are studied, which in turn may mean that remains of rarer, largebodied fishes are under- represented. The on-going research project has focused on buckets screened to $1 / 8$ in. mesh (called "C" buckets). I used STR to sample additional volumes of matrix screened to $1 / 4$ in. to examine whether expanding the volume studied would affect fish representation, which was a second goal of my project.

Overall, I studied remains from 269 "S" buckets out of a total of 419 buckets, or $47 \%$ of the buckets. STR was most helpful for six of the high bone abundance and density contexts, where I analyzed less than $50 \%$ of the total buckets, was moderately helpful for 14 contexts, and not at all helpful for the six contexts with low fishbone abundance, where I analyzed $100 \%$ of the buckets. This analysis took me a total of 154 hours, and based on the percentage of material analyzed, 174 hours were saved.

As to the second project goal, to assess whether adding fish remains documented from additional matrix volume affected fish representation, I found the differences were minimal. Both for my study units as a whole, and for each time period, adding the fish records from the "S" buckets did not alter the main trends in fish representation as documented by the larger study, using a smaller volume. To further examine whether the added volume from $>1 / 4$ in "S" buckets affected results, I explored specific research questions that are relevant to the larger project regarding environment-animal interactions 
and fishbone deposition and bone condition inside and outside of a house structure. Adding the "S" bucket samples did not affect fish representation or fishbone distribution and condition, which affirms that the sampling strategy used in the larger research project was sufficient in most cases to characterize the fish record at the site.

My approach to STR has focused on fish remains that were previously excavated from a Pacific coastal village site with dense archaeological deposits. STR could be employed in other types of archaeological settings in a range of environments (coast or interior) representing a range of cultural contexts (from hunting camps to urban centers) to establish sample redundancy after an excavation is complete. STR could be used during on-going excavation. Further research is required to explore the implications of STR in these settings, however it is likely that the success of STR in other contexts will be dependent on the density and overall abundance of remains, the diversity or material types being studied, as well of course in the range and specificity of questions in each case. 


\section{Acknowledgements}

There are many people, without whom this thesis would not have been possible, and I owe a great debt of gratitude to all of them for their support, guidance and assistance. First and foremost I would like to thank my advisor, Dr. Virginia Butler. Her unwavering enthusiasm and support for this project has made every challenge surmountable, and her whole hearted support for me as her student has encouraged me to strive harder to be the best at whatever task is at hand. I would also like to thank the Lower Elwha Klallam Tribe for their support of this project, whose support is essential for all the research on their homeland. To that end I would also like to thank the Washington Department of Transportation, and the Burke Museum for allowing me access to the collections used in this project. I would particularly like to thank Laura Phillips, who has been such an amazing advocate for me and my project. To all of the PIs on the Číx ${ }^{\mathrm{w}}$ icən project, Virginia Butler, Sarah Campbell, Kris Bovy, Mike Etnier, and Sarah Sterling, thank you so much for getting this project started in the first place, and for providing the groundwork that has made my project possible. I would also like to thank the National Science Foundation for their financial support of the Čî́x ${ }^{w}$ icən project. There have also been several students who have helped to make this project possible. Reno Nims, thank you for being my fishbone student mentor, my first line of quality control during my analysis, and for being a living human being to talk to in that windowless basement room where we both spent so many hours. To Justin Junge, Jonathan Duelks, and Brian Crabtree, thank you for your help with the re-screening process. Your extra hands made it possible for me to stick to my timeline and get everything back to the Burke on time. I would like to thank the members of my committee. Ken Ames, Shelby Anderson, and Ian 
Dinwoodie, each of you brings different and valuable insight to this project. Your expertise and thoughtful comments are what make this project everything that it is. There are also several individuals who are more indirectly responsible for the success of this thesis research. Among these, I would first like to thank my mentor and friend Mike Etnier. As the first zooarchaeologist in my life, you are the reason I work with bones. Thank you for taking a chance on me all those years ago, and giving me my zooarch foundation. To Sarah Campbell, my undergraduate advisor and mentor, you have provided me with my foundation in archaeology and I will be forever grateful and indebted to you for that. I also want to thank you for giving me my start with sampling to

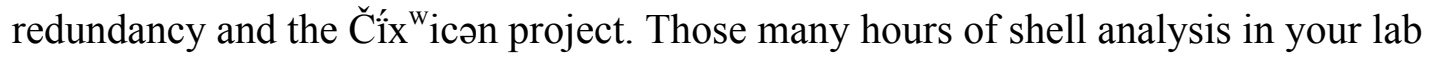
were an experience I will never forget. My partner Jonathan Thom, your undying support through this graduate school experience means the world to me. You have been there for me from beginning to end, watched me in joy and frustration, poured late night coffee and toasted my milestones with celebratory beer.

I would also like to thank the other graduate students in the Anthropology department. You have commiserated and celebrated the challenges of this program with me. Without your support and comradery I would be coming out the other side much less sane. Thank you to my parents Jim and Sue. Your belief in the importance of education have guided me to what I hope is a lifelong journey of learning and your cheerleading from afar has kept my spirits high. 


\section{Table of Contents}

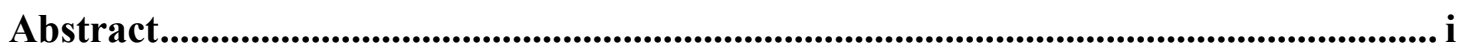

Acknowledgements .............................................................................................................. iv

List of Figures............................................................................................................................... viii

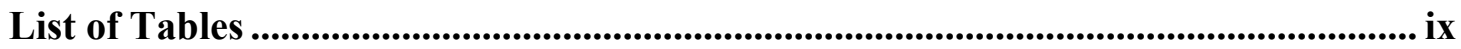

Chapter 1. Introduction .................................................................................................... 1

Chapter 2. Background ................................................................................................................... 5

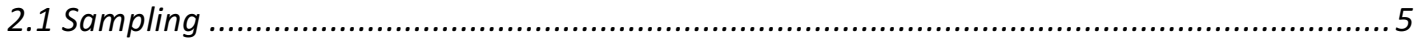

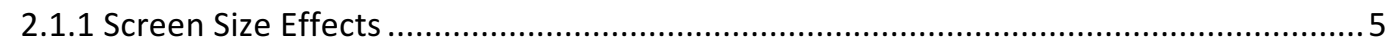

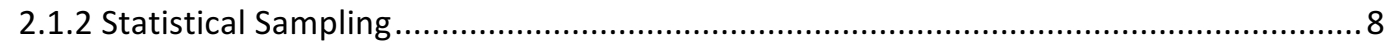

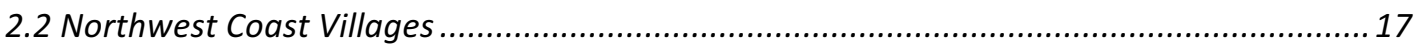

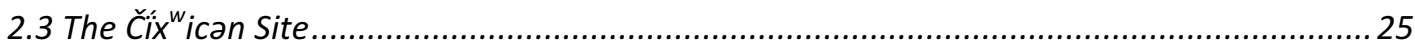

Chapter 3. Methods and Materials.............................................................................................. 31

Chapter 4. Results .............................................................................................................. 43

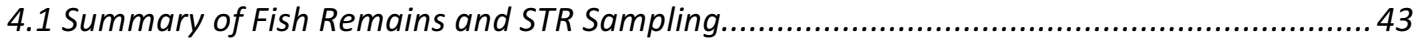

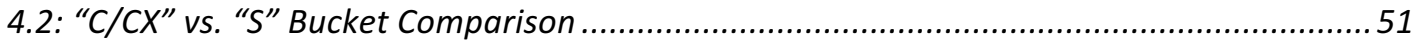

4.2.1 How does adding the " $\mathrm{S}$ " buckets affect interpretation of earthquake impacts? .......57

4.2.2 How does adding " $\mathrm{S}$ " buckets affect interpretation of fishbone densities and

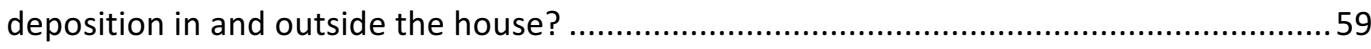

Chapter 5. Discussion ................................................................................................................. 64

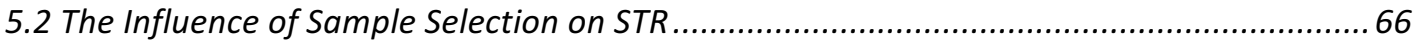

5.3 Applying this Method to the Northwest Coast and Beyond ...........................................6 


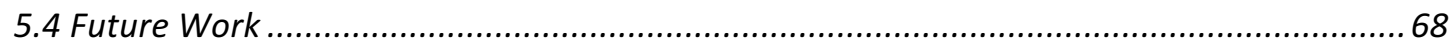

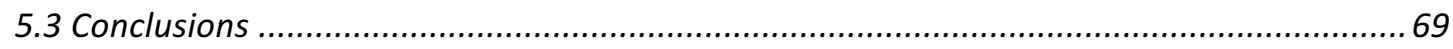

References Cited....................................................................................................................... 72

Appendices.................................................................................................................................... 87

Appendix A. On the Determination of Sample Sizes in Stratified Data ................... 87

Appendix B. Description and overview of Re-screening Process ............................ 93

Appendix C. List of cranial, paired fin, and vertebral elements included in fishbone

analysis. From Butler In Preparation ......................................................................... 107 


\section{List of Figures}

Figure 1. Location of the Číx ${ }^{w} i c ə n$ Site. 3

Figure 2. Cumulative richness of mammalian genera across cumulative annual samples (NISP) from the Meier site. Number adjacent to plotted points are cumulative NISP (Lyman and Ames 2007; Lyman 2008).

Figure 3. Číx ${ }^{\mathrm{w}}$ icən (45CA523) showing location of Areas and excavation units from 2004 project.

Figure 4. Map of Čî́x ${ }^{\mathrm{w}}$ icən showing areas included in NSF project. 30

Figure 5. Map of Area A4 showing excavation units chosen for STR study. Dotted line indicates approximate boundary of structure.

Figure 6. Flow chart showing the process for selecting "S" bucket samples and analysis to reach redundancy of proportional representation of fish family, outlined for unit $17, \mathrm{CZ} 5$.

Figure 7. Percent NISP analyzed by unit/CZ, "S" buckets.

Figure 8. Scatterplot showing relationship between "S" bucket Density (NSP/liter) and chronozone for unit/CZs.

Figure 9. Scatterplot showing the relationship between density (NSP/Liter) and percentage of buckets analyzed for each unit/CZ.

Figure 11. Proportional representation of fish families (\% NISP) from " $\mathrm{C} / \mathrm{CX}$ " buckets (> $1 / 4$ in only) as compared with proportional representation of fish families from "C/CX" + "S" buckets..

Figure 12. Hexagrammid Index for "C/CX" buckets and "C/CX" + "S" buckets. 60

Figure 13. Comparison of fishbone density (NSP/liter) inside and outside the house from $\mathrm{CZ} 4$, based on "C/CX" buckets vs. "C/CX+S" buckets. 63

Figure 14. Fragmentation (NISP/NSP) of fish remains inside and outside the household in A4 CZ 4 comparing "C/CX" vs. "C/CX"+ "S" Buckets. 


\section{List of Tables}

Table 1. NWC example projects highlighting fish remains recovered from column and bulk samples that illustrate the effect of mesh size on fishbone recovery. Number of identified specimens (NISP; number of identified specimens assigned to a taxon finer than class) from $1 / 4$ in. and 1/8 in. screens.

Table 2. Frequency (NISP) of select large and small-bodied taxa from four 10 liter buckets screened using 1/8 in. nested screens at the Číxwicon site (Butler, personal communication).

Table 3. Northwest Coast village sites, corresponding excavation strategies and mesh size used. 22

Table 4. List of chronozones and date ranges for the Číx ${ }^{w}$ icən Site 31

Table 5. Characteristics of units selected for analysis 35

Table 6. Number of "C/CX" and "S" Buckets by unit/CZ . 36

Table 7. List of taxa represented at Čîx ${ }^{w}$ icon within the order Scorpaeniformes 38

Table 8. Comparison of NISP between "Observed" vs. "Adjusted" values from unit $17 / \mathrm{CZ} 6$, to illustrate how adjusted values were obtained for all unit/CZs. Sampling ceased at 12 out of 29 buckets, thus the multiplier required to "adjust" for family NISP is 2.41 . 42

Table 9. Frequency (NISP) of fish taxa from "S" buckets

Table 10. Summary information about fish remains and "S" buckets from each unit/CZ

Table 11. Comparison of fishbone density (NSP/liter) between " $\mathrm{S}$ " and "C/CX" buckets. Values listed for "S" buckets represent those remains directly "observed" and tallied rather than those whose values were adjusted to account for variable volume of matrix studied in a given unit/CZ (see Table 8).

Table 12. Comparison of fish representation (\%NISP) between "S", "C/CX", and "C/CX" + "S" buckets from study units.

Table 13. Comparison of fish family rank order between "C/CX" and "C/CX"+"S" Buckets by CZ using Spearman's Rho Correlation

Table 14. Comparison of family richness in "C/CX" vs. "C/CX" + "S" Buckets 58 
Table 15. Frequency and Density (NSP/liter) of fishbones in CZ 4, within and outside the

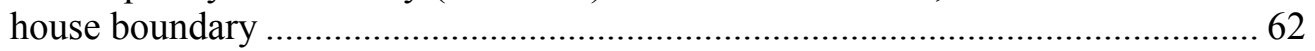




\section{Chapter 1. Introduction}

Researchers on the Northwest Coast (NWC) are often interested in complex questions regarding social organization, resource intensification, resource control, and impacts of environmental change on resources and in turn human groups (Ames and Maschner 1999; Ames 2001, 2007, 2008; Butler and Campbell 2004; Campbell and Butler 2010; Coupland 1996; Grier 2001; Matson et al. 1999; Matson et al. 2003; Moss 1993; Moss 2011). Researchers often use village site excavations to explore these questions. One would ideally have large samples from multiple contexts within and between houses from village sites, but this is generally not the case (Gray 2008; Monks 2000). Gray (2008) has noted that the excavation strategies used often do not provide the spatial and chronological control within a site that is necessary to capture their variability. Moreover, the total volume of material sampled is often very small. It is imperative that archaeologists explore alternative approaches to sampling that address the concerns of both sample control and sample size.

The main goal of my thesis is to demonstrate how Sampling to Redundancy (STR) can address the concerns of increasing sample size to a level that adequately represents population characteristics. Besides providing a way to make the most efficient use of resources (time and cost), STR could be used to identify locales that would benefit from more intensive sampling. I will use STR to sample the extremely large faunal assemblage recovered from the Číx ${ }^{w}$ ic WA, and in so doing, demonstrate these values. 
A large National Science Foundation (NSF)-funded zooarchaeological and geoarchaeological project began in 2012 to study changing human ecodynamics over the breadth of occupation at the Čî́x ${ }^{w}$ icon site (e.g. Mohlenhoff and Butler 2016) (Figure 1). Materials collected during the 2004 excavation were processed using nested screens, some ending at $1 / 4 \mathrm{in}$. mesh and some ending at $1 / 8 \mathrm{in}$. mesh (Reetz et al. 2006). To study animal use, the researchers focused attention on faunal remains collected from $10 \mathrm{~L}$ buckets screened to $\geq 1 / 8$ in. While the $\geq 1 / 8$ in. nested screen samples represent large quantities of fauna, they comprise a fraction of the total volume of matrix collected from the site. Moreover, remains of large-bodied vertebrates, like birds, mammals and even large fishes are rare in deposits, relative to small fishes. For this reason, mammal and bird faunal analysts have included additional $10 \mathrm{~L}$ bucket samples screened to $1 / 4 \mathrm{in}$. to increase their sample size. It would be useful to know if the $1 / 8$ in samples mainly used by the NSF project were adequate for representing the rarer, larger fish. My thesis project addressed this need by using STR to study fish remains recovered from a sample of the $>1 / 4$ in. bucket samples. The project thus will highlight the potential of using STR in faunal analysis, and at the same time allow me to assess whether the $>1 / 8$ in. buckets were sufficient to characterize abundance of relatively large-bodied fishes. 


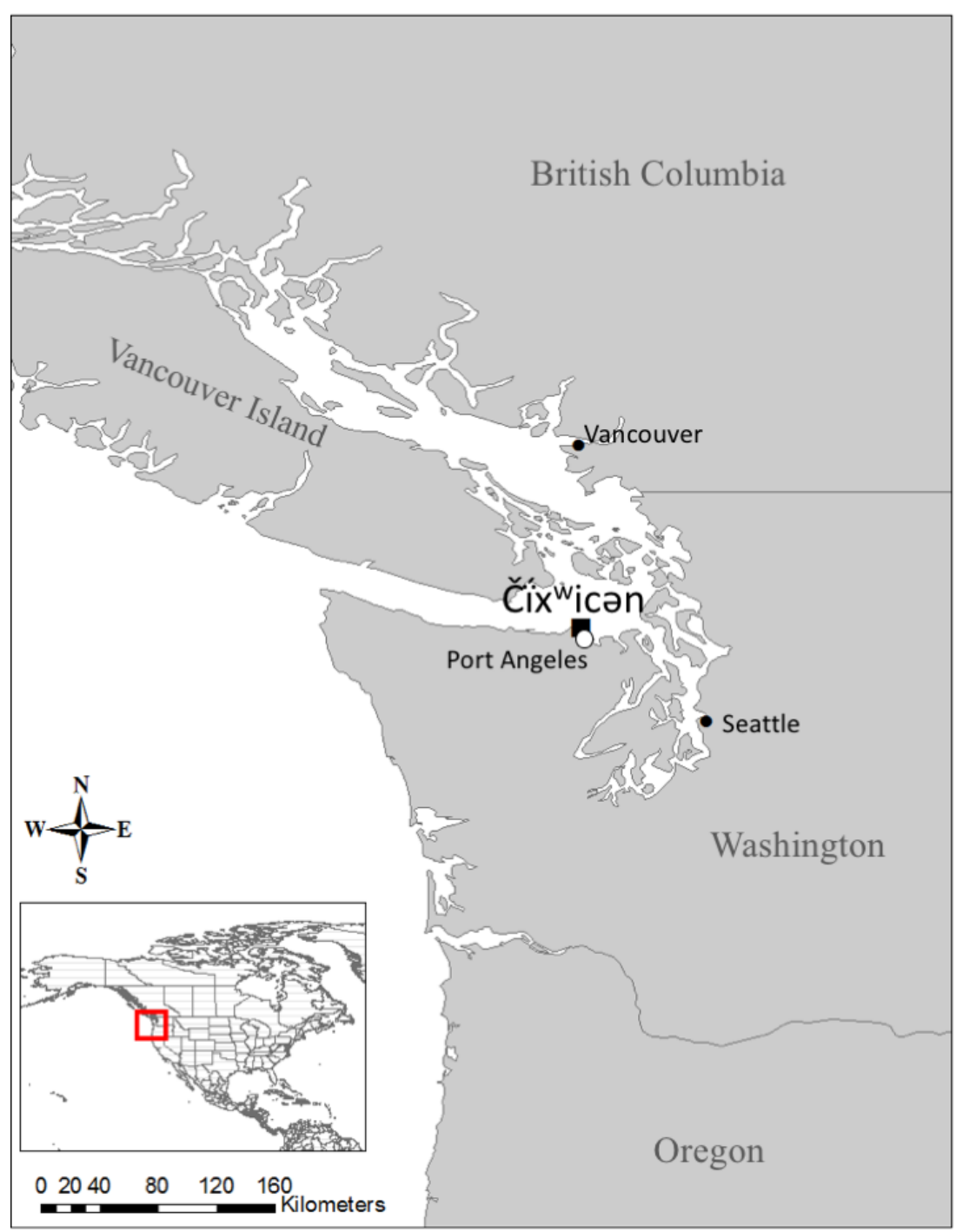

Figure 1. Location of the Číx ${ }^{\mathrm{w}}$ icən Site.

This thesis is organized into five chapters. Chapter 2 presents background information on sampling statistics, previous approaches to sampling Northwest Coast

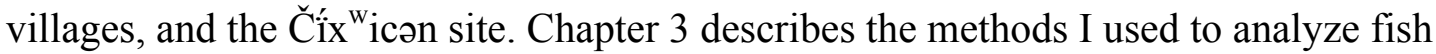
remains, focusing on how I used STR to establish redundancy in proportional representation for fish families present in the units included in my study. In Chapter 4, I summarize my results, including the time savings that STR provided for the analysis of fish remains collected using $>1 / 4$ in. mesh. I compare the results from my study with 
those obtained from previous faunal analysis at Číx $\mathrm{x}^{\mathrm{w}} \mathrm{icən}$ to see whether adding volume affects proportional representation of fish. To further examine whether the added volume from $>1 / 4$ in samples affects fish representation, I explore specific research questions that are relevant to the larger NSF project regarding environment-animal interactions and site use. The first question will address whether kelp-adapted fish taxa, such as greenling (Hexagrammidae) are adversely affected by earthquakes. I examine change in greenling abundance relative to a migratory fish less likely affected by earthquakes, dogfish (Squalidae), against the timing of a known earthquake. As the NSF project is also concerned with spatial patterning in animal remains and their link to site formation and social factors within and outside houses, I will compare-contrast fishbone distribution and density inside and outside a house structure, and in particular, whether increasing the sample size by adding the $>1 / 4$ in samples alters our understanding about cultural depositional practices and taphonomy. Chapter 5 considers the results in a larger context and discusses ways STR can be applied to sampling other Northwest Coast sites and in zooarchaeology generally. 


\section{Chapter 2. Background}

\subsection{Sampling}

Sampling can be applied at multiple levels, including regional survey, site excavation, and lab analysis. The type of sampling method used in each of these stages affects how the spatial and stratigraphic contexts are selected for examination, and the overall amount of examined area and material. One must select a sampling methodology to assess how large a sample is needed to answer the archaeological questions at hand and to select samples representative of the population of interest (Leonard 1987; Lyman and Ames 2007; Lyman 2008; Orton 2000; Poteate and Fitzpatrick 2013; Van der Veen and Fieller 1982; Woo et al. 2015). These methods for sampling include decisions about sample size (e.g. how many samples to take), sample selection (e.g. which parts of a site to take samples from), and methods for collecting samples (e.g. what screen size to use, how many bulk samples to take).

\subsubsection{Screen Size Effects}

Zooarchaeologists have focused much attention on the effects of screen size on faunal recovery (Ascher 1959; Cannon 1999; Casteel 1972; Gobalet 1989; Gordon 1993; Greenwood 1961; Grayson 1984; James 1997; McKechnie 2005; Moss 2007; Nagaoka 2005b; Nagaoka 1994; Partlow 2006; Rootenberg 1964; Shaffer 1992; Shaffer and Sanchez 1994; Sparks 1961; Stahl 1996; Thomas 1969; Vale and Gargett 2002; Zohar and Belmaker 2005). Screen size affects the recovery of small-bodied taxa, and various skeletal elements (Butler 1993; Casteel 1976; Nagaoka 2005b; Payne 1972; Thomas 1969). Screen size has been proven to affect the recovery of small mammals (Shaffer and Sanchez 1994; Stahl 1996; Thomas 1969), birds (Kirch et al. 1992; Stahl 1996; Steadman 
1995; Steadman and Rolett 1996), reptiles, and amphibians (Stahl 1996). This issue has been most intensively studied in regards to fish recovery (Butler 1993; Casteel 1976; Gordon 1993; James 1997; Nagaoka 1994; Partlow 2006; Vale and Gargett 2002; Zohar and Belmaker 2005).

The examination of fish representation in sites in coastal Alaska and British Columbia shows small mesh size of $1 / 8$ in. or even smaller is essential for the recovery of small-bodied taxa, such as herring (Clupea pallasii), which are often not recovered at all in larger mesh screens (McKechnie 2007; McMillan and St. Claire 2005; McMillan et al. 2008; McMillan and St. Claire 2012; Moss 2007, 2012). The degree of recovery of other small-bodied fish taxa such as small suckers, minnows, and eulachon also increases with the use of finer mesh screens (Butler 1996; Butler 2004; Butler and Delacorte 2004; Casteel 1976; McKechnie and Moss 2016; Partlow 2006; Rosenberg 2015).

Fine mesh screens provide important information on relatively small objects, but because more matrix is retained when using smaller mesh, both excavation and times increase. Studies of screen size in archaeology show that using 1/8 in. mesh or finer can more than quadruple the number of bones recovered and in some cases can even increase counts 10-20 times (James 1997; Thomas 1969). For example, fish remains from 18 bulk samples at the Cathlapotle site increased from a count of 184 bones to 1645 bones with the addition of samples from the 1/8 in. fraction, an increase of almost 10 times what was provided by the 1/4 in. fraction alone (Table 1). Fish remains from Meier, Burton Acres, and Duwamish show similar patterns (Table 1). This increase in quantity causes an increase in time spent on identification when analyzing material from fine mesh screens (Gordon 1993; Nagaoka 2005b). Smaller specimens also tend to lack distinguishing 
landmarks, which further increases time and energy spent on identification (Gordon 1993; Nagaoka 2005b). Because less matrix is retained and more identifiable landmarks are retained on larger boney specimens, large mesh samples take less time to study, so that one may sample a wider variety of contexts. However, the information about smaller objects is lost, as these objects fall through large mesh screens and are not retained for study. With a finite amount of time, focusing resources on fine mesh samples makes it difficult to study wide spatial or temporal contexts. One solution to the increased effort is to decrease the number or volume of samples analyzed. When volume is limited, as is often the chosen compromise, our understanding of spatial and temporal variation in fish also becomes limited (Moss 2007).

Table 1. NWC example projects highlighting fish remains recovered from column and bulk samples that illustrate the effect of mesh size on fishbone recovery. Number of identified specimens (NISP; number of identified specimens assigned to a taxon finer than class) from $1 / 4$ in. and $1 / 8$ in. screens.

\begin{tabular}{lccl}
\hline Site Name & $>$ 1/4" NISP & $>\mathbf{1 / 8}$ in. NISP & Citation \\
\hline $\begin{array}{l}\text { Meier } \\
\text { 35CO5 }\end{array}$ & 82 & 739 & Frederick 2007 \\
$\begin{array}{l}\text { Cathlapotle } \\
\text { 45CL1 }\end{array}$ & 184 & 1645 & Rosenberg 2015 \\
$\begin{array}{l}\text { Burton Acres } \\
45 \text { KI437 }\end{array}$ & 423 & 7798 & Kopperl and Butler 2002 \\
$\begin{array}{l}\text { Duwamish } \\
\text { 45KI23 }\end{array}$ & 403 & 3999 & Butler 1986 \\
\hline
\end{tabular}

As noted above, remains of small-bodied taxa, less than 100 to $200 \mathrm{~mm}$ in total length when living, dominate fine mesh samples. Conversely remains of large-bodied taxa, greater than $200 \mathrm{~mm}$ in total length when living, are typically rare and uncommon. This is clearly illustrated by comparing representation of small fish, such as herring and 
large-bodied fish such as Pacific cod (Gadus microcephalus) and greenling (Hexagrammidae) from 10 liter buckets screened using 1/8 in. nested screens from the Čî́xwicən site (Table 2) (Butler, personal communication). For each of these buckets the quantity of herring vastly outnumbers that of Pacific cod and greenling combined (Table 2) (Butler, personal communication). This example shows that in order to acquire large quantities of remains from large-bodied taxa, large volumes of sediment may need to be sampled.

Table 2. Frequency (NISP) of select large and small-bodied taxa from four 10 liter buckets screened using 1/8 in. nested screens at the Číxwicən site (Butler, personal communication).

\begin{tabular}{lcccc}
\hline & \multicolumn{4}{c}{ Bag Number } \\
Family & 8205 & 9448 & 9572 & 10706 \\
\hline herring & 14 & 1268 & 60 & 208 \\
Pacific cod & 0 & 5 & 5 & 5 \\
greenling & 1 & 2 & 0 & 2 \\
Total & 15 & 1275 & 65 & 215 \\
\hline
\end{tabular}

To acquire the benefits of both screen sizes, Frederick (2012) and McKechnie (2012) used a combination of 1/4 in. samples and column samples screened with $2 \mathrm{~mm}$ mesh from Huu7ii, southern Vancouver Island, to capture both spatial representation of fish and representation of smaller taxa (McMillan and St. Claire 2012). Including larger screen sizes allowed them to sample more contexts, while including finer mesh examples from column samples allowed examination of the full range of species preserved at the site (see also Rosenberg 2015).

\subsubsection{Statistical Sampling}

Statistical sampling methods do not solve the dilemma of screen size trade-offs but they do provide an empirical way to maximize the amount of information obtained, 
no matter the screening method chosen, with the least amount of effort. This thesis focuses on probabilistic sampling methods, with the goal of understanding the relationship between samples and the target population of interest, using probability theory. All statistical methods for sampling assume some level of homogeneity within a sample population to reduce error (Cochran 1977a; Neyman 1934). This means that in order for statistical methods to be effective, larger samples that do not have a unifying characteristic are better divided into smaller, more homogenous groups or dealt with as stratified samples (Cochran 1977b; Krishnaiah and Rao 1988; Neyman 1934).

Determining which type of statistical sampling to use depends on the researcher's questions and goals. Two probabilistic sampling methods often used during the laboratory phase of archaeological research on discrete objects (e.g. faunal remains or modified objects) are rarefaction and STR (Grayson 1984; Lyman 2008; Orton 2000).

\subsubsection{Rarefaction}

Rarefaction is the process of establishing redundancy for the maximum number of taxa, also referred to as NTaxa or richness, represented in a population (Grayson 1984; Leonard 1987; Lyman 2008; Sanders 1968; Tipper 1979). This method has been used by ecologists (Colwell and Coddington 1994; Colwell et al. 2004; Gotelli and Colwell 2001; Wolda 1981) and paleobiologists (Alroy 2000; Barnosky et al. 2005; Bush et al. 2004; Miller and Foote 1996) as well as zooarchaeologists (Grayson 1989, 1991; Kirch et al. 1987; Leonard 1989a, 1989b; McKechnie 2013; Meltzer et al. 1992; Simek and Snyder 1988).

This type of statistical sampling is predominantly used by researchers post-hoc to examine the point at which one might have stopped in order to reach the greatest 
taxonomic richness (Byrd 1997; Lyman and Ames 2004, 2007; McCartney and Glass 1990; Styles 1981). The greatest taxonomic richness found using rarefaction post-hoc has been used to verify whether differences in the NTaxa between multiple samples is a factor of sampling strategy, or a factor of true differences in the samples (Lyman 2008). Several statistical packages can be used to calculate rarefaction (Kintigh 1984; Holland 2005), but none are designed to be used as a predictive method that would specify when continuing to adding samples no longer adds taxa (Koch 1987; Lyman 2008). A number of researchers have argued against using rarefaction to predict when to stop adding samples, given the number of required assumptions (Grayson 1989; Lyman 2008), which include those about assemblage size, assemblage diversity, and the relationship between assemblage size and diversity.

Rarefaction used at the Meier site of the lower Columbia River determined whether enough mammalian fauna had been collected during excavations to represent the full range of mammalian taxa present. After four excavation seasons and 4080 specimens, additional taxa were not identified (Lyman and Ames 2004, 2007; Lyman 2008) (Figure 2). In addition, there were more taxa added between the first and second year, than between the third and fourth year where only two additional taxa were added (Figure 2). This example shows a search for rare taxa requires a large sampling effort (that would generate a large volume of matrix and a high NISP). 


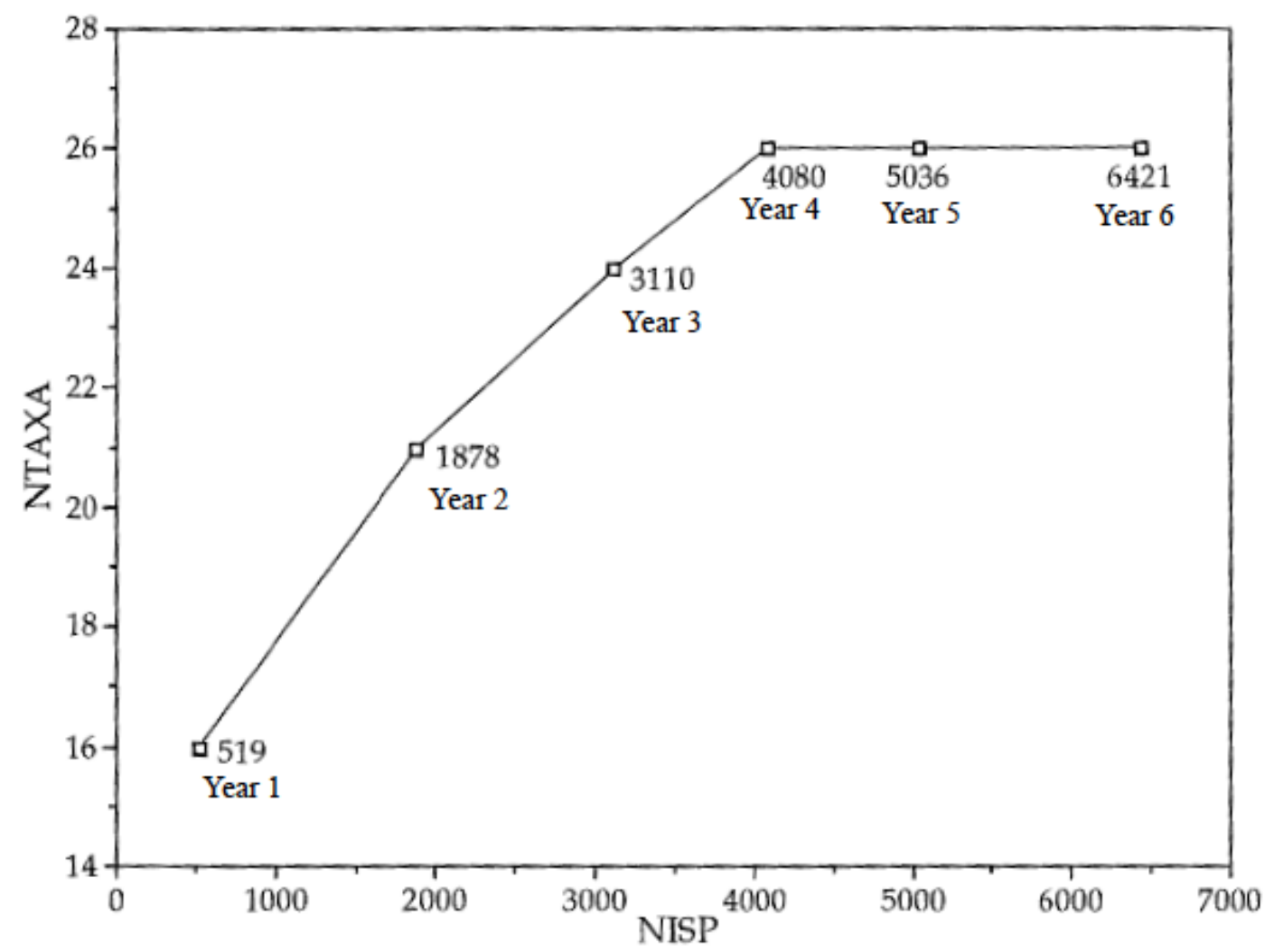

Figure 2. Cumulative richness of mammalian genera across cumulative annual samples (NISP) from the Meier site. Number adjacent to plotted points are cumulative NISP (Lyman and Ames 2007; Lyman 2008).

\subsubsection{Sampling to Redundancy (STR)}

Other research questions seek to establish redundancy for the proportional representation of taxa (Van der Veen and Fieller 1982). "Sampling to redundancy" (STR) estimates the changing proportions of taxa as subsamples are added to the sample of identified specimens. Redundancy is reached when taxonomic proportions stop changing with additional samples. These methods, as with binary redundancy for NTaxa, divide samples by context before identifying a subsample, but as stated above, the focus is on reaching a proportional representation rather than reaching the maximum richness of the population. STR as described by Van der Veen and Fieller (1982) and Cochran (1977a) 
addresses the issues associated with capturing variability in spatial and temporal contexts and empirically defines the stopping point for sampling. STR provides the opportunity to understand population characteristics of the maximum number of stratigraphic and spatial contexts, with the minimum amount of material analyzed.

STR is used extensively by paleobotanists worldwide (Church et al. 2007; Hosch and Zibulski 2003; Jacomet and Brombacher 2004; Jones and Halstead 1995; KohlerSchneider and Caneppele 2009; Neumann 1989). Archaeologists sampling plant remains from Holocene sites in Egypt and Sudan used STR to determine the number of charcoal specimens needed in order to reach redundancy for each site included in the study. This information was used to identify differing ecological zones in eastern Africa (Neumann 1989). For large samples consisting of 300 or more charcoal specimens, archaeologists examined $10-30 \%$ of the sample and for small samples with less than 300 charcoal specimens, $100 \%$ of the sample was examined. The reduced size of individual samples allowed researchers to examine a total of 320 samples from several sites in both ecological zones from Egypt and Sudan, covering a time span of almost 6,000 years (Neumann 1989). STR typically develops a stopping rule for an archaeological context such as a discrete entity (e.g., amphora, hearth, or other feature contents), an archaeological unit (e.g., excavation unit, level, or bulk sample), or an analytic unit (e.g., aggregate of archaeological samples such as time periods).

Despite its ubiquity in paleobotany, STR has rarely been used in zooarchaeology. Faced with extremely large numbers of fish remains from the Lower Columbia, Butler (2005) and Rosenberg (2015) have spearheaded the use of this method. Rosenberg (2015) analyzed $1810 \mathrm{~L}$ bulk samples screened through $1 \mathrm{~mm}(3 / 64 \mathrm{in})$ mesh to estimate the 
proportional representation of fish taxa in fine mesh samples from the Cathlapotle site. The number of subsamples analyzed for each bulk sample ranged from $50 \%-100 \%$ of the total sample depending on the bulk sample, with an average identification of $85 \%$ of each bulk sample. While some time was saved using this method, this example shows how the fraction studied and overall sample size can vary depending on the complexity, variability, and absolute sample size of the population being characterized. In contrast, Butler's 2005 study at the St. Johns site identified an average of $51 \%$ of the estimated total fish specimens in each bulk sample. The total fish specimens analyzed in each bulk sample ranged from $38 \%-63 \%$ analyzed at St. Johns.

There are at least two equations that can be used to determine redundancy: stratified STR (Equation 1) (stratification refers to subdivisions within a larger population) and simple random STR (Equation 2) (Cochran 1977b). These equations were developed by Cochran (1977b) to be used as deterministic sampling methods. I am adapting these equations for my thesis to be used as sequential sampling methods (Siegmund 2013). This will allow me to adjust the $\mathrm{n}$ in STR based on new information as I continue to sample more fish remains. All previous archaeological applications rely on Equation 2, which I also employ in my study. This method will allow me to treat each sample as an isolated entity, rather than as a sub sample of a larger entity. Doing so will allow me to collect slightly larger sample sizes than if each sample was treated as a sub sample.

When applying this methodology to samples that are stratified instead of homogenous, Cochran proposes the equation below: 
Equation 1. Stratified Sampling to Redundancy

$$
n_{h} \cong n\left[\frac{\frac{N_{h}}{N} \sqrt{P_{h} Q_{h}}}{\sum_{h=1}^{L} \frac{N_{h}}{N} \sqrt{P_{h} Q_{h}}}\right] \text {. }
$$

where:

$\mathrm{n}_{\mathrm{h}}=$ the number of required specimens from the total target population (also known as the point of redundancy)

$\mathrm{n}=$ the total number of strata in the population

$\mathrm{N}=$ the total number of specimens in the entire target population (all strata) represented here as Number of Identified Specimens (NISP)

$\mathrm{P}_{\mathrm{h}}=$ the proportion of a taxon in the target population

$$
\begin{aligned}
Q_{h}=\mathrm{d} / \mathrm{Za}_{\mathrm{a}}^{2} & \text { Where: } \\
\mathrm{d} & =\text { the required accuracy } \\
\mathrm{Z} \alpha & =\text { the two-sided } \alpha \text { percentage of the normal distribution }
\end{aligned}
$$

$\mathbf{N}_{\mathrm{h}}=$ The total number of specimens in a single stratum within the target population represented here as NISP

Stratified STR develops a stopping rule but in this case the stopping rule is developed for all statistical strata together instead of treating each statistical stratum as a separate sample population (Cochran 1946). A statistical stratum is defined as a unified subgroup of a population. Stratified STR has yet to be used in an archaeological context. This method can be used to include samples from multiple contexts in a single calculation, and in so doing almost always results in a smaller variance for the estimated total than if the same calculation was done using a simple random sampling method. This type of STR 
would be useful in future archaeological research for sampling large-scale complex sites where the research goal only requires a broad-scale comparison of materials. This method may not provide large enough sample sizes from individual spatial or temporal contexts within a site to analyze a specific spatial or temporal context's characteristics.

In cases where archaeological research questions require analysis of materials using finer contexts, Cochran's simple random method (1977b) may provide more statistically robust sample sizes. The simple random method for STR was first applied in archaeological contexts by Van der Veen and Fieller (1982) for the purposes of estimating proportional representation of seeds.

Equation 2. Simple Random Sampling to Redundancy

$$
n=\frac{N}{1+\frac{N-1}{P(1-P)^{d} / Z^{2}}}
$$

where :

$\mathrm{n}=$ the number of required specimens in the sample (also known as the point of redundancy)

$\mathrm{N}=$ the total number of specimens in the target population represented here as Number of Identified Specimens (NISP)

$\mathrm{P}=$ the proportion of a taxon in the target population

$\mathrm{d}=$ the required accuracy

$\mathrm{Z} \alpha=$ the two-sided $\alpha$ percentage of the normal distribution

Researchers have applied various iterations of Equation 2, but the terms used in each iteration are analogous (Cochran 1977a; Cochran 1977b; Van der Veen and Fieller 
1982) (Appendix A). STR (Equation 2) is designed to analyze homogenous samples of a multinomial nature using proportions. STR in this form analyzes proportions by dividing a sample into two groups where group one consists of a discrete category (e.g. fish family: Gadidae) and group two consists of all other categories (e.g. remaining fish families: Squalidae + Rajidae + Chimeridae + Embiotocidae + Cottidae + Pleuronectidae, etc.). The discrete category in this case is made up of whichever entity appears in the proportional majority (Cochran 1977b). This type of test is called a two classification test. Two classification tests are often used in statistics to deal with problems involving multinomial distributions, such as the distribution of taxa. These tests simplify multinomial problems by reducing them into binomials.

$\mathrm{P}$ in this equation sets the maximum value for group one. By setting $\mathrm{P}$ at 0.5 , group one cannot exceed $50 \%$ of the total population for redundancy to be reached. Setting $\mathrm{P}$ at 0.5 creates the largest possible $\mathrm{n}$ value by minimizing the value in the denominator. Assuming a normal distribution, changing P to any other value would decrease the NISP required to reach redundancy, thereby creating a less conservative estimate of the proportional representation of group one. The law of large numbers states that $\hat{\mathrm{p}}$ will approach $\mathrm{P}$ with a probability of 1 where $\hat{\mathrm{p}}$ is the sample proportion and $\mathrm{P}$ is the population proportion. This law allows one to use $\mathrm{P}$ instead of $\hat{\mathrm{p}}$ in this equation.

The margin of error is represented by $\mathrm{d}$, set in this case at 0.05 , which minimizes marginal error, while also minimizing the risk of a Type 2 error $(\alpha)$ where the actual error would be greater than $d$. The value of $d$ in this equation is derived from $\frac{\partial}{Z_{\alpha}}$ where $\partial=$ the population standard deviation. $\mathrm{Z}_{\alpha}$ (or $t$ as it is expressed by Cochran) can be explained as 
the parameter that sets the level of statistical confidence that our $\mathbf{n}$ value will be within the margin of error set by $\mathrm{d}$. Setting $\mathrm{Z}_{\alpha}$ at 1.96 sets the confidence at $95 \%$. The function $d Z_{\alpha}$ sets the standard error. By setting $d$ at .05 and $Z_{a}$ at 1.96 , the standard error is set at 0.1 , which is one standard deviation from the mean P. The result of this is that our majority taxon (group 1) will lie at $50 \% \pm 10 \%$ or somewhere between 40 and $60 \%$ of the total population.

An estimate of $\mathrm{N}$ can be calculated using data collected from a randomly selected sample population within the target population. The same law of large numbers that was applied for $\mathrm{P}$ can also be applied to this situation. This means that as more samples are added to the estimate of $\mathrm{N}$, the closer the estimate will be to actual $\mathrm{N}$. In this situation one must make an assumption that when redundancy has been reached, the number of samples is large enough to estimate N. For this reason, N should be re-calculated as each additional sample of the target population is added.

\subsection{Northwest Coast Villages}

The study of complex hunter-gatherers on the Pacific Northwest Coast is important to archaeologists for understanding the lifeways of native people in North America, and understanding how the landscape has been used and modified in the past (Ames and Maschner 1999; Butler and Campbell 2004; Coupland et al. 2009; Matson and Coupland 1994; Matson et al. 1999, 2003; Moss 2011). Archaeologists often focus excavation on large villages to study social complexity (Ames and Maschner 1999; Ames 2006). Questions guiding studies of social complexity include: the role of sedentary villages as a fundamental economic unit, the importance of population growth, and the development of storage. Social complexity is often interpreted as an evolutionary process 
where as houses get larger and settlements become more permanent over time, society and culture increases in complexity in other ways as well (Ames and Maschner 1999; Maschner 1991). This framework also leads to discussions about the durability of households over time (Ames and Maschner 1999) and the study of human-environment relationships (Butler and Campbell 2004; Campbell and Butler 2010).

Increases in house size in village sites world-wide are often associated with both an increase in population size, and an increase in degree of sedentism of the group (Ames and Maschner 1999; Boyd and Richerson 1985; Cosmides and Tooby 1987; Durham 1991; Mithen 1990). Both population size and sedentism are essential in the development labor organization on the Northwest Coast (Ames and Maschner 1999; Renouf 1991; Yesner 1981, 1987, 1998). Higher populations and increased resource use can cause resource depression (Butler and Campbell 2004; Broughton 1994, 2002a, Broughton et al. 2007, 2010, 2013; Campbell and Butler 2010; Grayson 2001).

On the Northwest Coast, changes in resource use (both faunal and floral), and increases in sedentism and population size are often associated with resource ownership. Systems of resource ownership create a more built environment where resources can be cultivated and traded (Ames 2006; Ames and Maschner 1999). Studies of developing cultural complexity, population growth, intra and inter-household dynamics use several measures: house size (Ames 1996), organization of sleeping quarters (Coupland et al. 2009), artifact and tool distribution (Ames 1995; Harris 2012; LaSalle 2008), and faunal distribution (Coupland 2006; Huelsbeck 1994; Frederick 2007; Matson et al. 1999, 2003; Moss 1993; Samuels 1994). 
Given the importance of animals to models of Northwest coast cultural change, the zooarchaeology of Northwest Coast villages is an important area of study. Studies on Northwest Coast fauna have shown how increased social organization impacts resource use and availability through rules to control resource use, which contributes to long-term sustainable resource use (Butler and Campbell 2004; Campbell and Butler 2010). For example, the variation of faunal use across a household has been used to study resource control at the Cathlapotle site on the lower Columbia River (Rosenberg 2015). This study, and similar studies worldwide, show that faunal remains can be attributed to particular social groups and status, reinforcing social structures (Gumerman 1997; Singer 1987; VanDerwarker 1999).

The household has been an iconic measure for social organization, and resource control on the Northwest Coast (Ames and Maschner 1999). For that reason, it is important to understand the individual size, and estimated number of houses in Northwest Coast villages. Houses documented in the historic period on the Northwest Coast measure between $25 \mathrm{~m}^{2}$ and 3,600 $\mathrm{m}^{2}$ (Ames and Maschner 1999; 163). Based on their size, 30 to more than 100 individuals occupied houses in this region (Ames and Maschner 1999). Villages were composed of anywhere between 1 and 15 houses, sometimes more (Ames and Maschner 1999). To characterize the lifeways represented within and between these households, ideally researchers should sample multiple contexts within multiple houses.

Investigation into the sampling strategies used by previous researchers has shown that this is rarely the case (Dolan 2015; Gray 2008; Monks 2000). Gray's 2008 thesis focuses on problems with the location, and quantity of excavation units in village sites 
and has noted that there are several issues with the comparability and robustness of traditional Northwest Coast village excavation sampling strategies. These issues include: differing sample sizes between sites, an overemphasis on excavation of the largest house in a village site, differing sampling strategies between houses in the same village site, and a lack of transparency when reporting how much material was excavated (such as volume excavated). Gray (2008) and Monks (2000) argue that NWC village sampling strategies often do not provide material that is representative of the range of contexts within and between house features.

Building on Gray's (2008) work and for the purpose of further documenting village site sampling and especially approaches to fish sampling, I synthesized excavation records from 16 village sites from coastal Oregon to Northern British Columbia (Table 3). I recorded information on number of houses sampled, the number of fish remains collected and identified, and the screen size used. Excavated volume was not generally provided. In some cases, such as at Meier and Broken Tops, only one or two houses were identified, and in such cases the small number of houses excavated is justified (Table 3 ). As well, most of the documented houses (four to five) at Ozette and McNichol Creek were sampled (Table 3). However, as shown in Table 3, most projects tested only one or two houses, while as many as 15 or 20 houses are present. Midden outside the house is often not sampled and when it is, the number of test units is limited. Limiting the number of houses sampled in this way reduces our information about household variation, and waste disposal practices.

I also found that faunal remains are collected using variable recovery methods, from hand picking, to screening using varying mesh sizes (Table 3) reducing 
comparability. Many researchers exclusively used 1/4 in. samples, such as at Broken Tops, Kiusta, Ozette, and Paul Mason. Projects which incorporated fine mesh samples, such as Shingle Point, Psacelay, and Dionisio Point, tended to sample fewer contexts.

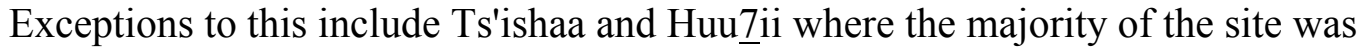
excavated using $1 / 4$ in. mesh (or metric equivalent) and 1/8 in. and finer samples were collected from carefully selected column samples (Table 3). 1/16 in sampling is rarely included, and when integrated it is generally from column samples or other small volume samples. The ubiquity of $1 / 4$ in. samples across contexts at village sites makes analysis of large-bodied fish easy to characterize. This is not the case for the small-bodied fish which, as noted above, are primarily encountered in finer mesh screens (1/8 in. or finer), and routine collection of fine mesh samples has only occurred in the past twenty years (Butler 2005; McKechnie 2005, 2007, 2012; McKechnie and Moss 2016; Rosenberg 2015).

Relatively limited sampling of large complex Northwest coast village sites is understandable. Excavation is expensive and time consuming. Exploring new and innovative methods for time savings is essential to maximizing the information retrieved from the data rich contexts of Northwest Coast village sites during future excavations.

STR would provide an innovative alternate approach to sampling that would allow material to be sampled from a wider variety of contexts. This statistical method allows researchers to sample large contexts without limiting the volume of material available to something as small as a column sample. Using STR allows the researcher to increase the volume of material represented without examining every specimen present in the samples included. 


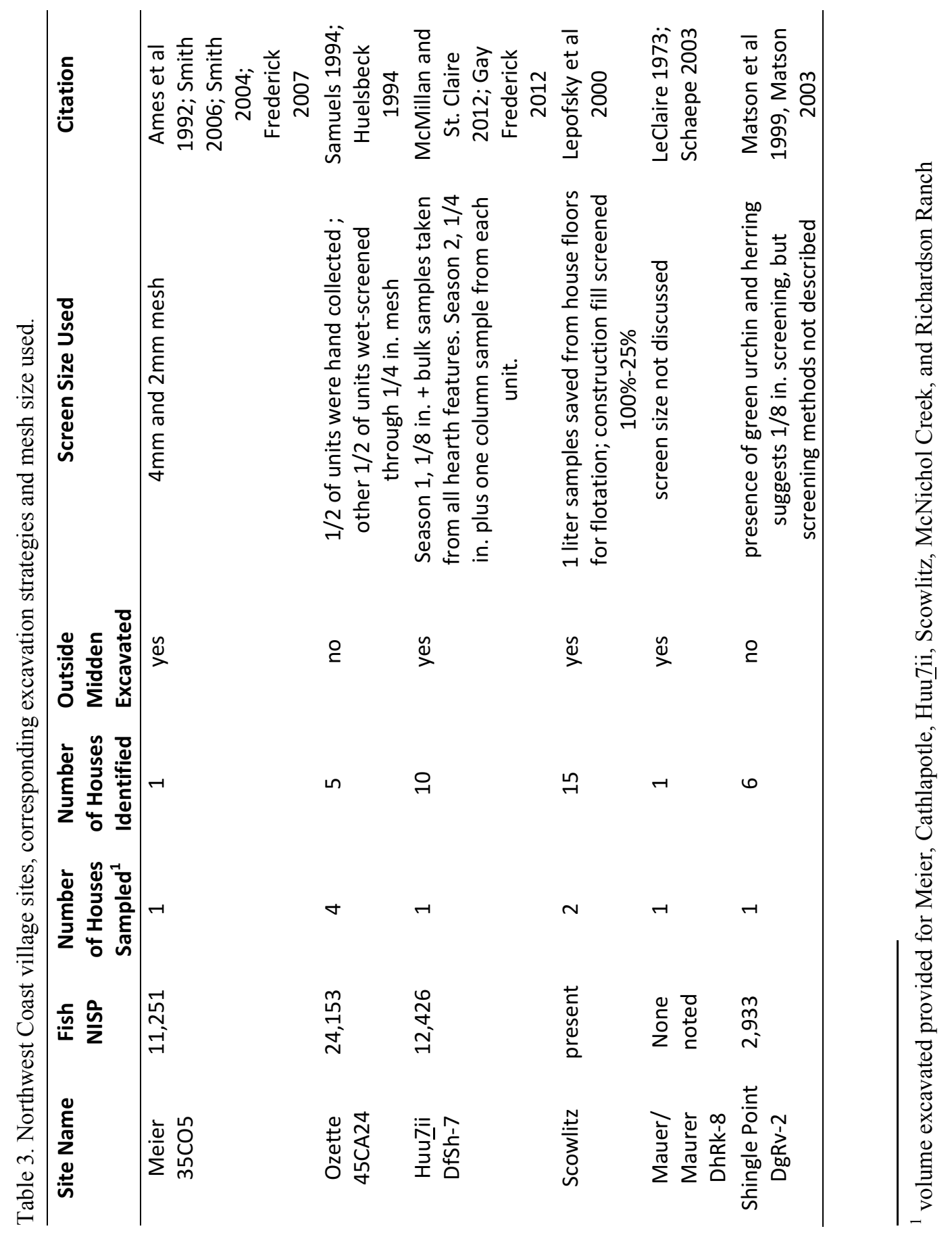




\begin{tabular}{|c|c|c|c|c|c|}
\hline \multicolumn{2}{|c|}{ 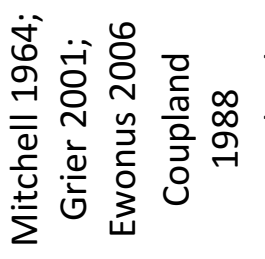 } & 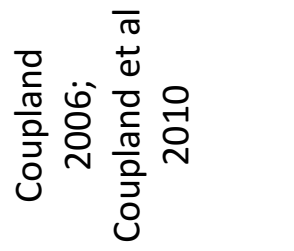 & 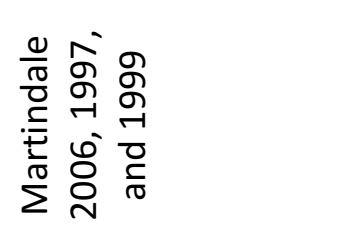 & 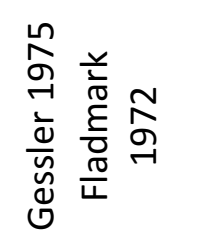 & 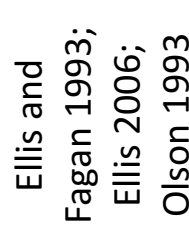 \\
\hline 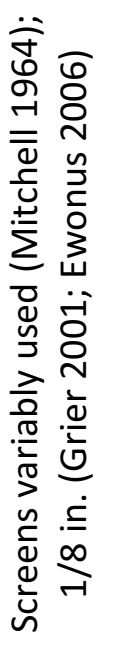 & 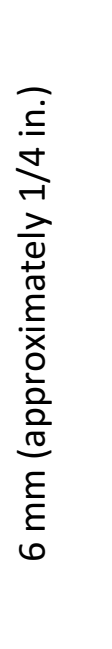 & 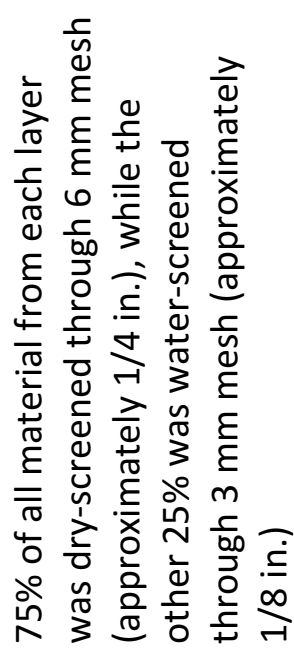 & 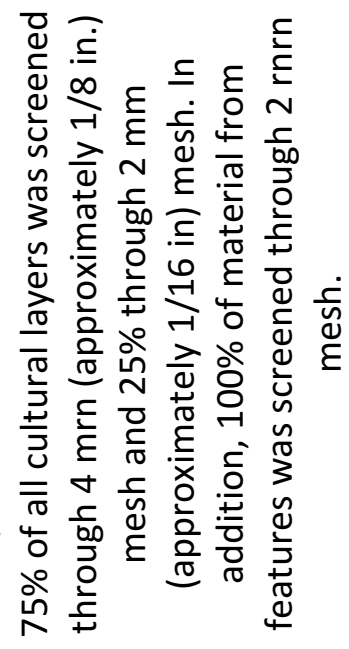 & 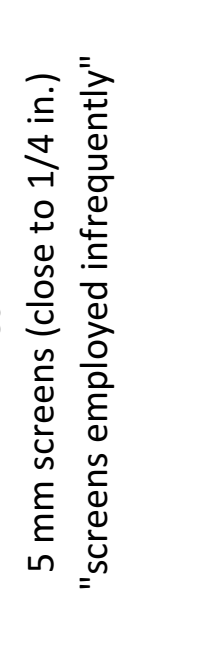 & 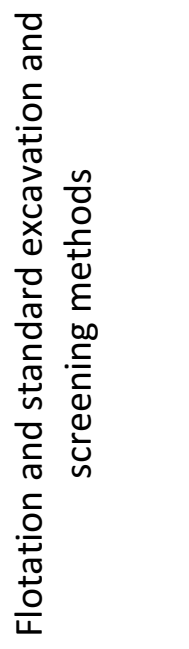 \\
\hline$\stackrel{\circ}{\subseteq}$ & $\stackrel{\nu}{\searrow}$ & $\stackrel{\Perp}{\nu}$ & $\stackrel{\check{D}}{>}$ & $\stackrel{\varrho}{\searrow}$ & 옫 \\
\hline in & $\underset{\sim}{\sim}$ & $\stackrel{n}{\sim}$ & $N$ & $\stackrel{\sim}{\sim} m$ & $N$ \\
\hline-1 & $\sim$ & in & $\stackrel{+}{\sim}$ & $\stackrel{+}{\rightarrow} \neg$ & $\sim$ \\
\hline $\begin{array}{l}\stackrel{\infty}{\infty} \\
\text { ָ } \\
\underset{ন}{-}\end{array}$ & $\stackrel{P}{N}$ & $\begin{array}{l}\text { ঃ } \\
\text { बे }\end{array}$ & ถิ & 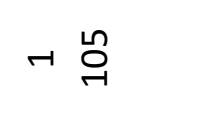 & రి \\
\hline 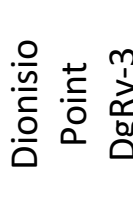 & 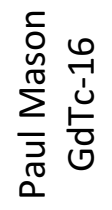 & 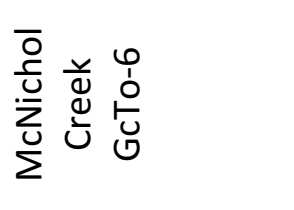 & 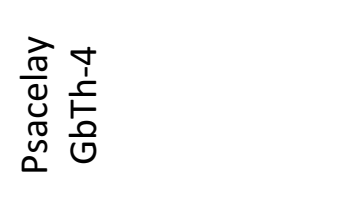 & 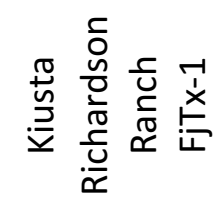 & 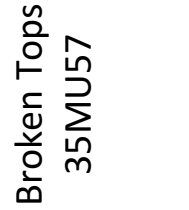 \\
\hline
\end{tabular}




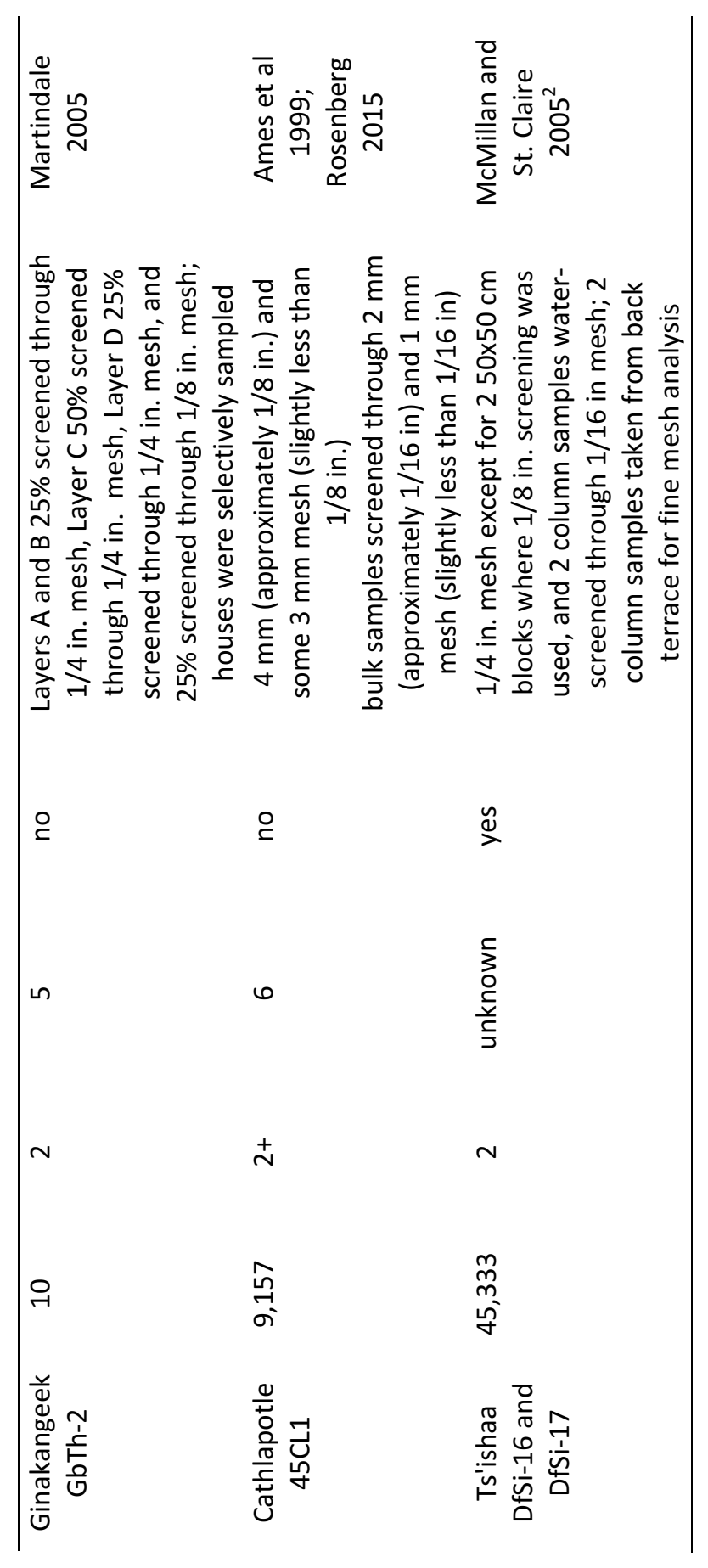

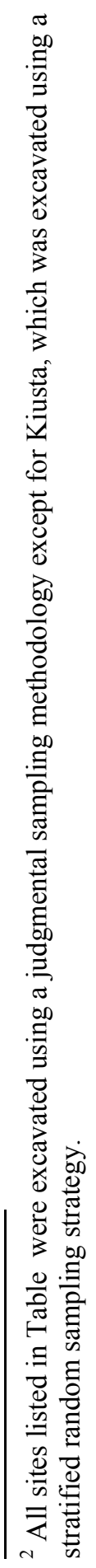




\subsection{The Číx ${ }^{w i c ə n}$ Site}

The Č́íx ${ }^{\mathrm{w}}$ icən site has the potential to address the limitations of previous Northwest Coast village site excavations because of its unique and robust sampling strategy, the wide expanse of time that it was occupied, and the multiple house structures present and available within the parameters of the NSF study. This site, located on the Strait of Juan de Fuca in Port Angeles, WA (Figure 1) was excavated in 2004 as part of a Washington State Department of Transportation (WSDOT) undertaking to build parts for the Hood Canal Bridge (Larson 2006; Mapes 2009). Číx ${ }^{w} i c ə n$ is a traditional village affiliated with the Lower Elwha Klallam Tribe (LEKT). After over 300 human remains were recovered, the project was halted because of tribal concerns and mounting costs of the undertaking (Larson 2006; Mapes 2009). A report summarizing excavation methods and depositional contexts was produced (Larson 2006), but most of the recovered materials were not studied, including the faunal remains, which are currently curated at the Burke Museum, Seattle, Washington. Plans are underway to transfer these and other Číx ${ }^{w}$ icən collections to the LEKT for curation.

This excavation resulted in $261.4 \mathrm{~m}^{3}$ of material over an area of approximately $528 \mathrm{~m}^{2}$ (Figure 3). Site excavations at the large village in 2004 focused on four large areas (Areas A, B, C, and D). Radiocarbon dates from the Čî́x ${ }^{w}$ icən site date its occupation starting at 2750 cal. BP (Sterling et al. 2017). Historic records suggest it was used by the Lower Elwha Klallam Tribe until the construction of a paper mill on the property in 1910. 


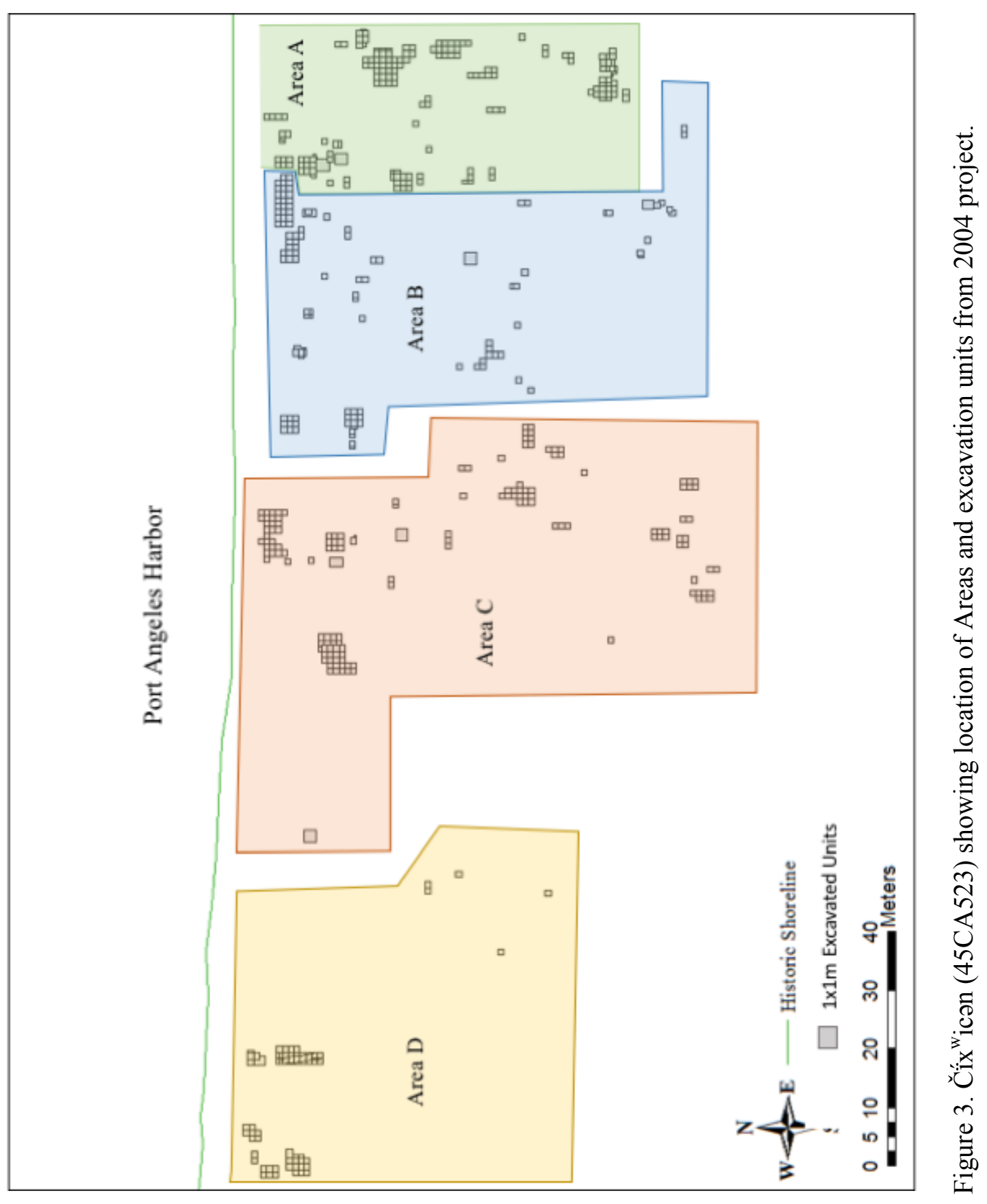


Číx ${ }^{w}$ icən was excavated with exceptionally fine stratigraphic control using methods developed by Stein (1992) and popularized after the mid 1990's West Point excavations (Larson and Lewarch 1995). Units were excavated in natural strata; each stratum was subdivided into $10 \mathrm{~cm}$ arbitrary levels. Excavated material was collected using $10 \mathrm{~L}$ buckets, and wet-screened using nested mesh starting at $1 \mathrm{inch}$, moving down in size to $1 / 2$ in with some ending at $1 / 4$ in. mesh and some ending at $1 / 8 \mathrm{in}$. mesh. The majority of buckets from each level were screened to $1 / 4 \mathrm{in}$. mesh and labeled "S" buckets. From every level in each $1 \times 1 \mathrm{~m}$ unit, every $20^{\text {th }} 10 \mathrm{~L}$ bucket (labeled as a "C" bucket) was screened to $1 / 8$ in. mesh. Where fewer than 20 buckets were recovered for a particular provenience, a minimum of one " $\mathrm{C}$ " bucket was collected.

During the 2004-2005 lab processing, faunal remains were sorted into broad animal types (bird, fish, mammal, and shell) and remains counted (Larson 2006). The preliminary counts of each animal type recorded during initial lab processing showed enormous quantities of animal remains, including fish. For example, from all areas combined $\left(518.59 \mathrm{~m}^{2}\right), 14,742$ "S" buckets were retained which generated minimally 283,983 fish remains. A total of 3,302 "C" buckets provided an estimated number of 175,466 fish remains (counts from Larson 2006 catalog retained by the Burke Museum).

In 2012, Drs. Virginia Butler, Sarah Sterling, Sarah Campbell, Mike Etnier, and Kris Bovy obtained a grant from the NSF to analyze a sample of the faunal remains primarily from seven block excavations in Area A and two units from Area B (Figure 3; Figure 4). The NSF study focuses on seven block excavation areas within Area A (Figure 4). Researchers chose to focus on areas A1, A4, and A5 as geoarchaeological work had suggested these areas contained remains of houses. A23, A18, BX1, and BX4 were 
selected to sample extramural areas. The study's goals are to examine community responses to seismic events and other environmental change through study of the subsistence strategies at the village site. In order to examine community responses to the environment, it is important to first identify the several types of environmental changes present at the site including both short term change such as seismic events and long term change such as climate and the stabilization of the Ediz Hook Spit (Mohlenhoff and Butler 2016). The knowledge gained from this NSF study will contribute to more general knowledge about coastal climate systems. In addition to the scientific values of this study, there are also values to the Lower Elwha Klallam people.

For various reasons the NSF project initially focused study on "C" buckets. Shell was retained only in the " $\mathrm{C}$ " buckets and since a key goal was to study all animal types from the same contexts, only "C" buckets provided such sample units. Also, including "C" buckets ensured recovery of small bones and shells, increasing representation of smaller fauna. The NSF project determined that about half the " $\mathrm{C}$ " buckets included in their study were in fact only screened to $1 / 4$ in. Such buckets were labeled as "CX". As noted above, the mammal and bird bone researchers have included "S" buckets screened to $1 / 4$ in. to increase the sample size of mammal and bird bone for study. My project will study the "S" buckets to consider whether adding more volume than the " $\mathrm{C}$ " and "CX" buckets affects fish representation. 


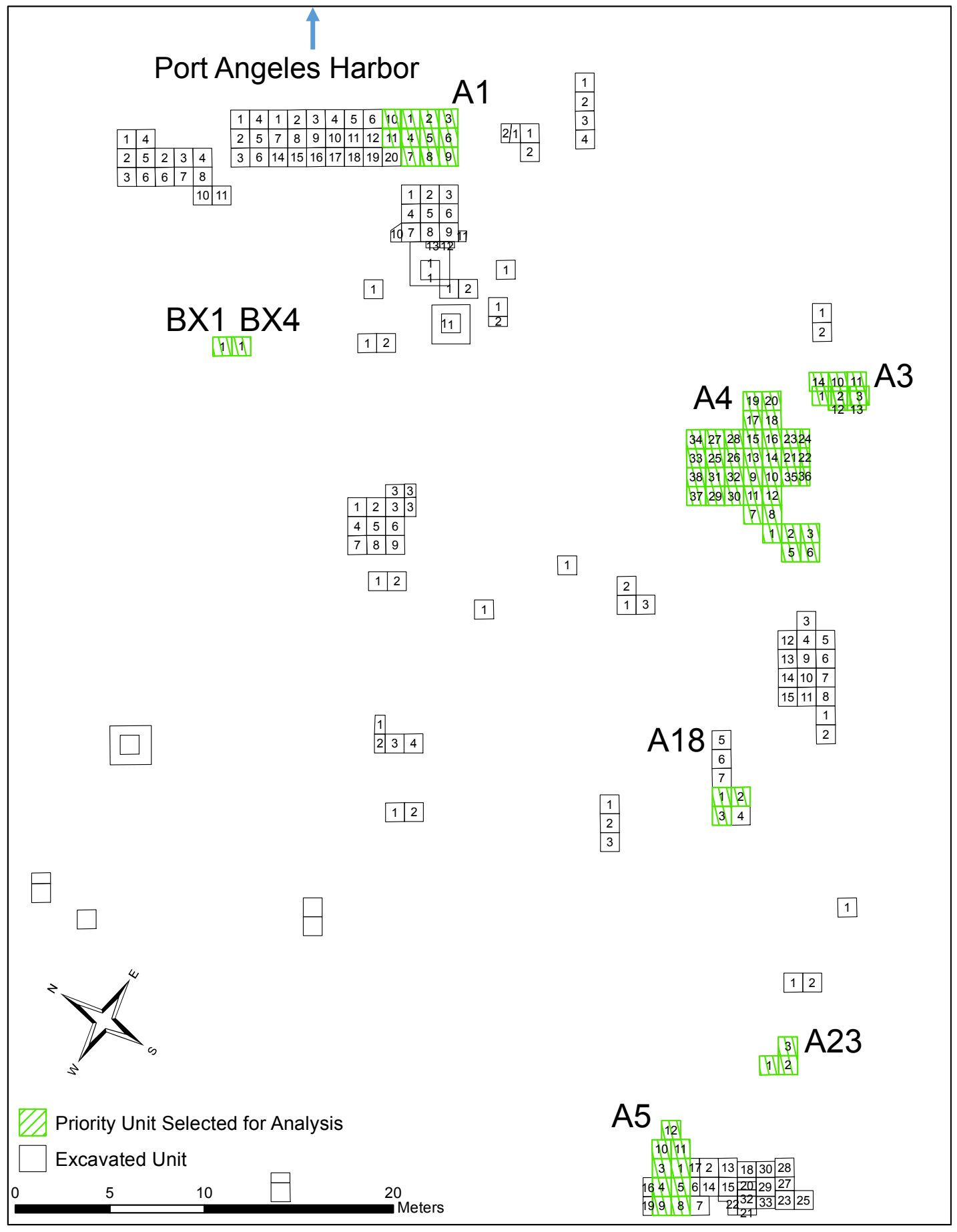

Figure 4. Map of Čî́x ${ }^{\mathrm{w}}$ icən showing areas included in NSF project. 
As part of the NSF project, Sterling and Campbell created Chronological Zones (CZs) by combining field-defined strata using associated calibrated radiocarbon ages and stratigraphic superposition. CZs are a temporal aggregate of field-defined strata with a range of properties (e.g. variation in faunal abundance, position within a hearth or architectural feature). These CZs, representing units of time, are the basis for chronological comparisons of faunal remains, and subsequently subsistence strategies. The seven chronozones span a period between $1910 \mathrm{AD}$ and $2150 \mathrm{cal}$ BP (Table ) (Sterling et al 2017).

Table 4. List of chronozones and date ranges for the Čî́x ${ }^{w} i c ə n$ Site

\begin{tabular}{cc}
\hline Chronozone & Date Range (cal BP) \\
\hline CZ 7 & 300 cal BP- 1910 AD* \\
CZ 6 & $550-300$ \\
CZ 5 & $1000-550$ \\
CZ 4 & $1300-1000$ \\
CZ 3 & $1550-1300$ \\
CZ 2 & $1750-1550$ \\
CZ 1 & $2150-1750$ \\
\hline
\end{tabular}

*End age based on an historic era papermill on the property. 


\section{Chapter 3. Methods and Materials}

The Č́̂́x wicən site's large excavated volume of matrix, quantity of faunal remains, and meticulously documented depositional history make it ideal for testing sampling methodologies. My thesis addresses the utility of STR particularly for sampling faunal remains from large village sites. Using STR, this project will try to document the variability of fish family representation across time and space in one part of the Čî́x ${ }^{w} i c ə n$ village, while minimizing the time and effort required to do so. This thesis applies STR to "S" (> 1/4 in.) bucket samples from eight units in Area A4 (Error! Reference source not found.). Fish representation in the "S" bucket samples will then be compared to the fish remains recovered from the $>1 / 4$ in. mesh samples from the " $\mathrm{C} / \mathrm{CX}$ " buckets, which has already been documented as part of the NSF project.

Because the " $\mathrm{C} / \mathrm{CX}$ " buckets represent only a fraction of the total zooarchaeological materials sampled from the site, it is possible that the " $\mathrm{C} / \mathrm{CX}$ " buckets alone may not be adequate for representing large-bodied fish. As previously stated in the background section, the NSF project focused its analysis efforts on the " $\mathrm{C} / \mathrm{CX}$ " $(>1 / 8 \mathrm{in}$.) buckets. These buckets represent $18 \%$ of the 18,044 buckets of material collected just from Area A at the site. As noted above (Table 2), remains of large-bodied taxa occur in much smaller quantities per " $\mathrm{C} / \mathrm{CX}$ " bucket.

I chose to use "S" bucket samples for my study to compare representation of fish taxa in the "S" buckets to the representation of fish taxa in " $\mathrm{C} / \mathrm{CX}$ " bucket samples to test whether fish representation remains consistent with the addition of the "S" bucket fish remains. If the volume studied from the " $\mathrm{C} / \mathrm{CX}$ " buckets is sufficient to accurately represent large-bodied fish in site matrix, fish representation should not significantly 
change with the addition of the "S" bucket fish remains. I anticipate, however, that adding "S" bucket samples may change proportional representation of taxa as it increases the volume of material analyzed. I predict that these effects will be most dramatic in chronozones with low densities and small matrix volume.

I chose Area A4 because this block of units has a long time span, encompasses a house, and has received the most attention in the larger NSF project. Given a key goal of my project is to show the usefulness of STR for sampling NWC house sites, it is important to establish the feasibility of applying the method to a house. I selected "S" buckets from a total of eight $1 \times 1 \mathrm{~m}$ excavations units (Figure 5). I reasoned these eight units would provide sufficient faunal remains to meet the two major goals of this project: to illustrate the value of STR and to assess whether the $>1 / 8$ in mesh samples adequately represented large-bodied fish. I chose "S" buckets explicitly from four units because preliminary catalog counts suggested relatively large sample sizes were present; the units included house floor and outside midden. These units also encompassed occupations from several time periods (Table 5). Four additional units (17-20) were chosen for practical reasons as the faunal remains from those units were already on loan from the Burke Museum. These eight units provide a quantity of material that is feasible for a Master's thesis project, and provide sufficient material to test the utility of my sampling method. By using fish from A4, which encompasses a house structure, my research may also contribute to understanding of variation in fish deposition and taphonomy within a household (Ewonus 2006; Frederick 2007; Huelsbeck 1994; Rosenberg 2015). 


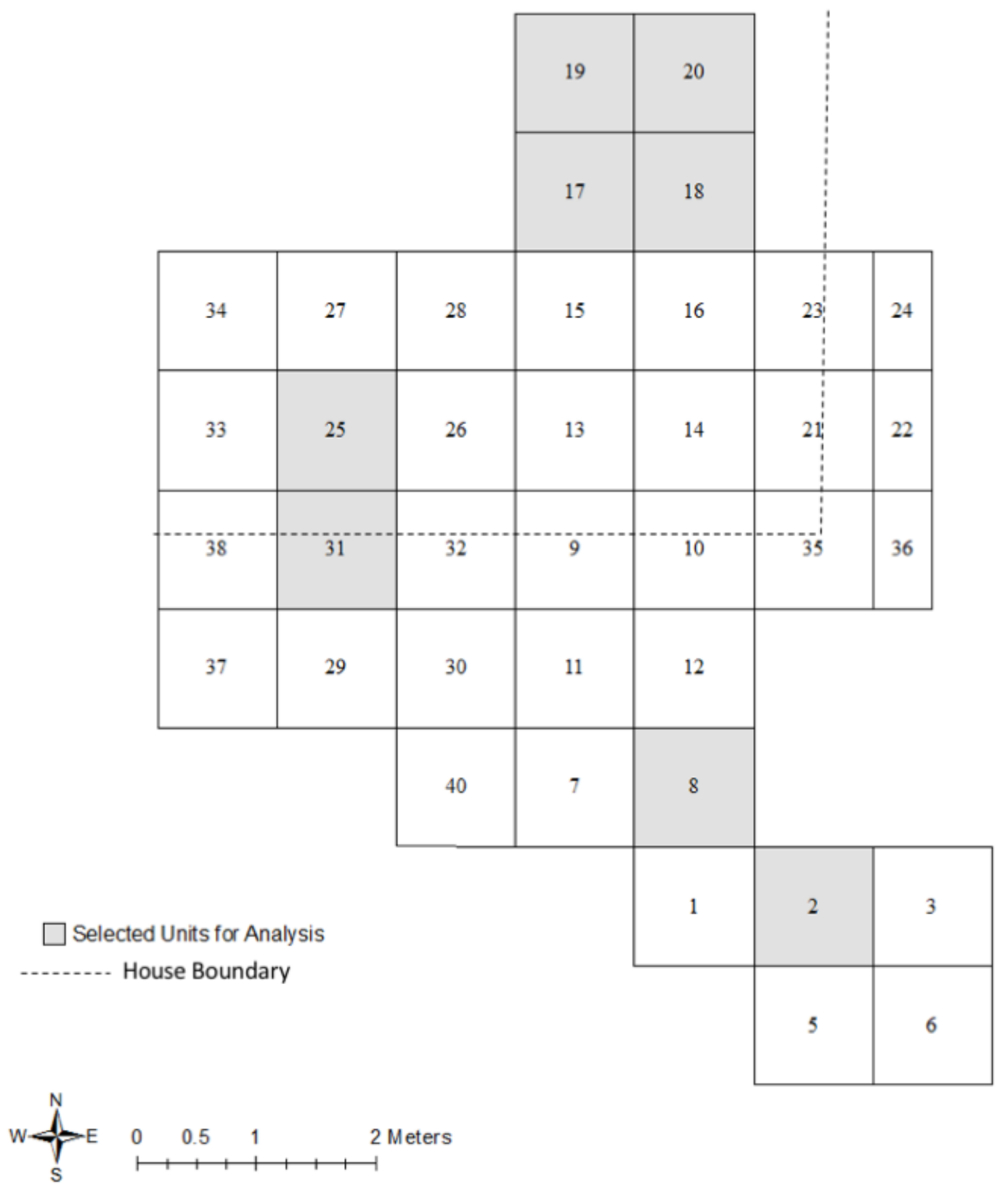

Figure 5. Map of Area A4 showing excavation units chosen for STR study. Dotted line indicates approximate boundary of structure. 
Table 5. Characteristics of units selected for analysis

\begin{tabular}{ll}
\hline Unit & Characteristics \\
\hline 17 & CZ 4, 5 and 6; during house occupation \\
18 & CZ 4, 5 and 6; during house occupation \\
19 & CZ 4, 5 and 6; during house occupation \\
20 & CZ 4, 5 and 6; during house occupation \\
& CZ 2, 4, and 7; oldest and youngest \\
deposits in A4 & CZ 2, 3, 4, and 7; oldest and youngest \\
& deposits in A4 \\
& CZ 3, 4, 5, and 6; large estimated \\
& sample size and broad occupation range \\
25 & CZ 3, 4, 5, and 6; large estimated \\
& sample size and broad occupation range \\
&
\end{tabular}

Since I would like to characterize fish representation in each $\mathrm{CZ}$ and examine variation within and outside an identified house, I established redundancy as proportional representation of fish families for each $\mathrm{CZ}$ within an excavation unit. A total of 26 such unit/CZ contexts exist in the eight units in my study (Table 6). My subsamples are the buckets within a given chronological zone and unit, which allows me to study variation in fish representation across space and through time. An alternative sampling strategy could take subsamples from a single bucket to establish redundancy for that bucket. However, fishbone quantities from $1 / 4$ in mesh in a given bucket were insufficient for this. 
Table 6. Number of "C/CX" and "S" Buckets by unit/CZ

\begin{tabular}{|c|c|c|c|c|}
\hline Unit & Chronozone & $\begin{array}{l}\text { Total Number of } \\
\text { "C/CX" Buckets }\end{array}$ & $\begin{array}{l}\text { Number of "S" } \\
\text { Buckets Analyzed }\end{array}$ & $\begin{array}{l}\text { Total Number } \\
\text { of "S" } \\
\text { Buckets* }\end{array}$ \\
\hline \multirow[t]{3}{*}{2} & CZ 7 & 5 & 15 & 21 \\
\hline & $\mathrm{CZ} 4$ & 15 & 15 & 61 \\
\hline & CZ 2 & 3 & 7 & 9 \\
\hline \multirow[t]{4}{*}{8} & CZ 7 & 3 & 17 & 20 \\
\hline & $\mathrm{CZ} 4$ & 7 & 14 & 33 \\
\hline & CZ 3 & 1 & 4 & 5 \\
\hline & $\mathrm{CZ} 2$ & 4 & 14 & 18 \\
\hline \multirow[t]{3}{*}{17} & CZ 6 & 4 & 12 & 29 \\
\hline & CZ 5 & 4 & 7 & 13 \\
\hline & $\mathrm{CZ} 4$ & 3 & 8 & 8 \\
\hline \multirow[t]{3}{*}{18} & CZ 6 & 8 & 14 & 27 \\
\hline & CZ 5 & 4 & 7 & 7 \\
\hline & $\mathrm{CZ} 4$ & 2 & 3 & 3 \\
\hline \multirow[t]{3}{*}{19} & CZ 6 & 3 & 9 & 23 \\
\hline & CZ 5 & 2 & 8 & 18 \\
\hline & $\mathrm{CZ} 4$ & 5 & 10 & 11 \\
\hline \multirow[t]{3}{*}{20} & CZ 6 & 5 & 9 & 23 \\
\hline & CZ 5 & 3 & 7 & 13 \\
\hline & $\mathrm{CZ} 4$ & 5 & 6 & 10 \\
\hline \multirow[t]{3}{*}{25} & CZ 6 & 10 & 6 & 8 \\
\hline & CZ 5 & 3 & 7 & 13 \\
\hline & $\mathrm{CZ} 4$ & 3 & 2 & 2 \\
\hline \multirow[t]{5}{*}{31} & CZ 6 & 5 & 7 & 9 \\
\hline & CZ 5 & 5 & 14 & 18 \\
\hline & $\mathrm{CZ} 4$ & 1 & 1 & 1 \\
\hline & CZ 3 & 5 & 9 & 14 \\
\hline & Grand Total & 118 & 232 & 419 \\
\hline
\end{tabular}

*The NSF project determined that the mesh size listed for a given faunal sample was sometimes incorrect. For example, fish remains that were supposed to be from 1/4 in. mesh contained much larger specimens that should have been captured in the $1 / 2$ in. mesh, as well as much smaller specimens that should have fallen through to $1 / 8$ in. mesh. I addressed this problem for the " $\mathrm{S}$ " buckets fish remains by passing all the remains from a given bucket through nested screens $(1 / 2$ in., 1/ 4 in., 1/8 in.) and re-bagging and labelling the mesh size. For my STR project, I rescreened and analyzed remains from a sample of buckets from each unit/CZ, stopping when I had reached redundancy as described in the text. After this process of re-screening buckets from all the unit/CZs, 19 buckets no longer contained identifiable fish remains in the $>1 / 4$ in. mesh; and therefore such buckets could not be included in my study. The bucket counts listed above are 
based on the original " $S$ " bucket counts, that were listed as $>1 / 4$ in. fish remains before rescreening (Appendix B). 
Another decision influencing the rate at which I achieved redundancy is the taxonomic level chosen to calculate proportional representation. The intensity of sampling to reach proportional representation at the species level is much higher than it would be for the family level, simply because there are more categories as Linnaean classification becomes more specific. For example, the order Scorpaeniformes is represented by four families in Číx ${ }^{\mathrm{w}}$ icən deposits (Table 7). Each family is represented by between one and five species. Achieving redundancy at the species level would require considerably higher sampling intensity because faunal counts would be distributed across a larger number of categories (Table 7). I have chosen to use the family taxonomic level because family level identification should provide enough detail to show taxonomic differences across CZs without requiring an excessive sampling effort, in line with my thesis goal. [Note: remains of flatfish represented by two families in the north Pacific, Pleuronectidae and Paralichthyidae, are difficult to distinguish, but can easily be assigned to the order Pleuronectiformes. Thus for flatfish, the taxonomic level applied was actually order, not family.

Table 7. List of taxa represented at Čîx ${ }^{\mathrm{w}}$ icon within the order Scorpaeniformes

\begin{tabular}{lll}
\hline Order & Family & Species \\
\hline Scorpaeniformes & Cottidae & Leptocottus armatus \\
& & Myoxocephalus polyacathocephalus \\
& & Enophrys bison \\
& Hemilepidotus sp. \\
& Scorpaenichthys marmoratus \\
& & \\
& & Ophiodon elongatus \\
& & Hexagrammos sp. \\
& Anoplopomidae & Anoplopoma fimbria \\
& Scorpaenidae & Sebastes sp. \\
\hline
\end{tabular}


While family level identifications were used to calculate proportional representation, all specimens were also identified to finest taxon and element following the protocol established for the Čî́x ${ }^{w}$ icən project (Butler et al. in preparation). Thus genus and species identifications provide nominal records of fish representation, which can be compared with other fish records from the Čî́x ${ }^{w}$ icən site.

Another consideration is specimen quantification. Commonly used quantification methods include: Minimum Number of Individuals (MNI), Minimum Number of Elements (MNE), Minimum Animal Units (MAU) and Number of Identified Specimens (NISP) (Grayson 1984; Lyman 1994). MNI, MNE, and MAU are all derived counts, meaning that there is always some researcher interpretation involved in arriving at the final quantification (Lyman 1994).

My chosen quantification method is NISP, which has been shown to correlate with MNI and MAU (Grayson 1979, 1984). Because I also recorded whether specimens had unique landmarks, it will be possible to calculate MNE for future research if needed. One other quantification method I will use is Number of Specimens (NSP), which includes all remains that can be assigned to fish, including those identified to family, and simply can be assigned to "fish".

A total of 419 "S" bucket samples (4190 L) with fish remains were collected from the eight units in my study (Table 6). A total of 118 "C/CX" buckets (1180 L) were retained from the same units (Table 6). Thus adding "S" bucket samples will increase the volume of material sampled by a factor of nearly four. Some CZs in units are represented by extremely small numbers of buckets (e.g. Units 18/CZ 3 with three buckets), while others contain much larger numbers of buckets (e.g. Unit 2/CZ 7 with 15 buckets). 
The protocol I used to identify specimens is the same as that established by Butler for the larger Čî́ $\mathrm{x}^{\mathrm{w}}$ icən project (Butler et al. in preparation). Specimens were identified using the collections housed in the Department of Anthropology at Portland State University with additional comparative specimens from the personal collections of Robert Kopperl (Willamette Cultural Resources Associates) and Ross Smith (University of Oregon). A list of all elements identified for each taxon is listed in Butler et al. (in preparation) (Appendix C). For remains from each bucket selected in my STR study, I initially identified each specimen to family and finest taxon and element, which were then checked and adjusted by Butler. I recorded all my hours spent analyzing fish remains for this project. By calculating the number of hours spent on identification, and comparing that to the percentage of samples analyzed, I have estimated the amount of time saved by using STR when compared with the amount of time spent, had all "S" bucket samples from my project area been analyzed.

To implement STR I followed a series of steps, which began by selecting one of the 26 unit/CZ contexts to sample (Figure 6). The buckets in the selected unit/CZ were then randomly ordered for selection using an online random number generator (Figure 6). I then analyzed the first three buckets listed in the random order sequence (Figure 6).

The counts of specimens which could be identified to at least family level were then used to calculate $\mathrm{N}$ (Equation 2) (Figure 6), which represents an estimate of the total NISP if all fish remains were identified. In an iterative process, I began by taking the total NISP of the first three buckets, then dividing that NISP by the number of buckets analyzed, and then multiplying that number by the total number of buckets in a unit/CZ being analyzed (Figure 6). 
The estimated N was then inserted into the Van der Veen and Fieller (1982) equation with the constants $\mathrm{d}, \mathrm{P}$, and $\mathrm{Z} \alpha$ to find out what NISP must be studied to achieve redundancy (Equation 2). For my study I analyzed a minimum of three buckets, which was possible for all but two unit/CZs where only one or two buckets were collected (Table 6). In cases where my initial study of three buckets showed the NISP was insufficient, additional buckets were sorted and analyzed. These additional identifications were then used to recalculate N and re-run STR (Equation 2) (Figure 6) Redundancy was reached when the selected unit/CZs total NISP was greater than or equal to $\mathrm{n}$, also known as the point of redundancy. This process was repeated for each unit/CZ.

Once the analysis was complete, I developed several additional measures to explore how bone distribution and abundance affected STR (the number of samples I needed to study to reach redundancy). I calculated bone density for each unit/CZ by taking the total NSP from a unit/CZ, and dividing it by the total volume in that same unit/CZ. Since each bucket is approximately 10 liters, the volume sampled in a given unit/CZ was easily calculated. For example, in unit $2 / \mathrm{CZ} 4$ the fish NSP is 1543 , and the total number of " $\mathrm{S}$ " buckets is 15 , thus providing a density of $\frac{1543}{150}$ or 10.3 . I also calculated an adjusted NISP, which will allow me to directly compare counts for each taxon from the " $\mathrm{S}$ " buckets to counts from the " $\mathrm{C} / \mathrm{CX}$ " buckets from a given unit/CZ or for larger aggregates such as CZ. Such a comparison is important to one my research questions, which is to see if increased sample size from the " $\mathrm{S}$ " buckets changed our understanding of fish representation. I calculated the adjusted NISP for each family within each unit/CZ by dividing the observed NISP for a family by the number of buckets analyzed in a unit/CZ, and then multiplying that number by the total number of buckets in 
the same unit/CZ. For example, in unit 17/CZ 6, sampling ceased at 12 buckets out of a total 29 buckets available. To find the "adjusted" family NISP, I multiplied each observed family NISP by $\frac{29}{12}$ or 2.41 (Table 8 ). The observed NISP for ratfish (Chimaeridae) in unit 17/CZ 6 was eight, and, after multiplying that observed count by 2.41, the adjusted NISP for Chimaeridae in unit 17/CZ 6 is 19 (Table 8). Such a process was carried out for each of the 26 unit/CZs.

Table 8. Comparison of NISP between "Observed" vs. "Adjusted" values from unit $17 / \mathrm{CZ} 6$, to illustrate how adjusted values were obtained for all unit/CZs. Sampling ceased at 12 out of 29 buckets, thus the multiplier required to "adjust" for family NISP is 2.41 .

\begin{tabular}{lrr}
\hline Family & $\begin{array}{l}\text { Observed } \\
\text { NISP }\end{array}$ & \multicolumn{2}{c}{$\begin{array}{l}\text { Adjusted } \\
\text { NISP }\end{array}$} \\
\hline Chimaeridae & 8 & 19 \\
Rajidae & 5 & 12 \\
Squalidae & 15 & 36 \\
Embiotocidae & 4 & 10 \\
Salmonidae & 28 & 68 \\
Gadidae & 109 & 263 \\
Cottidae & 57 & 138 \\
Hexagrammidae & 8 & 19 \\
Pleuronectiformes & 25 & 60 \\
Scorpaenidae & 3 & 7 \\
Total & 262 & 632 \\
\hline
\end{tabular}




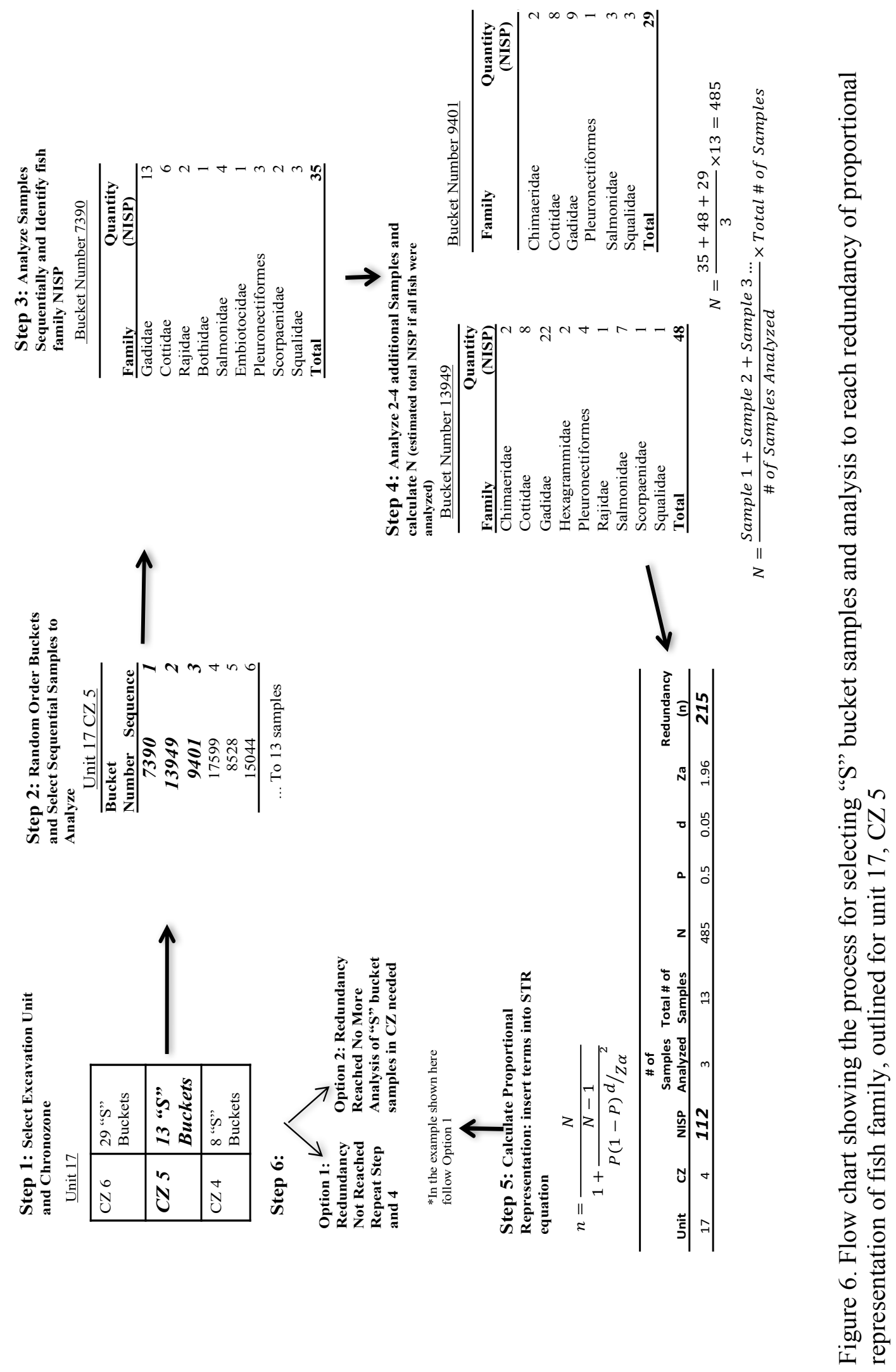




\section{Chapter 4. Results}

\subsection{Summary of Fish Remains and STR Sampling}

A total of 3,646 fish remains were identified to some taxon below "fish" from the "S" buckets (Table 9). A total of 29 taxa, including thirteen families and 22 species are represented (Table 9). The families with the highest abundance are: dogfish (Squalidae), salmon and trout (Salmonidae), cod (Gadidae), and sculpin (Cottidae), which represent $80 \%$ of the total NISP. As expected from $1 / 4$ in. mesh, the fish fauna is dominated by large-bodied fish, which is seen in the finest taxa present. Large bodied Pacific cod (Gadus macrocephalus) and great sculpin (Myoxocephalus polyacanthocephalus) dominate the cod (Gadidae) and sculpin (Cottidae) families respectively. Small-bodied taxa such as Pacific tomcod (Microgadus proximus), and staghorn sculpin (Leptocottus armatus) are either absent or present in much smaller quantities than large-bodied fishes (Table 9). Unidentifiable fish make up 51\% of the total 7,307 Number of Specimens (NSP). The "S" bucket fish remains were identifiable to a taxon below fish at a rate of $49 \%$.

I studied remains from 269 "S" buckets out of a total of 419 buckets, or $47 \%$ of the buckets (Table 10). For some unit/CZs only a fraction of the buckets needed to be studied, while for others all the buckets needed to be studied. Translating this to volume, my STR study estimated fish representation for 4190 liters of matrix in A4, though I studied remains from only 2690 liters. The percentage of buckets I analyzed out of the total number of available buckets for each unit/CZ ranged from 22\% - 100\% (Table 10; Figure 7). $100 \%$ of the specimens were analyzed for six of the unit/CZs. STR was most helpful for six other unit/CZs where I analyzed less than $50 \%$ of the total buckets and was 
moderately helpful for the remaining 14 unit/CZs. This analysis took me a total of 154 hours, and based on the percentage of material analyzed, 174 hours were saved.

Table 9. Frequency (NISP) of fish taxa from "S" buckets

\begin{tabular}{|c|c|c|}
\hline Family & Finest Taxon & NISP \\
\hline & Elasmobranchii & 5 \\
\hline Rajidae & Raja sp. & 69 \\
\hline Squalidae & Squalus acanthias & 329 \\
\hline Chimaeridae & Hydrolagus colliei & 81 \\
\hline Clupeidae & Clupea pallasii & 12 \\
\hline Salmonidae & Oncorhynchus sp. & 600 \\
\hline \multirow[t]{2}{*}{ Gadidae } & Gadidae & 873 \\
\hline & Gadus macrocephalus & 205 \\
\hline \multirow[t]{2}{*}{ Embiotocidae } & Embiotocidae & 54 \\
\hline & Damalichthys vacca & 1 \\
\hline Anoplopomatidae & Anoplopoma fimbria & 1 \\
\hline Scorpaenidae & Sebastes sp. & 19 \\
\hline \multirow[t]{3}{*}{ Hexagrammidae } & Hexagrammidae & 3 \\
\hline & Hexagrammos sp. & 59 \\
\hline & Ophiodon elongatus & 76 \\
\hline \multirow[t]{6}{*}{ Cottidae } & Cottidae & 38 \\
\hline & Enophrys bison & 182 \\
\hline & Hemilepidotus sp. & 146 \\
\hline & Hemilepidotus/Scorpaenichthys & 168 \\
\hline & Leptocottus armatus & 147 \\
\hline & $\begin{array}{l}\text { Myoxocephalus } \\
\text { polyacanthocephalus }\end{array}$ & 229 \\
\hline \multirow[t]{7}{*}{ Pleuronectiformes } & & 300 \\
\hline & Citharichthys sp. & 8 \\
\hline & Pleuronectidae & 32 \\
\hline & Atheresthes stomias & 1 \\
\hline & Eopsetta jordani & 2 \\
\hline & $\begin{array}{l}\text { Hippoglossus stenolepis } \\
\text { Lepidopsetta bilineata }\end{array}$ & $\begin{array}{l}4 \\
1\end{array}$ \\
\hline & Platichthys stellatus & $\begin{array}{c}1 \\
3,646\end{array}$ \\
\hline Unidentified Fish & & 3,661 \\
\hline Grand Total & & 7,307 \\
\hline
\end{tabular}


Table 10. Summary information about fish remains and "S" buckets from each unit/CZ

\begin{tabular}{|c|c|c|c|c|c|c|c|}
\hline Unit & $\overline{\mathrm{CZ}}$ & $\begin{array}{l}\text { Observed } \\
\text { NISP } \\
\text { Analyzed }\end{array}$ & $\begin{array}{c}\text { Estimated } \\
\text { Total } \\
\text { NISP (N) }\end{array}$ & $\begin{array}{c}\text { NISP } \\
\text { Required to } \\
\text { reach } \\
\text { Redundancy } \\
\text { (n)* }\end{array}$ & $\begin{array}{c}\# \text { of } \\
\text { Buckets } \\
\text { Analyzed } \\
* *\end{array}$ & $\begin{array}{c}\begin{array}{c}\text { Total \# } \\
\text { of } \\
\text { Buckets } \\
* * * *\end{array} \\
\end{array}$ & $\begin{array}{c}\text { Percent } \\
\text { Buckets } \\
\text { Analyzed }\end{array}$ \\
\hline \multirow[t]{3}{*}{2} & 7 & 83 & 109 & 85 & 16 & 21 & 76 \\
\hline & 4 & 336 & 1206 & 292 & 17 & 61 & 28 \\
\hline & 2 & 2 & 2 & 2 & 9 & 9 & 100 \\
\hline \multirow[t]{4}{*}{8} & 7 & 142 & 312 & 173 & 15 & 33 & 45 \\
\hline & 4 & 352 & 414 & 200 & 17 & 20 & 85 \\
\hline & 3 & 9 & 9 & 9 & 5 & 5 & 100 \\
\hline & 2 & 16 & 17 & 16 & 17 & 18 & 94 \\
\hline \multirow[t]{3}{*}{17} & 6 & 234 & 424 & 202 & 16 & 29 & 55 \\
\hline & 5 & 224 & 364 & 187 & 8 & 13 & 62 \\
\hline & 4 & 39 & 39 & 35 & 8 & 8 & 100 \\
\hline \multirow[t]{3}{*}{18} & 6 & 302 & 582 & 232 & 14 & 27 & 52 \\
\hline & 5 & 60 & 60 & 52 & 7 & 7 & 100 \\
\hline & 4 & 7 & 7 & 7 & 3 & 3 & 100 \\
\hline \multirow[t]{3}{*}{19} & 6 & 289 & 739 & 253 & 9 & 23 & 39 \\
\hline & 5 & 359 & 808 & 261 & 8 & 18 & 44 \\
\hline & 4 & 35 & 39 & 35 & 10 & 11 & 91 \\
\hline \multirow[t]{3}{*}{20} & 6 & 288 & 662 & 243 & 10 & 23 & 43 \\
\hline & 5 & 258 & 373 & 189 & 9 & 13 & 69 \\
\hline & 4 & 17 & 15 & 15 & 11 & 10 & 100 \\
\hline \multirow[t]{3}{*}{25} & 6 & 55 & 55 & 48 & 8 & 8 & 100 \\
\hline & 5 & 99 & 117 & 90 & 11 & 13 & 85 \\
\hline & 4 & 6 & 6 & 6 & 4 & 4 & 100 \\
\hline \multirow[t]{4}{*}{31} & 6 & 124 & 159 & 113 & 7 & 9 & 78 \\
\hline & 5 & 98 & 118 & 90 & 15 & 18 & 83 \\
\hline & 4 & 2 & 2 & 2 & 1 & 1 & 100 \\
\hline & 3 & 50 & 50 & 44 & 14 & 14 & 100 \\
\hline Total & 26 & 3,646 & 6,688 & & 269 & 419 & \\
\hline
\end{tabular}

* calculated from Cochran (1977b)

**These bucket counts reflect the number of buckets with fish remains from $>1 / 4$ in. screens before re-screening. This means that even those buckets that did not retain $>1 / 4$ in. fish remains are included. (Appendix B)

***These bucket counts reflect the original number of "S" buckets as listed in the Burke catalog, prior to re-screening. See Table 6 and Appendix B for further information. 


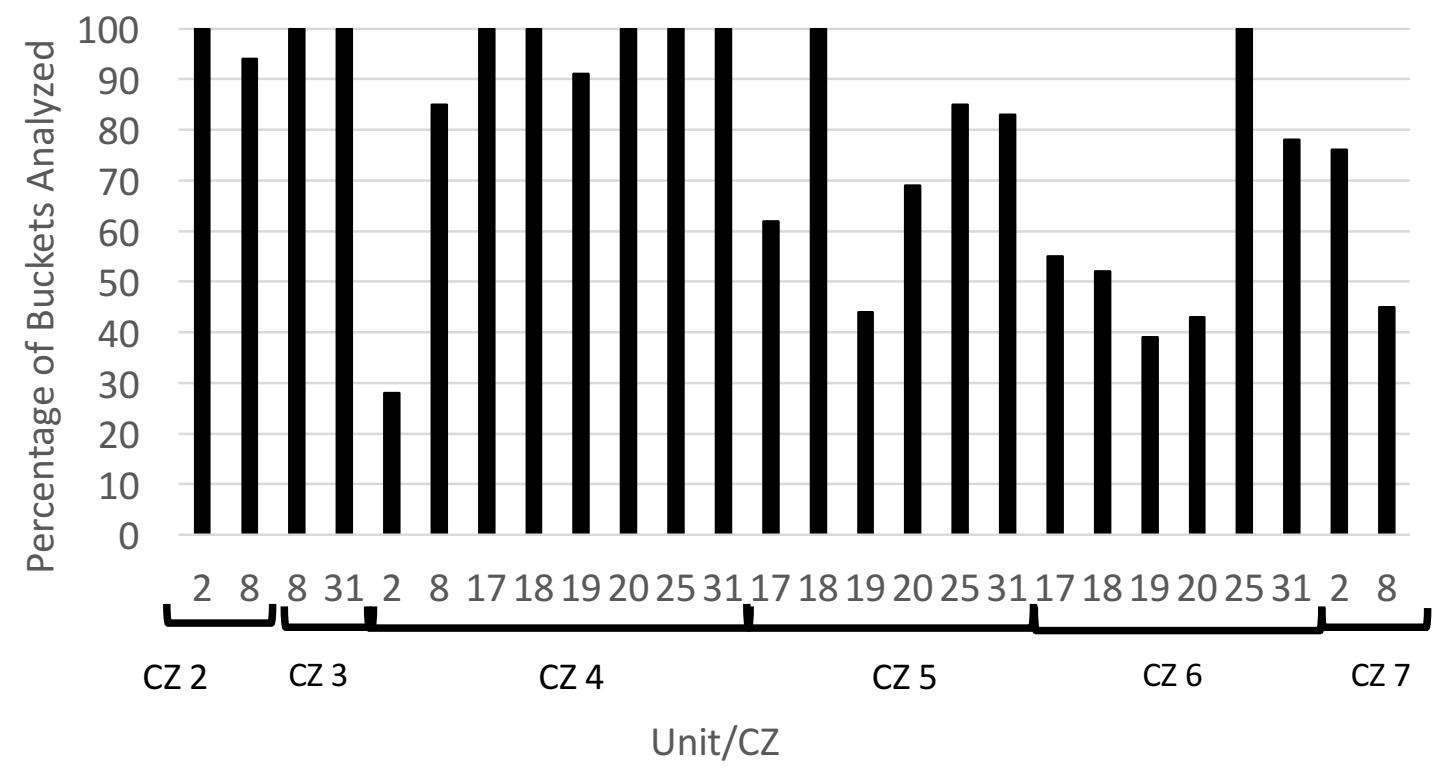

Figure 7. Percent NISP analyzed by unit/CZ, "S" buckets.

Fishbone density in the "S" buckets varies greatly across unit/CZs, from a low of 0.2 to a high of 10.3 (Table 11). The average unit/CZ density of fish remains for the "S" buckets is 3.04. Densities tend to be lowest in CZ 2, and 3, under 1.0, much lower than the average (Figure 8). CZ 4 is the most variable with densities ranging from 0.2 to 10.3 . Densities in CZs 5, 6, and 7 range from 1.4 to 9.6 (Figure 8).

CZs with limited representation across the eight excavation units tended to have low bone frequency (Figure 8). For example, CZ 2, 3, and 7 were only present in two or three excavation units and in all cases density is 3.0 or lower. On the other hand, CZs 4 , 5 , and 6 were distributed across all eight units, and bone density showed high and low values.

There is a strong inverse relationship between the percentage of buckets analyzed and bone density (NSP/liter) across unit/CZs: the lower a unit/CZ's density, the more 
buckets were analyzed (Figure 9; $\mathrm{R}=0.812 \mathrm{p}$-value $=<0.0001$ ). For example, unit $17 / \mathrm{CZ} 5$ has a mid-range density of 4.8 and $62 \%$ of the buckets were sampled, while unit 25/CZ 4 had a low density of 0.2 and $100 \%$ of the sample was analyzed (Figure 9). One major exception to this pattern is unit 20/CZ 5, where $69 \%$ of the buckets were studied despite having a bone density of 6.8 .

The relationship between the estimated total NISP and the percent of buckets analyzed in a unit/CZ (Figure 10) mirrors that of density (NSP/liter) and percent of buckets analyzed (Figure 9). As NISP in a unit/CZ increases, the percent of buckets in the same unit/CZ decreases (Error! Reference source not found.; $\mathrm{R}=0.915$, $\mathrm{p}$-value $=<$ 0.0001). For example, in unit 19/CZ 5 there is an estimated total NISP of 898 and I analyzed $44 \%$ of the buckets. Conversely, in unit $18 / \mathrm{CZ} 4$ there is an estimated total NISP of 7 and I analyzed $100 \%$ of the buckets. One outlier to the trend is unit 4/CZ 4. With an estimated total NISP of 868 , I should have had to study less than $50 \%$ of buckets, whereas I actually studied $85 \%$ of the total buckets.

The relationships between density or NISP and percentage of buckets analyzed do not follow a perfect linear trend because of heterogeneity in the CZs, which are aggregates of various deposit types, such as those dominated by shell, sand, or architectural components such as posts. Bone distribution and abundance is not uniform across such deposits. Therefore, one should not expect STR to conform directly to bone density, or absolute bone frequencies. 
Table 11. Comparison of fishbone density (NSP/liter) between " $\mathrm{S}$ " and "C/CX" buckets. Values listed for "S" buckets represent those remains directly "observed" and tallied rather than those whose values were adjusted to account for variable volume of matrix studied in a given unit/CZ (see Table 8).

\begin{tabular}{|c|c|c|c|c|c|c|c|}
\hline \multirow[b]{2}{*}{ Unit } & \multirow[b]{2}{*}{$\mathbf{C Z}$} & \multicolumn{3}{|c|}{$\begin{array}{c}\text { "S" Buckets (only analyzed } \\
\text { buckets) }\end{array}$} & \multicolumn{3}{|c|}{ "C/CX" Buckets (> 1/4 in. only) } \\
\hline & & NSP & $\begin{array}{c}\mathrm{N} \text { of } \\
\text { Buckets }\end{array}$ & $\begin{array}{l}\text { NSP/ } \\
\text { Liter }\end{array}$ & NSP & $\begin{array}{c}\mathrm{N} \text { of } \\
\text { Buckets }\end{array}$ & $\begin{array}{l}\text { NSP/ } \\
\text { Liter }\end{array}$ \\
\hline \multirow[t]{3}{*}{2} & $\mathrm{CZ} 7$ & 193 & 16 & 2.7 & 31 & 5 & 0.6 \\
\hline & $\mathrm{CZ} 4$ & 854 & 17 & 10.3 & 371 & 15 & 2.0 \\
\hline & $\mathrm{CZ} 2$ & 39 & 9 & 1.0 & 3 & 3 & 0.1 \\
\hline \multirow[t]{4}{*}{8} & $\mathrm{CZ} 7$ & 356 & 15 & 2.1 & 53 & 3 & 1.8 \\
\hline & $\mathrm{CZ} 4$ & 721 & 17 & 5.2 & 240 & 7 & 3.3 \\
\hline & $\mathrm{CZ} 3$ & 13 & 5 & 0.3 & 0 & 1 & 0.0 \\
\hline & $\mathrm{CZ} 2$ & 48 & 17 & 0.3 & 4 & 4 & 0.1 \\
\hline \multirow[t]{3}{*}{17} & $\mathrm{CZ} 6$ & 474 & 16 & 4.0 & 192 & 4 & 4.8 \\
\hline & CZ 5 & 387 & 8 & 5.5 & 170 & 4 & 4.3 \\
\hline & $\mathrm{CZ} 4$ & 73 & 8 & 0.9 & 14 & 3 & 0.5 \\
\hline \multirow[t]{3}{*}{18} & CZ 6 & 586 & 14 & 4.2 & 266 & 8 & 3.3 \\
\hline & CZ 5 & 110 & 7 & 1.6 & 134 & 4 & 2.9 \\
\hline & $\mathrm{CZ} 4$ & 8 & 3 & 0.3 & 1 & 2 & 0.1 \\
\hline \multirow[t]{3}{*}{19} & CZ 6 & 512 & 9 & 5.7 & 158 & 3 & 5.3 \\
\hline & CZ 5 & 767 & 8 & 9.6 & 102 & 2 & 5.0 \\
\hline & $\mathrm{CZ} 4$ & 83 & 10 & 0.8 & 44 & 5 & 0.9 \\
\hline \multirow[t]{3}{*}{20} & CZ 6 & 589 & 10 & 6.5 & 119 & 5 & 2.4 \\
\hline & CZ 5 & 614 & 9 & 8.8 & 138 & 3 & 4.6 \\
\hline & $\mathrm{CZ} 4$ & 14 & 10 & 0.2 & 24 & 5 & 0.5 \\
\hline \multirow[t]{3}{*}{25} & CZ 6 & 93 & 8 & 1.6 & 205 & 10 & 2.1 \\
\hline & CZ 5 & 253 & 11 & 3.6 & 93 & 3 & 3.1 \\
\hline & $\mathrm{CZ} 4$ & 8 & 4 & 0.4 & 1 & 3 & 0.0 \\
\hline \multirow[t]{5}{*}{31} & CZ 6 & 245 & 7 & 3.5 & 133 & 5 & 2.7 \\
\hline & CZ 5 & 193 & 15 & 1.4 & 42 & 5 & 0.8 \\
\hline & $\mathrm{CZ} 4$ & 2 & 1 & 0.2 & 0 & 1 & 0.0 \\
\hline & $\mathrm{CZ} 3$ & 104 & 14 & 1.2 & 20 & 5 & 0.4 \\
\hline & Total & 7295 & 269 & & 2480 & 121 & \\
\hline
\end{tabular}




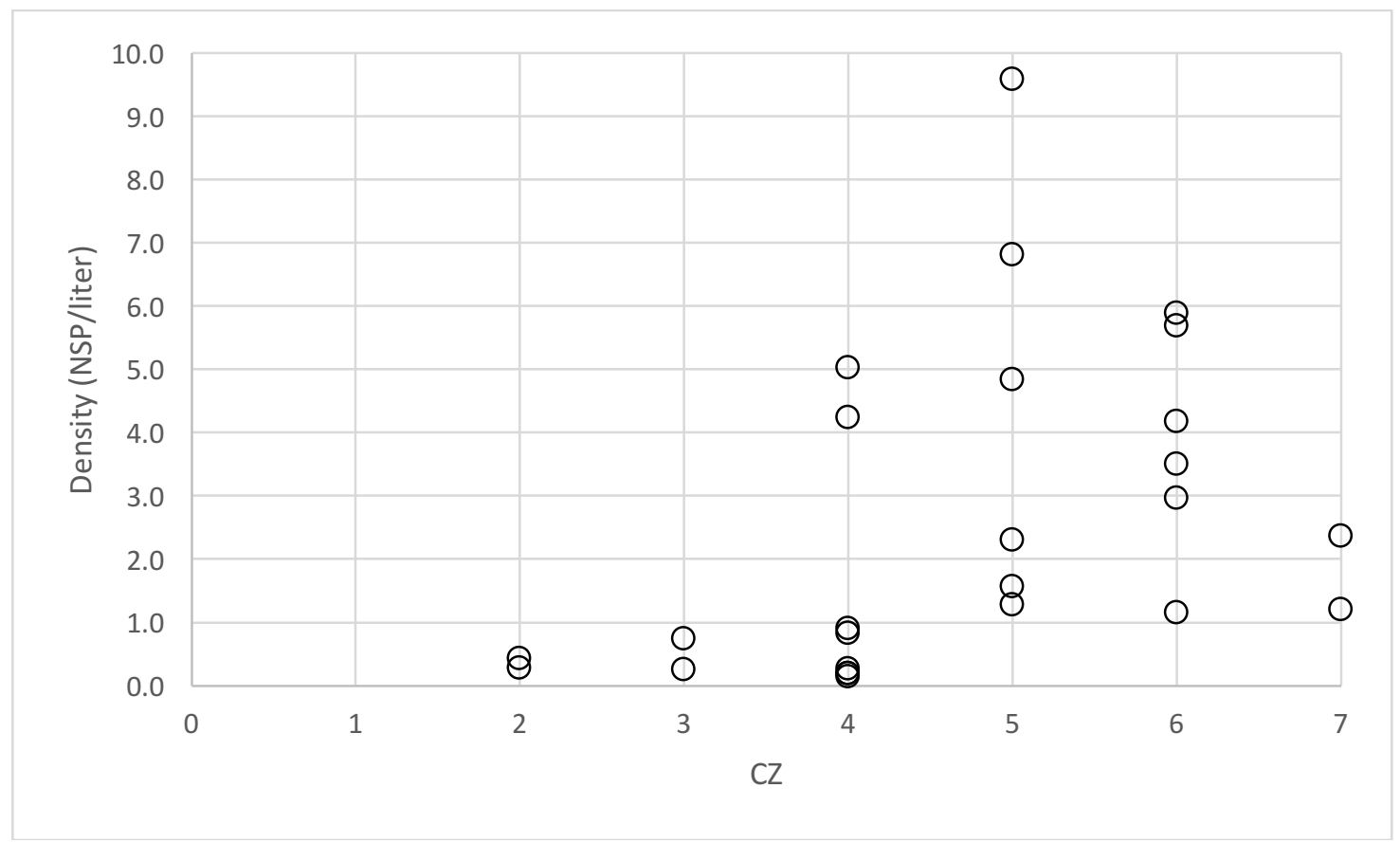

Figure 8. Scatterplot showing relationship between "S" bucket Density (NSP/liter) and chronozone for unit/CZs.

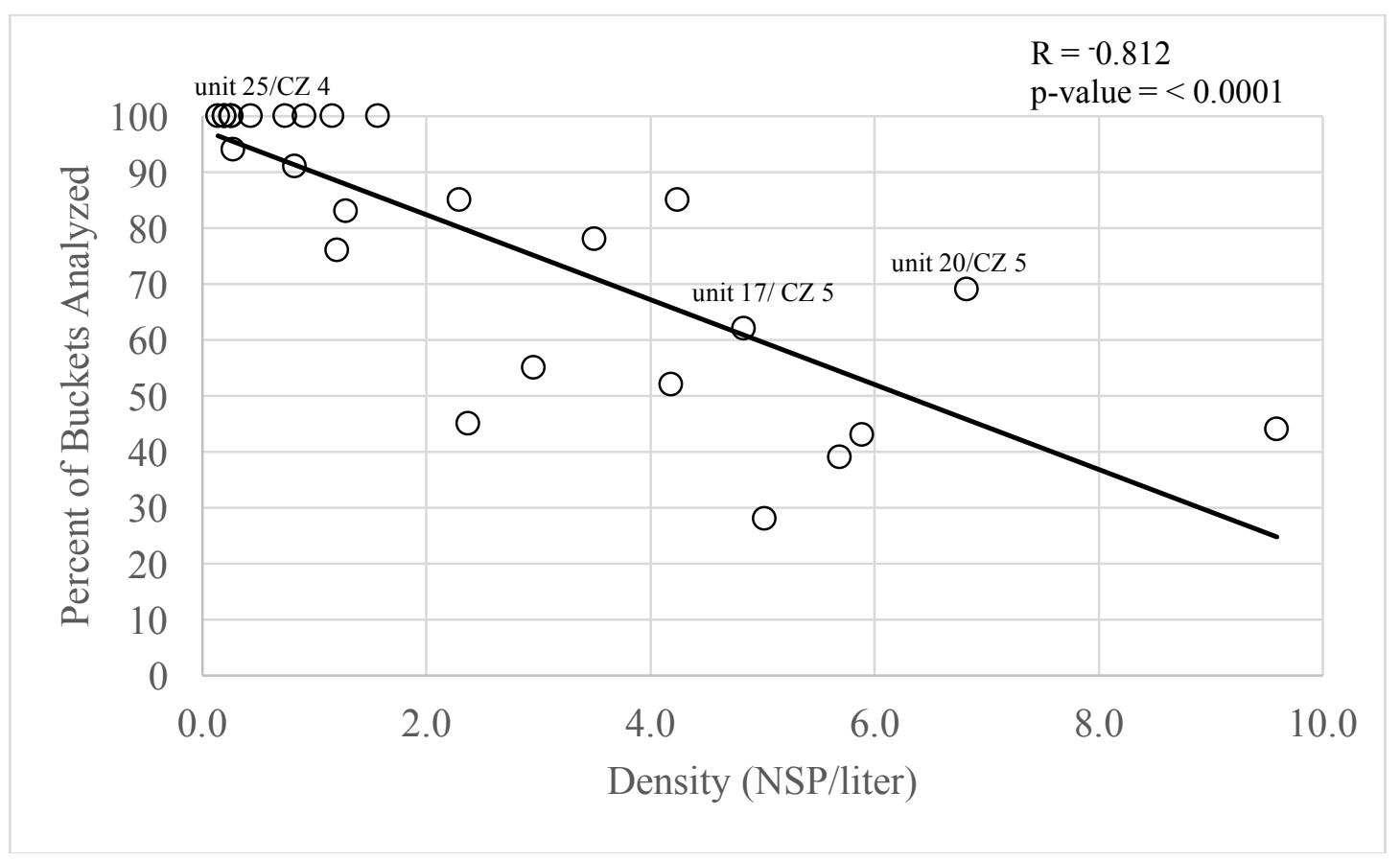

Figure 9. Scatterplot showing the relationship between density (NSP/Liter) and percentage of buckets analyzed for each unit/CZ. 


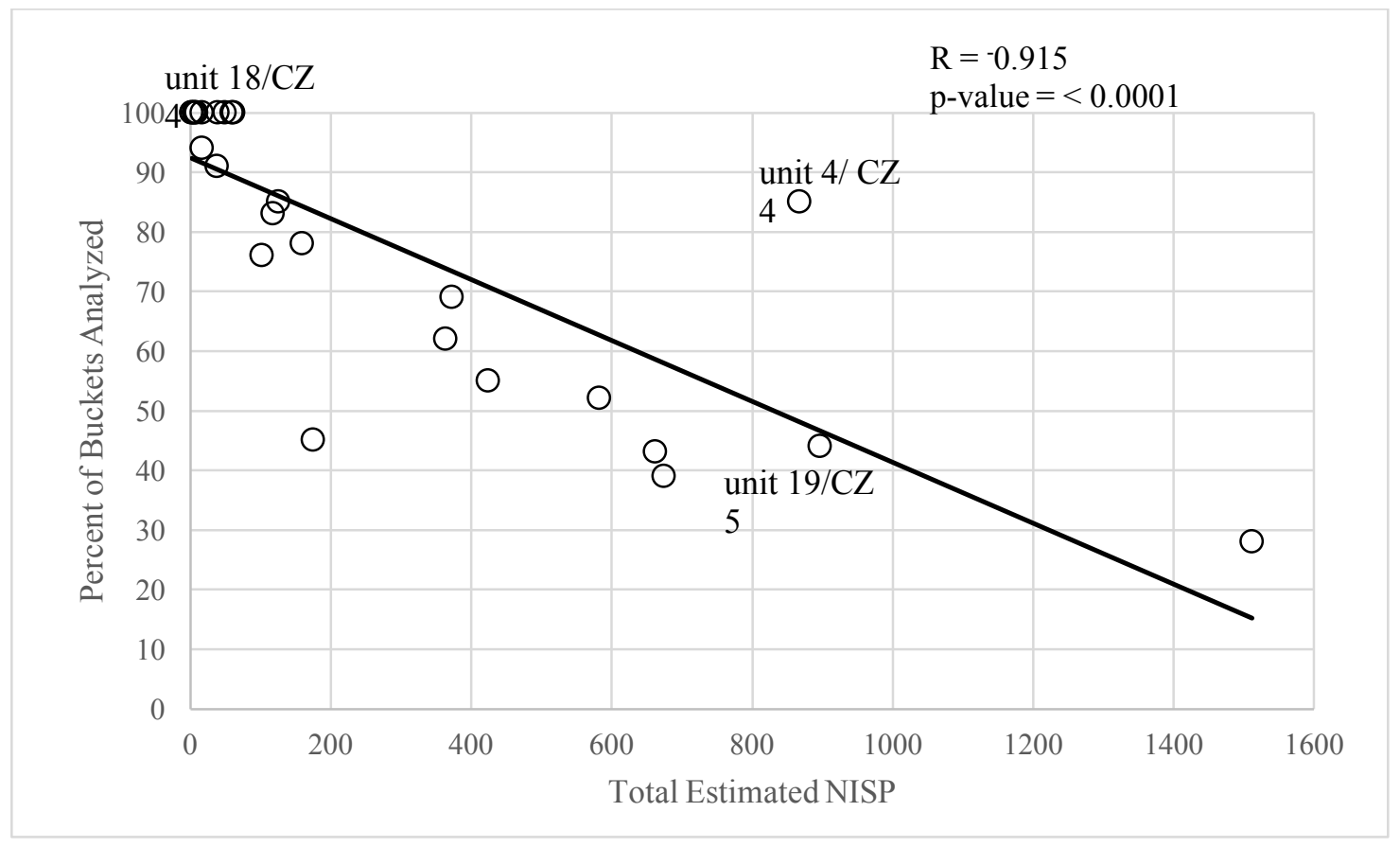

Figure 10. Scatterplot showing the relationship between the estimated total NISP of fish remains and the percent of buckets analyzed in a given unit/CZ. 


\section{2: "C/CX" vs. "S" Bucket Comparison}

As previously stated, the " $\mathrm{C} / \mathrm{CX}$ " buckets make up a small portion of the available material from the site as a whole. This is also true for my study samples. In the 26 unit/CZs that I included, I analyzed 269 buckets (2690 liters) of " $\mathrm{S}$ " ( $>1 / 4$ in.) buckets, which represent 419 buckets (4190 liters) of matrix (Table 10). The "C/CX" buckets from the same unit/CZs make up 121 buckets (1210 liters), or $22 \%$ of the combined "C/CX" + "S" buckets from the 26 unit/CZs (Table 11).

Because large-bodied fish make up a small proportion of the fish remains collected from the " $\mathrm{C} / \mathrm{CX}$ " buckets in particular, the $22 \%$ sample the " $\mathrm{C} / \mathrm{CX}$ " buckets represent may not be adequate to represent large-bodied fish. To test whether the " $\mathrm{C} / \mathrm{CX}$ " buckets are adequate for representing large-bodied fish, I have compared the NISP for fishes from " $\mathrm{C} / \mathrm{CX}$ " buckets to fish representation with " $\mathrm{S}$ " bucket fish remains added. If "C/CX" buckets have adequately represented fish families, then fish family representation for " $\mathrm{C} / \mathrm{CX}$ " vs. "C/CX" + "S" buckets should be similar. For this comparison, I used the adjusted NISP values for "S" buckets, which were calculated for each unit/CZ (see Table 8). The adjusted "S" bucket NISP (8062) make up 83\% percent of the combined total (9815) (Table 12). This is largely because the "S" buckets represent a much larger volume of material. 
Table 12. Comparison of fish representation (\%NISP) between "S", "C/CX", and "C/CX" + "S" buckets from study units.

\begin{tabular}{lcccccc}
\hline & \multicolumn{2}{c}{ "S" Buckets } & "C/CX" Buckets & \multicolumn{2}{c}{$\begin{array}{c}\text { "CX" + "S" } \\
\text { Buckets }\end{array}$} \\
Family & $\begin{array}{c}\text { Adjusted } \\
\text { NISP }\end{array}$ & \% & NISP & \% & NISP & \% \\
\hline Rajidae & 147 & 2.02 & 144 & 2.07 & 291 & 2.05 \\
Squalidae & 666 & 8.17 & 722 & 10.40 & 1388 & 9.78 \\
Chimaeridae & 166 & 2.29 & 165 & 2.38 & 331 & 2.33 \\
Clupeidae & 22 & 0.30 & 95 & 1.37 & 117 & 0.82 \\
Salmonidae & 1356 & 16.68 & 958 & 13.80 & 2314 & 16.30 \\
Gadidae & 2471 & 31.03 & 2323 & 33.47 & 4794 & 33.76 \\
Merluccidae & 0 & 0.00 & 2 & 0.03 & 2 & 0.01 \\
Embiotocidae & 95 & 1.31 & 78 & 1.12 & 173 & 1.22 \\
Anoplopomatidae & 3 & 0.03 & 9 & 0.13 & 12 & 0.08 \\
Scorpaenidae & 42 & 0.57 & 90 & 0.01 & 132 & 0.93 \\
Hexagrammidae & 349 & 3.80 & 406 & 5.85 & 755 & 5.31 \\
Cottidae & 1836 & 24.29 & 1793 & 25.84 & 3629 & 25.56 \\
Pleuronectiformes & 780 & 9.51 & 847 & 11.10 & 1591 & 11.21 \\
\hline Total & 8062 & 100 & 1753 & 100 & 9815 & 100 \\
\hline
\end{tabular}

As shown in Figure, for the unit/CZs as a whole, adding the "S" buckets does not affect the proportional representation of fish families. The Spearman's rank order correlation for this relationship is high and significant $\left(\mathrm{R}_{\mathrm{s}}=.990, \mathrm{P}\right.$-value $\left.=<0.001\right)$, which suggests that for the study as a whole, the "C/CX" buckets were sufficient to characterize fish family representation. 


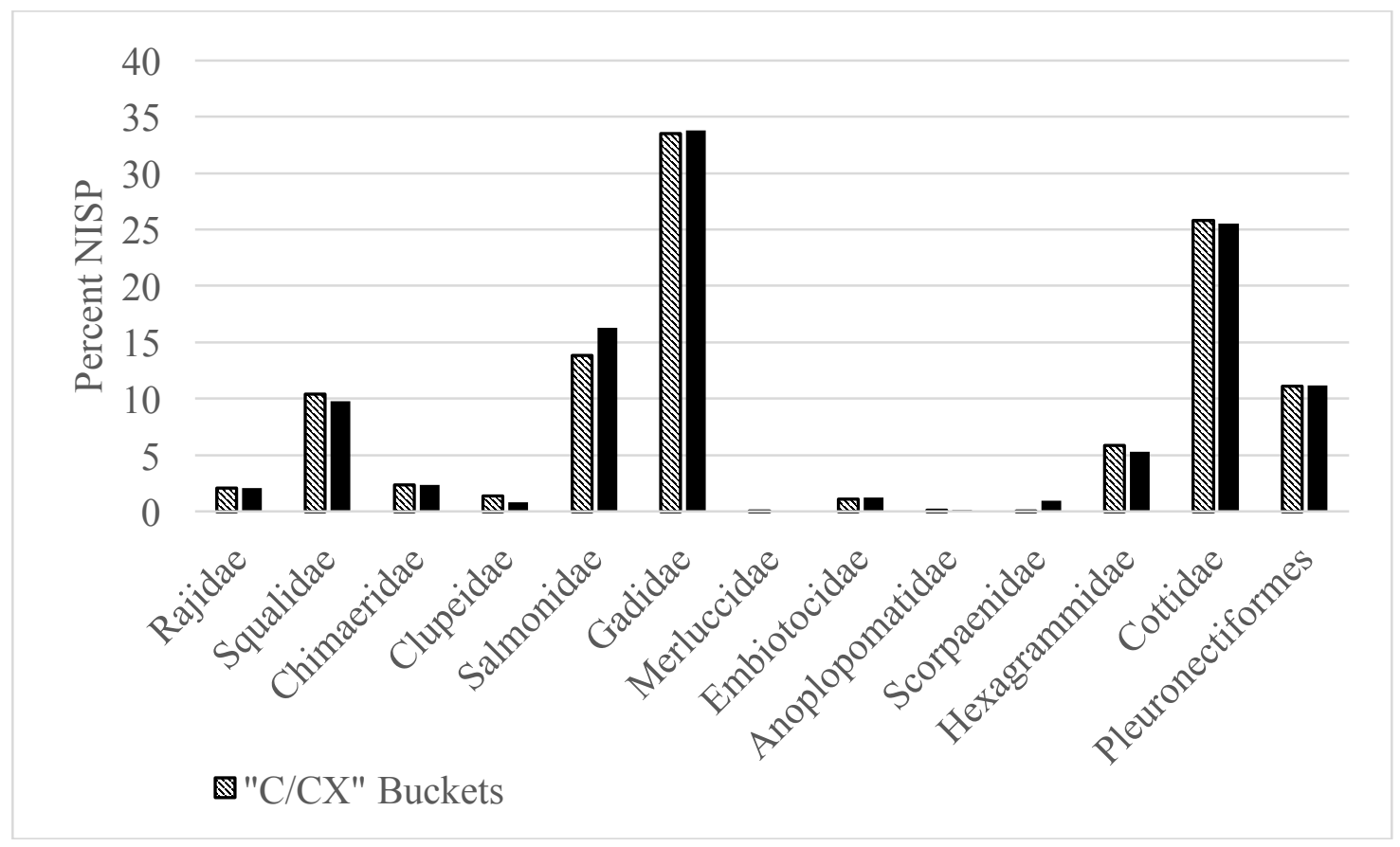

Figure 11. Proportional representation of fish families (\% NISP) from "C/CX" buckets ( $>$ $1 / 4$ in only) as compared with proportional representation of fish families from " $\mathrm{C} / \mathrm{CX}$ " + "S" buckets.

A closer look at family representation within each $\mathrm{CZ}$ shows that the rank order correlation between " $\mathrm{C} / \mathrm{CX}$ " and " $\mathrm{C} / \mathrm{CX}$ " + "S" buckets are significant, but the strength of the relationship varies between $\mathrm{R}_{\mathrm{s}}=0.982(\mathrm{CZ} 4)$ and $\mathrm{R}_{\mathrm{s}}=0.728(\mathrm{CZ} 3)$ (Table 13). The shifts in CZ 3 rank order are greatest, where Salmonidae is ranked $6^{\text {th }}$ when the "S" buckets are added, but the same family is ranked $2^{\text {nd }}$ for the " $\mathrm{C} / \mathrm{CX}$ " buckets alone. Overall, however, the " $\mathrm{C} / \mathrm{CX}$ " bucket samples provided good estimates of fish family rank order abundance.

Moving beyond rank order representation, fish family richness in two CZs is affected by adding the " $\mathrm{S}$ " buckets. As discussed in Chapter 2, richness is simply the number of taxa, in this case families, present. The "S" buckets added three families in $\mathrm{CZ}$ 7 and four families in CZ 2 (Table 14). These patterns are related to small sample size, as 
$\mathrm{CZ} 2$ and $\mathrm{CZ} 7$ have the smallest samples among the $\mathrm{CZs}$; much previous zooarchaeological research shows a high correlation between richness and sample size (Lyman 2008). While the taxa added from the "S" buckets in these few instances illustrate that CZs with small sample sizes are insufficient for characterizing fish family richness, the eight units included in my study represent only $20 \%$ of the units in A4, in which the " $\mathrm{C} / \mathrm{CX}$ " bucket fish remains were studied. This additional volume from the remaining units in A4 and elsewhere in the site will document richness for those CZs. It is also important to note that the purpose of STR as used in my study was not to cease sampling when all taxa were added, but rather when proportional representation of families stabilized.

Table 13. Comparison of fish family rank order between " $\mathrm{C} / \mathrm{CX}$ " and "C/CX"+"S" Buckets by CZ using Spearman's Rho Correlation

\begin{tabular}{|c|c|c|c|c|c|c|c|}
\hline $\mathbf{C Z}$ & $\begin{array}{l}\text { P- } \\
\text { Value }\end{array}$ & Rs & Family & 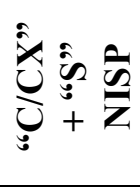 & 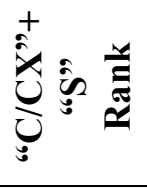 & 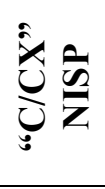 & 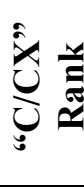 \\
\hline \multirow[t]{11}{*}{$\mathrm{CZ} 7$} & $<.001$ & 0.909 & Gadidae & 228 & 1 & 13 & 1 \\
\hline & & & Cottidae & 100 & 2 & 8 & 2 \\
\hline & & & Squalidae & 85 & 3 & 4 & 4 \\
\hline & & & Salmonidae & 65 & 4 & 5 & 3 \\
\hline & & & Pleuronectiformes & 38 & 5.5 & 3 & 7 \\
\hline & & & Hexagrammidae & 35 & 5.5 & 3 & 7 \\
\hline & & & Chimaeridae & 24 & 7 & 4 & 5 \\
\hline & & & Scorpaenidae & 14 & 8 & 0 & 10 \\
\hline & & & Embiotocidae & 9 & 9.5 & 3 & 7 \\
\hline & & & Rajidae & 9 & 9.5 & 0 & 10 \\
\hline & & & Clupeidae & 1 & 11 & 0 & 10 \\
\hline \multirow[t]{4}{*}{$\mathrm{CZ} 6$} & $<.001$ & 0.954 & Cottidae & 985 & 1 & 196 & 1 \\
\hline & & & Gadidae & 899 & 2 & 152 & 2 \\
\hline & & & Salmonidae & 378 & 3 & 55 & 4 \\
\hline & & & Pleuronectiformes & 356 & 4 & 81 & 3 \\
\hline
\end{tabular}




\begin{tabular}{|c|c|c|c|c|c|c|c|}
\hline & & & Squalidae & 222 & 5 & 28 & 5 \\
\hline & & & Chimaeridae & 109 & 6.5 & 18 & 6.5 \\
\hline & & & Hexagrammidae & 96 & 6.5 & 18 & 6.5 \\
\hline & & & Embiotocidae & 51 & 8.5 & 5 & 10 \\
\hline & & & Rajidae & 49 & 8.5 & 8 & 10 \\
\hline & & & Clupeidae & 27 & 10.5 & 14 & 8 \\
\hline & & & Scorpaenidae & 21 & 10.5 & 3 & 10 \\
\hline & & & Anoplopomatidae & 1 & 12 & 1 & 12 \\
\hline \multirow[t]{12}{*}{ CZ 5} & $<.001$ & 0.948 & Cottidae & 678 & 1 & 101 & 2 \\
\hline & & & Gadidae & 633 & 2 & 164 & 1 \\
\hline & & & Salmonidae & 418 & 3 & 64 & 3.5 \\
\hline & & & Squalidae & 275 & 4.5 & 45 & 5 \\
\hline & & & Pleuronectiformes & 267 & 4.5 & 62 & 3.5 \\
\hline & & & Chimaeridae & 34 & 7.5 & 6 & 7 \\
\hline & & & Embiotocidae & 34 & 7.5 & 3 & 7 \\
\hline & & & Hexagrammidae & 30 & 7.5 & 6 & 7 \\
\hline & & & Rajidae & 19 & 7.5 & 1 & 10.5 \\
\hline & & & Clupeidae & 9 & 11 & 1 & 10.5 \\
\hline & & & Anoplopomatidae & 4 & 11 & 1 & 10.5 \\
\hline & & & Scorpaenidae & 3 & 11 & 2 & 10.5 \\
\hline \multirow[t]{11}{*}{$\mathrm{CZ} 4$} & $<.001$ & 0.982 & Gadidae & 1140 & 1 & 117 & 1 \\
\hline & & & Salmonidae & 636 & 2 & 47 & 3 \\
\hline & & & Cottidae & 422 & 3 & 59 & 2 \\
\hline & & & Pleuronectiformes & 257 & 4 & 39 & 4 \\
\hline & & & Hexagrammidae & 224 & 5 & 25 & 5 \\
\hline & & & Squalidae & 158 & 6 & 11 & 6 \\
\hline & & & Rajidae & 81 & 7 & 6 & 7.5 \\
\hline & & & Chimaeridae & 31 & 8 & 7 & 7.5 \\
\hline & & & Embiotocidae & 13 & 10 & 1 & 11 \\
\hline & & & Scorpaenidae & 11 & 10 & 3 & 9.5 \\
\hline & & & Clupeidae & 2 & 10 & 2 & 9.5 \\
\hline \multirow[t]{4}{*}{$\mathrm{CZ} 3$} & 0.04 & 0.728 & Gadidae & 43 & 1 & 34 & 1 \\
\hline & & & Hexagrammidae & 19 & 2 & 11 & 3 \\
\hline & & & Squalidae & 11 & 3 & 7 & 4.5 \\
\hline & & & Rajidae & 10 & 4 & 7 & 4.5 \\
\hline
\end{tabular}




\begin{tabular}{|c|c|c|c|c|c|c|c|}
\hline & & & Pleuronectiformes & 9 & 6 & 4 & 6 \\
\hline & & & Cottidae & 9 & 6 & 1 & 7.5 \\
\hline & & & Salmonidae & 37 & 6 & 14 & 2 \\
\hline & & & Clupeidae & 1 & 8 & 1 & 7.5 \\
\hline \multirow[t]{8}{*}{$\mathrm{CZ} 2$} & 0.006 & 0.863 & Gadidae & 9 & 2 & 1 & 3 \\
\hline & & & Cottidae & 9 & 2 & 1 & 3 \\
\hline & & & Pleuronectiformes & 8 & 2 & 2 & 1 \\
\hline & & & Salmonidae & 5 & 4.5 & 1 & 3 \\
\hline & & & Hexagrammidae & 5 & 4.5 & 0 & 6.5 \\
\hline & & & Chimaeridae & 2 & 7 & 0 & 6.5 \\
\hline & & & Squalidae & 2 & 7 & 0 & 6.5 \\
\hline & & & Rajidae & 1 & 7 & 0 & 6.5 \\
\hline
\end{tabular}


Table 14. Comparison of family richness in "C/CX" vs. "C/CX" + "S" Buckets

\begin{tabular}{lcccc}
\hline & "C/CX" Buckets & "C/CX" + "S" Buckets \\
\hline CZ & NISP & $\begin{array}{c}\text { N of } \\
\text { Families }\end{array}$ & NISP & $\begin{array}{c}\text { N of } \\
\text { Families }\end{array}$ \\
\hline CZ 7 & 43 & 8 & 609 & 11 \\
CZ 6 & 579 & 12 & 3194 & 12 \\
CZ 5 & 456 & 12 & 2404 & 12 \\
CZ 4 & 317 & 11 & 2976 & 11 \\
CZ 3 & 79 & 8 & 139 & 8 \\
CZ 2 & 5 & 4 & 42 & 8 \\
\hline
\end{tabular}

\subsubsection{How does adding the " $S$ " buckets affect interpretation of earthquake impacts?}

One of the major goals of the NSF project is to examine ways environmental change affected animals and in turn humans. To do this, researchers will be examining faunal representation before and after several major earthquake events. One of these events is Event "U", dated to between 1260 and 1230 cal BP (Atwater et al 2004), which falls approximately at the beginning of $\mathrm{CZ} 4$. Earthquake events often result in subsidence and liquefaction, directly impacting sea floors and intertidal landscapes. As a result, kelp beds are likely to be negatively affected by the earthquake events at Čî́x ${ }^{w} i c ə n$, such as event $\mathrm{U}$, also documented in the sedimentation at the site. It is likely that kelp dependent taxa, such as Hexagrammidae (greenling), will also be negatively affected by earthquake events at Číx ${ }^{w} i c ə n$, and their representation should decrease after the event. On the other hand, migratory fishes, such as fish in the family Squalidae (dogfish), are less likely to be affected by environmental shifts that negatively affect kelp.

To examine whether adding the "S" buckets affect interpretations of fish use and representation at Číx ${ }^{w}$ icən, I examined the impact earthquake event $U$ might have on 
hexagrammid use at the site. I created the Hexagrammid Index

$\left(\frac{\text { Hexagrammidae NISP }}{\text { Hexagrammidae NISP }+ \text { Squalidae NISP }}\right)$ for each $\mathrm{CZ}$ based on fish records from the "C/CX" buckets and the "S" buckets from the eight study units. As the index approaches 1.0, NISP of hexagrammid increases, which would suggest kelp beds are not affected. While several researchers have created such indices (Broughton 2002b; Butler 2000;

Hildebrandt and Jones 1991), as a ratio, changes in the value could reflect change in the target taxon (in this case greenling), or change in the secondary taxa (here, dogfish). For example, an increase in value could indicate that dogfish are declining, rather than that greenling are increasing. The inverse is also true. Given the relative nature of this measure, one should seek independent evidence for environmental impacts. I use the Hexagrammid Index here more to evaluate sampling issues, and only secondarily to evaluate earthquake impacts.

For $\mathrm{CZs} 4,5,6$, and 7, the indices created for the two samples are extremely similar (Figure 12). In both cases the index declines after CZ 4 and increases continually after CZ 5 (Figure 12). On the other hand, the index for CZ 2 and to a lesser extent for CZ 3 diverge, which is likely due to extremely small sample sizes (Figure 12).

Importantly, the Hexagrammid Index declines after event $\mathrm{U}$, which is consistent with my predictions of the earthquake impact (Figure 12). This is true both for the "C/CX" buckets alone, and when the "S" buckets are added. As noted, given the limitations with the index, more work is needed to confirm this finding. 


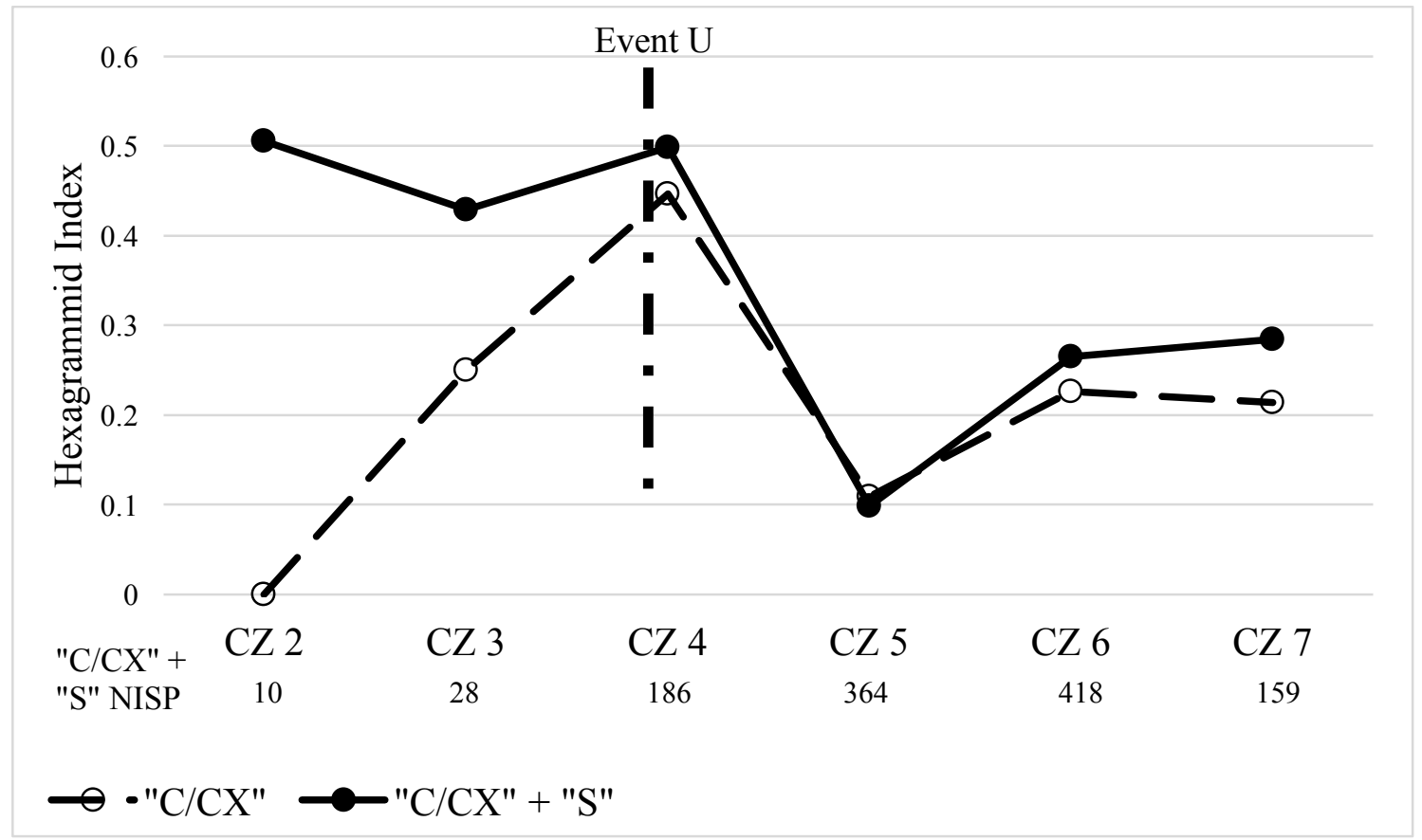

Figure 12. Hexagrammid Index for "C/CX" buckets and "C/CX" + "S" buckets.

\subsubsection{How does adding " $S$ " buckets affect interpretation of fishbone densities and}

deposition in and outside the house?

Researchers studying NWC archaeology have long noted differences in the way fauna are distributed across village contexts (Frederick 2007; Matson 2003; McMillan and St. Claire 2005, 2012; Samuels 1994; Rosenberg 2015). These differences represent differential resource access, and disposal patterns. Here, I focus on disposal patterns by examining changes in faunal frequency and taphonomy.

I included excavation units both inside and outside the house structure in A4, allowing me to explore the spatial patterns in fish representation. This will also allow me to assess whether adding the "S" buckets to the " $\mathrm{C} / \mathrm{CX}$ " buckets affected fish representation across space. The Čî́x ${ }^{w i c ə n}$ house occupation in Area A4 spans CZs 4, 5, 
and 6. For my study, I focus on fish remains from the earliest period of house occupation, CZ 4, which represents an occupation from 1300-1000 cal BP. I split the fish remains into excavation units inside the house (units 17, 18, 19, 20, 25, and 31) and excavation units outside the house (units 2 and 8 ) in CZ 4. To assess whether fish remains are treated differently inside versus outside the house, I will measure both fragmentation and density of fish remains.

The extent to which waste from fish processing or consumption is disposed of inside versus outside houses has been little studied. Researchers have studied within house patterning of faunal remains to explore questions of prestige or resource control (Ewonus 2006; Frederick 2012; Rosenberg 2015), but whether more or less disposal takes place inside or outside a house is not known. Therefore, my comparison is exploratory. My goal is simply to assess whether the abundance estimates of fish remains inside and outside the house varies between the two samples, "S" vs. "C/CX" + "S". As seen in Table 15, units outside the house have orders of magnitude more fishbone than interim units. Some of this difference is related to volume excavated (Table 15). Density (NSP/liter) is also higher outside the house than inside (Table 15, Figure 13). Densities in units 2 and 8 , outside the house, are above 1.5 fish remains per liter (Figure 13). For example, densities in units 2 and 8, outside the house, are above 1.5 fish remains per liter (Figure 13). Both the "C/CX" buckets alone and the "C/CX" + "S" buckets show this trend, suggesting that added volume did not change interpretations of fish distribution. However, the difference in density for outside units after " $\mathrm{S}$ " buckets were added is considerable. This pattern will be further studied in the larger fishbone project. 
Table 15. Frequency and Density (NSP/liter) of fishbones in CZ 4, within and outside the house boundary

\begin{tabular}{|c|c|c|c|c|c|c|c|c|c|}
\hline & \multicolumn{5}{|c|}{$\begin{array}{l}\text { "C/CX" } \\
\text { Buckets }\end{array}$} & \multicolumn{4}{|c|}{$\begin{array}{c}\text { "C/CX" + "S" } \\
\text { Buckets }\end{array}$} \\
\hline & 咅 & $\frac{\hat{n}}{\bar{Z}}$ & $\hat{\bar{n}}$ & $\stackrel{\stackrel{\Xi}{\Xi}}{\partial}$ & 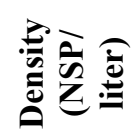 & $\frac{\hat{n}}{z}$ & $\frac{\tilde{\sigma}}{\bar{Z}}$ & 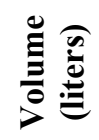 & 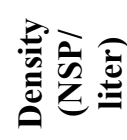 \\
\hline $\begin{array}{l}\text { Outside } \\
\text { the } \\
\text { House }\end{array}$ & 2 & 128 & 305 & 170 & 1.79 & 1503 & 3369 & 760 & 4.43 \\
\hline & 8 & 110 & 233 & 170 & 1.37 & 1100 & 1081 & 270 & 4.0 \\
\hline Total & & 238 & 538 & 340 & 1.58 & 2603 & 4450 & 1030 & 4.32 \\
\hline \multirow{6}{*}{$\begin{array}{l}\text { Inside } \\
\text { the } \\
\text { House }\end{array}$} & 17 & 8 & 14 & 80 & 0.47 & 47 & 87 & 110 & 0.15 \\
\hline & 18 & 1 & 1 & 30 & 0.05 & 8 & 9 & 50 & 0.05 \\
\hline & 19 & 12 & 44 & 100 & 0.88 & 51 & 135 & 160 & 0.15 \\
\hline & 20 & 13 & 24 & 100 & 0.48 & 20 & 37 & 150 & 0.06 \\
\hline & 25 & 0 & 1 & 40 & 0.03 & 4 & 6 & 70 & 0.02 \\
\hline & 31 & 0 & 0 & 10 & 0.00 & 2 & 2 & 20 & 0.10 \\
\hline Total & & 34 & 84 & 360 & 0.23 & 132 & 276 & 560 & 0.49 \\
\hline
\end{tabular}




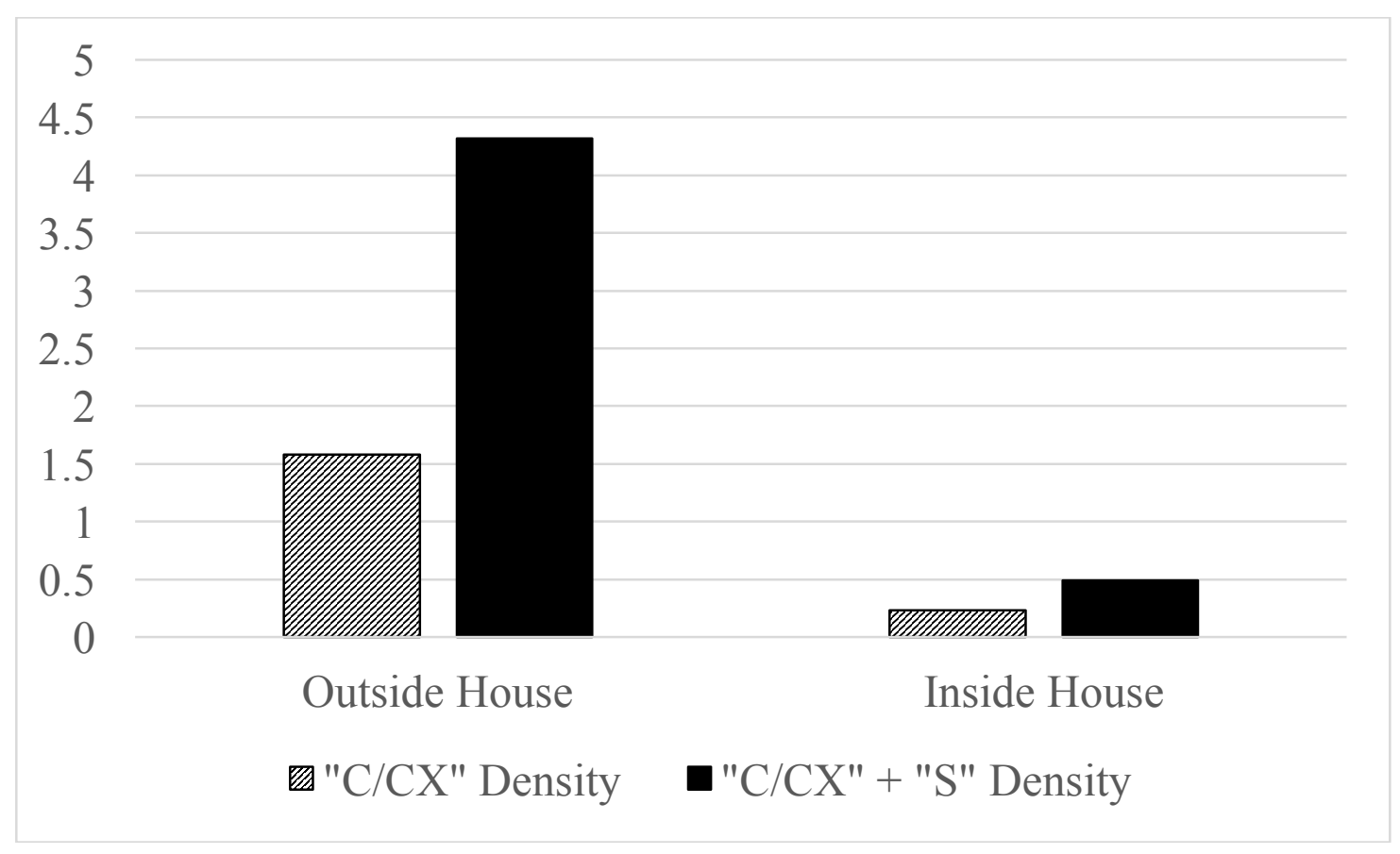

Figure 13. Comparison of fishbone density (NSP/liter) inside and outside the house from $\mathrm{CZ} 4$, based on "C/CX" buckets vs. "C/CX+S" buckets.

I anticipate that fragmentation will be higher inside the house than outside the house, as fish remains are more likely to be trampled where there is more foot traffic. To measure fragmentation, I am using a ratio of NISP/NSP, which has been used for such purpose previously (Grayson 1991; Mohlenhoff and Butler 2016; Nagaoka 2005a). This measure is based on the reasoning that specimens which can be assigned to family and element are less fragmented than specimens which cannot be assigned to family and element. In this way, the higher the ratio, the lower the fragmentation. As Figure 14 shows, fragmentation is slightly lower inside the house vs. outside, which is contrary to my expectation. One possible explanation for this is that most of the remains are being disposed of outside the house where they cannot be trampled. This hypothesis is supported by the higher densities of fish remains, higher NISPs, and higher volumes of 
material from units outside the house (Table 16). These conclusions do not change with the addition of the "S" buckets, thus the " $\mathrm{C} / \mathrm{CX}$ " buckets were sufficient to document this patterning (Figure 14).

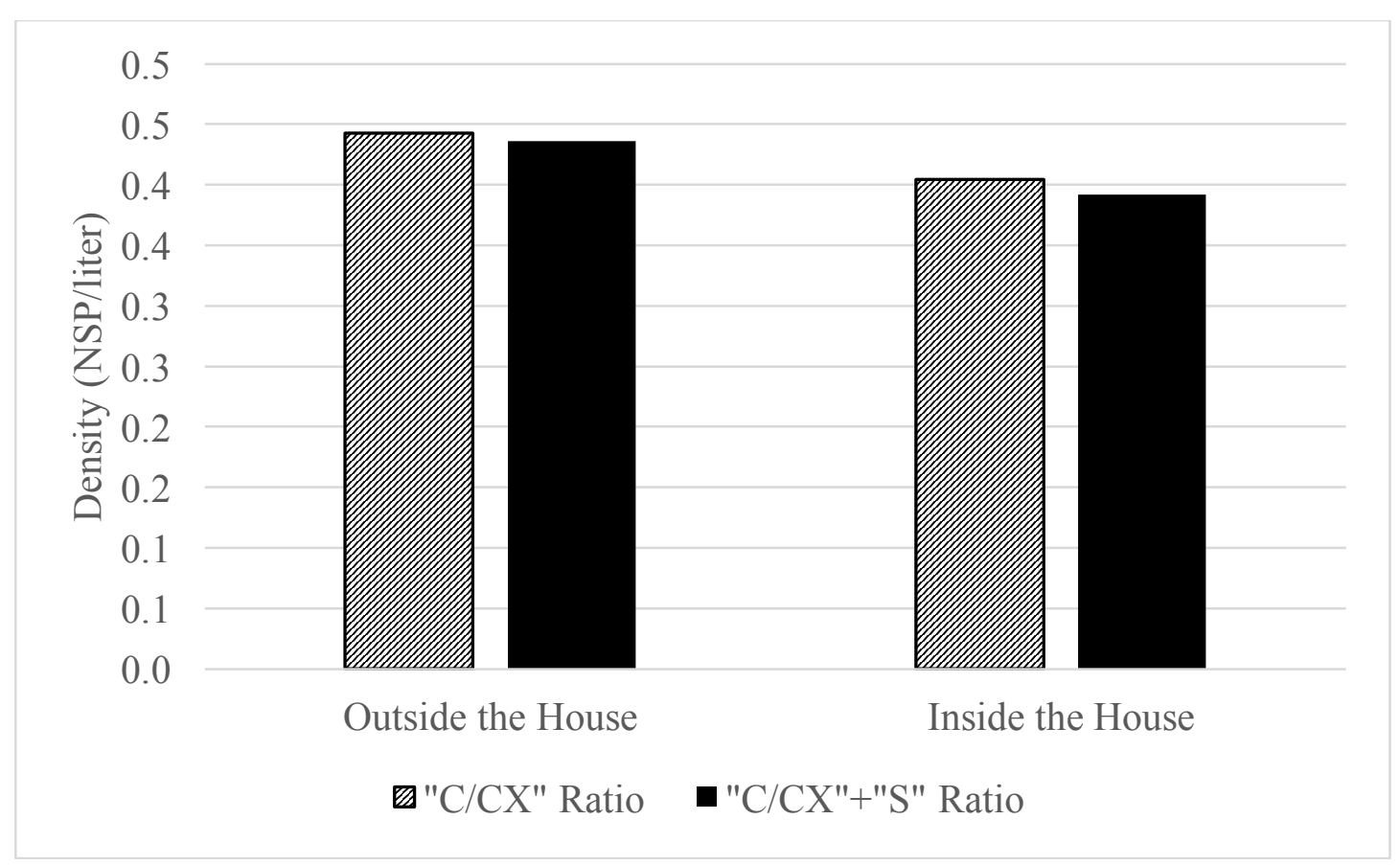

Figure 14. Fragmentation (NISP/NSP) of fish remains inside and outside the household in A4 CZ 4 comparing "C/CX" vs. "C/CX"+ "S" Buckets. 


\section{Chapter 5. Discussion}

Most previous research on the sampling of archaeological fish remains has emphasized the use of fine mesh screens to adequately document small-bodied fish. This focus often means that less matrix is actually studied, limiting the spatial and temporal contexts examined. This has two main consequences: less matrix studied means that we may not be characterizing abundance of larger-bodied fish adequately, given their remains are relatively rare in fine mesh samples. As well, we may not be sampling the range of deposits critical to questions of resource use in Northwest Coast households. STR provides a general way to study larger volumes of matrix to the point at which any additional analysis would be redundant.

My project had several goals. My first goal was to show the value of STR,

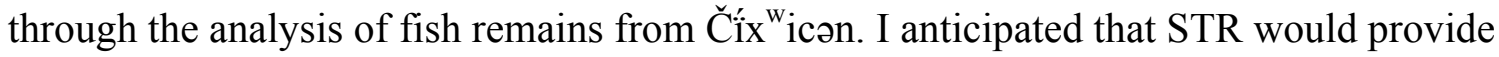
substantial time savings, and it did. I saved more than 100 hours of time on analysis over the course of this study by using STR, there was a substantial increase to the overall NISP for the unit/CZs included, and all of this was achieved without sacrificing accuracy of fish family proportional representation for each unit/CZ. Not surprisingly, the greatest time savings came from unit/CZs with higher densities and NISPs where I was able to analyze a lower percentage of buckets. Other unit/CZs with lower densities and NISPs provided less time savings, as I was required to analyze a larger percentage of buckets.

My second goal was determining whether adding additional volume, the " $\mathrm{S}$ " buckets, changed our understanding of fish representation based on "C/CX" buckets alone. Analyzing the "S" buckets allowed me to investigate whether the " $\mathrm{C} / \mathrm{CX}$ " buckets were adequate for representing large-bodied, but rarer fish families. By focusing on the 
"C/CX" buckets, the NSF researchers analyzing the Čî́x"icən site have chosen to limit the volume of matrix studied, much like many others with a few notable differences, in order to document small-bodied fish, such as herring. As the "S" bucket fish remains I analyzed using STR represented over four times the volume of the "C/CX" buckets, I anticipated that this addition might alter our picture of large-bodied fish representation. I have shown that, with the exception of low density, low NISP unit/CZs (especially in the oldest CZ 2 and $\mathrm{CZ}$ 3) the "C/CX" buckets are sufficient to represent fish at the site. The oldest CZs 2 and 3 had fewer bones and less matrix, however a test of the Spearman's rank order was still relatively high. I have demonstrated that the " $\mathrm{C} / \mathrm{CX}$ " buckets are sufficient both for my sample overall, but also for $\mathrm{CZs} 4,5,6$, and 7 .

This case study demonstrates how STR can be used at the beginning of analysis to minimize effort towards characterizing an assemblage (in this case "S" bucket fish remains, recovered from 1/ 4 in.) and to identify locales (in this case CZs) that could benefit from increased sampling. In the case of the Číx ${ }^{w} i c ə n$ site, the larger NSF project has already analyzed material from all of the " $\mathrm{C} / \mathrm{CX}$ " buckets available in $\mathrm{A} 4$, and in several other locales at the site.

I found the "C/CX" buckets to be adequate for addressing more specific research questions as well. To tie my research in with the NSF research and examine fish representation over time, I examined the representation of an individual taxon, in this case Hexagrammidae relative to dogfish, in response to an environmental event (Event $\mathrm{U}$ earthquake). My interpretations of the hexagrammid's response to the Event $\mathrm{U}$ earthquake, did not change with the addition of the "S" buckets. My interpretations held despite some minor differences in the Hexagrammid Index between the " $\mathrm{C} / \mathrm{CX}$ " buckets 
alone and the " $\mathrm{C} / \mathrm{CX}$ " and " $\mathrm{S}$ " buckets combined. In addition to demonstrating that the "C/CX" buckets are sufficient for assessing a particular taxon's trends over time, I also affirmed my hypothesis on the effect of the earthquake event $U$ on the Hexagrammid Index. The index declined after event $\mathrm{U}$, consistent with the prediction that event $\mathrm{U}$

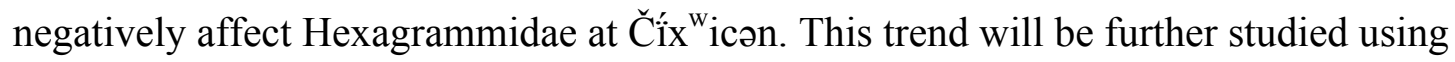
additional samples from Číx ${ }^{\mathrm{w}}$ icən, based on fish as well as other faunal resources.

An examination of trends in fishbone representation and fragmentation within and outside a house, also shows that the " $\mathrm{C} / \mathrm{CX}$ " buckets were adequate, that adding additional volume from the "S" buckets did not affect trends. I measured density (NSP/liter) and fragmentation (NISP/NSP) of fishbone during the CZ 4 house occupation in A4, between 1300 and 1000 cal BP. Density and absolutely abundance of fishbone is higher outside the house than inside, suggesting differences in disposal patterns. While I expected that bone fragmentation would be higher inside the house than outside, the differences were minor. More important than specific spatial patterns in density and fragmentation is whether the addition of " $\mathrm{S}$ " buckets affected my interpretation. Overall, adding the "S" buckets did not affect the main trends.

\subsection{The Influence of Sample Selection on STR}

There are more ways to use STR than I have explored here. The rate at which one reaches redundancy using STR is influenced by the methods one chooses to select what is included in a sample. If one chooses to seek redundancy for the site as a whole, a stable proportional representation will be reached much faster, but the nuance of differences between contexts will be lost, as the sample sizes will be much smaller than if one seeks redundancy for a smaller sample group, such as unit/CZ, a unique strata, or an individual 
bucket. By choosing to sample at unit/CZ I have lost some of the nuance of variability between strata that represent a variety of contexts, however the units of time that each $\mathrm{CZ}$ represents provide enough resolution to track large- scale temporal changes and meet the research goals of the NSF project.

\subsection{Applying this Method to the Northwest Coast and Beyond}

On the NWC many researchers have reached various conclusions about households, often using small sample sizes and limited contexts, as Gray (2008), and Monks (2000) have both noted. The dense deposits from villages make large-scale analyses somewhere between difficult and impossible to complete. This has led researchers to focus excavations on one or two houses out of a village consisting of as many as 15 or more houses. The density of village deposits has also led to variable quantities of excavation of midden outside house boundaries, and a variety of screening methods. In cases where the analysis of fish remains is further limited by column samples or selective sampling, sampling issues are only compounded.

By analyzing fish remains from one large NWC village site, I have demonstrated that STR can provide the means to better answer the big questions being asked about social and ecodynamics in this region. The Číix ${ }^{w} i c ə n$ site has many characteristics in common with other NWC village sites that make it an excellent candidate for the application of STR including excellent faunal preservation, dense faunal deposits, and identifiable boundaries from multiple houses. Despite including samples from only eight excavation units, I have shown that STR can expand the spatial and temporal breadth of analyses without significantly increasing the data burden of innumerable quantities of data. 
Using STR at NWC village sites, as I have done, to highlight locales that require larger sample sizes can serve as a model for future researchers that would allow them to direct their sampling efforts more efficiently. STR does so by highlighting low frequency locations that would benefit from increasing sample sizes, while still adequately sampling higher frequency locations. Those samples with higher densities and NISPs will likely reach redundancy faster, saving time that can be focused on the lower density, lower NISP samples that require more intensive sampling to reach redundancy. This would provide future researchers with the ability to minimize effort towards characterizing an assemblage as a whole, while also increasing sample sizes in necessary targeted locations.

\subsection{Future Work}

My approach to STR has focused on fish remains that were previously excavated from a Pacific coastal village site with dense archaeological deposits. STR could be employed in other types of archaeological settings in a range of environments (coast or interior) representing a range of cultural contexts (from hunting camps to urban centers) to establish sample redundancy after an excavation is complete. STR could also be used during on-going excavation (Leonard 1987). Further research is required to explore the implications of STR in these settings, however it is likely that the success of STR in other contexts will be dependent on the density and overall abundance of remains, the diversity or material types being studied, as well of course in the range and specificity of questions in each case. 


\subsection{Conclusions}

Researchers on the Northwest Coast (NWC) are often interested in complex questions regarding social organization, resource intensification, resource control, and impacts of environmental change on resources and in turn human groups. Gray (2008) has noted that the excavation strategies used on the NWC often do not provide the spatial and chronological control within a site that is necessary to document their variability and answer these research questions. The Číx ${ }^{w}$ icən site allowed me to address some of the limitations of previous Northwest Coast village site excavations because of its unique and robust sampling strategy, the wide expanse of time that it was occupied, and the multiple house structures present.

This site, located on the Strait of Juan de Fuca in Port Angeles, WA was excavated in 2004 as part of a Washington State Department of Transportation (WSDOT) undertaking to build parts for the Hood Canal Bridge Large scale excavation of $\left(261.4 \mathrm{~m}^{3}\right.$ $528 \mathrm{~m}^{2)}$ generated enormous quantities of faunal remains. Radiocarbon dates and historic records show occupation extents from 2750 cal. BP to the early $20^{\text {th }}$ century. An ongoing NSF project is using these records to examine changing human ecodynamics over the breadth of site occupation, focusing on zooarchaeology and geoarchaeological records.

Statistical sampling methods provide an empirical way to maximize the amount of information obtained with the least amount of effort. My thesis addressed the utility of Sampling to Redundancy (STR) as a statistical sampling method for sampling faunal remains from large village sites. My project has documented the variability of fish family representation across time and space in one part of the Čî́x ${ }^{\mathrm{w}}$ icən village, while minimizing the time and effort required to do so. This thesis applies STR to "S" $(>1 / 4$ 
in.) 10 Liter bucket samples from eight excavation units and a total of 26 separate unique temporal and spatial contexts. I focused on 1/ 4 in. samples for my study for a particular reason. Previous fish faunal studies have focused on effects of mesh size on fish representation; and emphasized the need to use fine mesh (e.g., $1 / 8$ in. or finer) to document small-bodied fishes. This focus on fine mesh typically means that only limited volumes of matrix are studied, which in turn may mean that remains of rarer, largebodied fishes are under- represented. The on-going NSF research project has focused on buckets screened to $1 / 8$ in. mesh (called "C" buckets). I used STR to sample additional volumes of matrix screened to $1 / 4$ in. to examine whether expanding the volume studied would affect fish representation, which was a second goal of my project.

Overall, I studied remains from 269 "S" buckets out of a total of 419 buckets, or $47 \%$ of the buckets. STR was most helpful for six of the high bone abundance and density contexts, where I analyzed less than $50 \%$ of the total buckets, was moderately helpful for 14 contexts, and not at all helpful for the six contexts with low fishbone abundance, where I analyzed $100 \%$ of the buckets. This analysis took me a total of 154 hours, and based on the percentage of material analyzed, 174 hours were saved.

As to the second project goal, to assess whether adding fish remains documented from additional matrix volume affected fish representation, I found the differences were minimal. Both for my study units as a whole, and for each time period, adding the fish records from the "S" buckets did not alter the main trends in fish representation as documented by the larger study, using a smaller volume. To further examine whether the added volume from $>1 / 4$ in "S" buckets affected results, I explored specific research questions that are relevant to the larger project regarding environment-animal interactions 
and fishbone deposition and bone condition inside and outside of a house structure. Adding the "S" bucket samples did not affect fish representation or fishbone distribution and condition, which affirms that the sampling strategy used in the larger research project was sufficient in most cases to characterize the fish record at the site.

My approach to STR has focused on fish remains that were previously excavated from a Pacific coastal village site with dense archaeological deposits. STR could be employed in other types of archaeological settings in a range of environments (coast or interior) representing a range of cultural contexts (from hunting camps to urban centers) to establish sample redundancy after an excavation is complete. STR could be used during on-going excavation (Leonard 1987). Further research is required to explore the implications of STR in these settings, however it is likely that the success of STR in other contexts will be dependent on the density and overall abundance of remains, the diversity or material types being studied, as well of course in the range and specificity of questions in each case. 


\section{References Cited}

Alroy, John

2000 New methods for quantifying macroevolutionary patterns and processes.

Paleobiology 26(4): 707-733.

Ames, Kenneth M.

1996 Life in the big house, household labor and dwelling size on the Northwest Coast. In People who lived in Big Houses, Archaeological Perspectives on large domestic structures, edited by Gary Coupland and E.B. Banning, pp. 178 - 200. Prehistory Press, Madison.

2001 Slaves, chiefs and labour on the northern Northwest Coast. World Archaeology 33(1): $1-17$.

2006 Thinking about household archaeology on the Northwest Coast. In Household Archaeology on the Northwest Coast, edited by Elizabeth A. Sobel, Ann Trieu-Gahr, and Kenneth M. Ames, pp. 16-36. International Monographs in Prehistory, Ann Arbor.

2007 Chinook Households on the Lower Columbia River: Contact and Complexity. Portland.

2008 Slavery, household production, and demography on the Southern Northwest Coast: cables, tacking and ropewalks. In Invisible Citizens: Captives and Conquerers, edited by Catherine M. Cameron, pp. 138-158. University of Utah Press, Salt Lake City.

Ames, Kenneth M., and Herbert D.G. Maschner 1999 Peoples of the Northwest Coast: Their Archaeology and Prehistory. Ed. Kenneth M. Ames and Herbert D.G. Maschner. Thames and Hudson, London, England.

Ames, Kenneth M., Doria F. Raetz, Stephen Hamilton, Christine McAffee 1992 Household Archaeology of a Southern Northwest Coast Plankhouse. Journal of Field Archaeology 19(3): 275-290.

Ascher, Robert

1959 A prehistoric population estimate using midden analysis and two population models. Southwestern Journal of Archaeology 15(2): 168-178.

Atwater, B. F., M. P. Tuttle, E. S. Schweig, C. M. Rubin, D. K. Yamaguchi, and E. Hemphill-Haley 
2004 Earthquake Recurrence Inferred from Paleoseismology. In The Quaternary Period in the United States (A. R. Gillespie, S. C. Porter, and B. F. Atwater, eds.):331-350. Developments in Quaternary Science, 1 (J. Rose, series ed.). Amsterdam: Elsevier.

Barnosky, Anthony D., Marc A. Carrasco, and Edward B. Davis 2005 The impact of the species-area relationship on estimates of paleodiversity. PLoS Biology 3(8): 1356-1361.

Boyd, Robert, and Peter J. Richerson

1985 Culture and Evolutionary Process. University of Chicago Press, Chicago.

Broughton, Jack M.

1994 Declines in Mammalian foraging efficiency during the Late Holocene, San

Francisco Bay, California. Journal of Anthropological Archaeology 13: 371-401.

2002a Pre-Columbian human impact on California Vertebrates. In Wilderness and Political Ecology: Aboriginal Influence and the Original State of Nature, edited by E Kay and Randy T Simmons.

2002b Prey spatial structure and behavior affect archaeological tests of optimal foraging models: Examples from the Emeryville Shellmound vertebrate fauna. World Archaeology 34(1): 60-83.

Broughton, Jack M., R. Kelly Beck, Joan B. Coltrain, Dennis H. O. Rourke, and Alan R. Rogers

2013 Ancient DNA Analysis Confirms a Late Holocene Population Bottleneck in California Tule Elk (Cervus elaphus nannodes) Department of Anthropology University of Utah 270 S 1400 E RM 102 Salt Lake City, Utah 84112-0060 Email : jack.broughton@anthro.utah.ed. Ed. University of Utah Department of Anthropology. SWCA Environmental Consultants, Salt Lake City.

Broughton, Jack M., Michael D. Cannon, and Eric J. Bartelink 2010 Evolutionary Ecology, Resource Depression, and Niche Construction Theory: Applications to Central California Hunter-Gatherers and Mimbres-Mogollon Agriculturalists. Journal of Archaeological Method and Theory 17(4): 371-421.

Broughton, Jack M., Daniel Mullins, and Tamara Ekker 2007 Avian resource depression or intertaxonomic variation in bone density? A test with San Francisco Bay avifaunas. Journal of Archaeological Science 34(3): 374-391.

Bush, Andrew M., Molly J. Markey, and Charles R. Marshall 2004 Removing bias from diversity curves: the effects of spatially organized biodiversity on sampling-standardization. Paleobiology 30(4): 666-686.

Butler, Virginia L. 
In Progress. Butler Descriptive Summary. In Tse-whitzen Faunal Report, edited by Virginia L. Butler, Sarah K. Campbell, Kristine M. Bovy, Michael A. Etnier, and Sarah L. Sterling.

1993 Natural Versus Cultural Salmonid Remains: Origin of The Dalles Roadcut Bones, Columbia River, Oregon, U.S.A. Journal of Archaeological Science 20(1): 1-24.

1996 Tui Chub taphonomy and the importance of marsh resources in the western Great Basin of North America. American Antiquity 61(4): 699-717.

2000 Resource Depression on the Northwest Coast of North America. Antiquity 74(285): 649-661.

2004 Fish Remains. In Marmes Rockshelter: A Final Report on 11,000 Years of Cultural Use, edited by Brent A. Hicks, pp. 320-337. Washington State University Press, Pullman.

2005 Fish Remains from the St. Johns Site. In Archaeological Excavations at the St. Johns Site (35MU44/46), Portland, Oregon, edited by Richard Pettigrew. Cascadia Archaeology, Seattle, WA.

Butler, Virginia L., and Sarah K. Campbell

2004 Resource intensification and resource depression in the Pacific Northwest of North America: A zooarchaeological review. Journal of World Prehistory 18(4): 327-405.

Butler, Virginia L., and Michael G. Delacorte 2004 Doing zooarchaeology as if It mattered: use of faunal data to address current issues in fish conservation biology in Owens, Valley, California. In Zooarchaeology and Conservation Biology, edited by R. Lee Lyman and Kenneth P. Cannon, pp. 25-44. University of Utah Press, Salt Lake City.

Byrd, John E

1997 The Analysis of Diversity in Archaeological Faunal Assemblages: Complexity and Subsistence Strategies in the Southeast during the Middle Woodland Period. Journal of Anthropological Archaeology 16: 49-72.

Campbell, Sarah K., and Virginia L. Butler 2010 Archaeological Evidence for Resilience of Pacific Northwest Salmon Populations and the Socioecological System over the last 7, 500 years. Ecology and Society 15(1): $1-17$.

Cannon, Michael D

1999 A mathematical model of the effects of screen size on zooarchaeological relative abundance measures. Journal of Archaeological Science 26: 205-214. 
Casteel, Richard W.

1972 Some biases in the recovery of archaeological faunal remains. Proceedings of the Prehistoric Society 38: 382-388.

1976 Comparison of column and whole unit samples for recovering fish remains. World Archaeology 8(2): 192-196.

Church, M.J., A.J. Dugmore, K.A. Mairs, A.R. Millard, G.T. Cook, G.

Sveinbjarnardottir, P.A. Ascough, and K.H. Roucoux

2007 Charcoal production during the Norse and early medieval periods in Ey Jaf

Jallahreppur, Southern Iceland. Radiocarbon 49(2): 659-672.

Cochran, William G.

1946 Relative accuracy of systematic and stratified random samples for a ertain class of populations. The Annals of Mathematical Statistics 17(2): 164-177.

1977a The estimation of sample size. In Sampling Techniques, pp. 72-88. 3rd ed. John Wiley \&Sons Inc.

1977b The Estimation of Sample Size: The Formula for $\mathrm{n}$ in Sampling for Proportions. In Sampling Techniques. 3rd ed. John Wiley\& Sons, Inc., New York.

Colwell, Robert K., and Jonathan A. Coddington

1994 Estimating terrestrial biodiversity through extrapolation. Philosophical

Transactions of the Royal Society (Series B) 311(1311): 118-345.

Colwell, Robert K., Chang Xuan Mao, and Jing Chang

2004 Interpolating, Extrapolating, and Comparing Incidence-Based Species

Accumulation Curves. Ecology 85(10): 2717-2727.

Cosmides, Leda, and John Tooby

1987 From evolution to behavior: evolutionary psychology as the missing link. In The Latest on the Best: Essay on Evolution and Optimality, edited by John Dupré, pp. 277306. Massachusetts Institute of Technology, Cambridge, Massachusetts.

Coupland, Gary Graham

1985 Prehistoric Cultural Change at Kitselas Canyon. Pp. 1-547. Doctor of Philosophy, Department of Anthropology and Sociology, University of British Columbia.

1996 The evolution of multi-family households on the Northwest Coast of North America. In People who lived in Big Houses: Archaeological Perspectives on large domestic structures, edited by Gary Coupland and E.B. Banning. Prehistory Press.

2003 Preliminary Analysis of socioeconomic organization at the McNIchol Creek Site, British Columbia In Emerging from the Mist: Studies in Northwest Coast Culture 
History. Pp. 152 - 169. Ed. Matson, Richard Ghia, Gary Coupland, Quentin Mackie.

Vancouver, B.C. Canada, UBC Press.

2006 A Chief's House Speaks: Communicating Power on the Northwest Coast. In Household Archaeology of the Northwest Coast, edited by Elizabeth Sobel, Ann TrieuGahr, and Kenneth M. Ames, pp. 80-96. International Monographs in Prehistory, Ann Arbor.

Coupland, Gary Graham, Terence Clark, and Amanda Palmer 2009 Hierarchy, communalism, and the spatial order of Northwest coast plank houses: a comparative study. American Antiquity 74(1): 77-106.

Coupland, Gary Graham, Kaitln Stewart, and Katherine Patton 2010 Do you never get tired of samon? Evidence for extreme salmon specialization at Prince Rupert harbor, British Columbia. Journal of Anthropological Archaeology. 29(2) pp. 189-207.

Dolan, James Patrick

2015 Economics and integration in a Marpole phase plank-house village. Doctor of Philosophy, Washington State University, Department of Anthropology, Pullman, WA.

Durham, William H.

1991 Coevolution: Genes, Culture, and Human Diversity. Standford University Press, Stanford, California.

Ellis, David V.

2006 Of a more temporary cast: household production at the Broken Tops Site In Household Archaeology on the Northwest Coast. pp. Ed Elizabeth Sobel, Ann TrieuGahr, and Kenneth Ames. Ann Arbor, MI, International Monographs in Prehistory

Ellis, David V. and John L.Fagan

1993 Data recovery and excavations at Broken Tops Site (35MU57). Archaeological Investigaitons Northwest Inc. Report No. 31. Report submitted to Scientific Resources, Inc. Lake Oswego, Oregon.

Ewonus, Paul Andrew2006 The Social Economy of a Northwest Coast Plank House in Perspective. Master of Arts. Department of Anthropology. McMaster University, Hamilton, Ontario.

Fladmark 1972 The Richardson Ranch Site: The Ethno-Archaeology of a $19^{\text {th }}$ Century Haida House. Pp. 1 -51. Calgary, Alberta Canada, University of Calgary

Frederick, S. Gay 2007 Report on the Fish Faunal Remains from the Meier Site, C3505, Oregon, U.S.A. Victoria. 
2012 Vertebrate fauna from the Huu-ay-aht Archaeology Project: Results from the 2006 Huu7ii Village Excavations and Summary of 2004 and 2006 Data In Huu7ii: Household Archaeology at a Nuu-chah-nulth Village Site in Barkley Sound. pp. 115 - 153. Ed. Allan D. McMillan and Denis E. St. Claire. Burnaby, B.C., Canada, Simon Frasier University.

Gessler, Nicholas

1975 Archaeology at K'yuust' aa (Kiusta): Interim Report. Pp. 1 -14. Masset, Haida Museum.

Gobalet, Kenneth W.

1989 Remains of tiny fish from a late prehistoric Pomo site near Clear Lake, California. Journal of California and Great Basin Anthropology 11(2): 231-239.

Gordon, Elizabeth A.

1993 Screen Size and Differential Faunal Recovery : A Hawaiian Example. Journal of Field Archaeology 20(4): 453-460.

Gotelli, N. J., and Robert K. Colwell

2001 Quantifyinf biodiversity: procedures and pitfalls in the measurement and comparison of species richness. Ecology Letters 4: 379-391.

Gray, Brendan

2008 Sampling Methods in Northwest Coast household archaeology: a simulation approach using faunal data from the Ozette site. Simon Frasier University, Department of Anthropology, Master of Arts.

Grayson, Donald K.

1979 On the quantification of vertebrate archaeofaunas. Advances in Archaeological Method and Theory 2: 199-237.

1984 Quantitative zooarchaeology: topics in the analysis of archaeological faunas. Academic Press. New York.

1989 Sample size and relative abundance in archaeological analysis: illustrations from spiral fractures and seriation. In Quantifying Diversity in Archaeology, edited by R. D. Leonard and G.T. Jones, pp. 79-84. Cambridge University Press, Cambridge.

1991 Alpine Faunas from the White Mountains, California: Adaptive Change in the Late Prehistoric Great Basin?

2001 The archaeological record of human impacts on animal populations. Journal of World Prehistory 15(1).

Greenwood, Roberta 
1961 Quantitative analysis of shells from a site in Goleta, California. American Antiquity 26(3): 416-420.

Grier, Colin

2001 The social economy of a prehistoric Northwest Coast plankhouse. Arizona State University.

Gumerman, George IV

1997 Food and Complex Societies. Journal of Archaeological Method and Theory 4(2): 105-139.

Hildebrandt, William R., and Terry L. Jones 1991 Evolution of Marine Mammal Hunting : A View from the California and Oregon Coasts(1985).

Holland, S.

2005 Analytical Rarefaction version 1.3.

Hosch, Sabine, and Petra Zibulski

2003 The influence of inconsistent wet-sieving procedures on the macroremain concentration in waterlogged sediments. Journal of Archaeological Science 30(7): 849857.

Huelsbeck, David R.

1994 The fish-bone collection. In Ozette Archaeological Project Research Reports, edited by Stephan R Samuels, pp. 71-91. Department of Anthropology, Washington State University, Pullman.

Jacomet, Stefanie, and Christoph Brombacher 2004 Reconstructing intra-site patterns in Neolithic lakeshore settlements : the state of archaeobotanical research and future prospects. Wetland Economies and Societies(March 2004): 69-94.

James, Steven R 1997 Methodological issues concerning screen size recovery rates and their effects on archaeofaunal interpretations. Journal of Archaeological Science 24: 385-397.

Jones, Glynis, and Paul Halstead 1995 Maslins, mixtures and monocrops: on the interpretation of archaeobotanical crop samples of heterogeneous composition. Journal of Archaeological Science 22: 103-114.

Kintigh, Keith W.

1984 Measuring archaeological diversity by comparsion with simulated assemblages. American Antiquity 49(1): 44-54. 
Kirch, P.V., Melinda S. Allen, Virginia L. Butler, and Terry L. Hunt 1987 Is there an early far Western Lapita province? Sample size effects and new evidence from Elouaua Island, Archaeology. Oceania 22: 123-127.

Kirch, Patrick V., J.R. Flenley, D. W. Steadman, F. Lamont, and S. Dawson 1992 Environmental Degradation. National Geographic Research and Exploration 8: $166-179$.

Koch, Carl F

1987 Prediction of sample size effects on the measured temporal and geographic distribution patterns of species. Paleobiology 13(1): 100-107.

Kohler-Schneider, Marianne, and Anita Caneppele 2009 Late Neolithic agriculture in eastern Austria: archaeobotanical results from sites of the Baden and Jevišovice cultures (3600-2800 b.c.). Vegetation History and Archaeobotany 18(1): 61-74.

Krishnaiah, P.R., and C.R. Rao 1988 Sampling. In Handbook of Statistics 6, edited by P.R. Krishnaiah and C.R. Rao, pp. 1-589. Elsevier Science Publishers B.V., Amsterdam.

Larson, Lynn L.

2006 Data Recovery Excavation and Archaeological Monitoring at the Tse-whit-zen Site (45CA523), Clallam County, Washington. Ed. Washington Larson Anthropological Archaeological Services Limited, Gig Harbor. Final report submitted to Washington State Department of Transportation, Tumwater, Washington, Gig Harbor, Washington.

Larson, Lynn L., and Dennis E. Lewarch

1995 The Archaeology of West Point, Seattle, Washington, 4,000 years of HunterFisher-Gatherer Land Use in Souther Puget Sound. Seattle, WA.

LeClair, Ron

1973 Investigations at the Maurer Site, an early Pith

Leonard, Robert D.

1987 Technical study: incremental sampling in artifact analysis. Journal of Field Archaeology 14: 498-500.

1989a Anasazi faunal exploitation: prehistoric subsistens on Northern Black Mesa, Arizona. In Center for Archaeological Investigations Occasional Paper No. 13. Southern Illinois University Press, Carbondale.

1989b Resource specialization, population growth and agricultural production in the American southwest. American Antiquity 54: 491-503. 
Lepofsky, Dana, Michael Blake, Douglas Brown, Sandra Morrison, Nicole Oakes, and Natasha Lyons.

1997 Archaeology of the Scowlitz site, SW British Columbia. Pp. 391 -416. Burnaby, B.C. Canada, Simon Frasier University.

Lepofsky, Dana, and Kenneth P. Lertzman

2005 More on sampling for richness and diversity in archaeobiological assemblages.

Journal of Ethnobiology 25(2): 175-188.

Lyman, R. Lee

1994 Quantitative units and terminology in Zooarchaeology. American Antiquity 59(1): 36-71.

2008 Quantitative Paleozoology. Cambridge University Press, New York, NY.

Lyman, R. Lee, and Kenneth M. Ames

2004 Sampling to redundancy in zooarchaeology: lessons from the Portland Basin, Northwestern Oregon and Southwestern Washington. Journal of Ethnobiology 24(2): 329-346.

2007 On the use of species-area curves to detect the effects of sample size. Journal of Archaeological Science 34(12): 1985-1990.

Mapes, Lynda

2009 Breaking Ground: the Lower Elwha Klallam Tribe and the Unearthing of Tse-whitzen Village. Ed. Lynda Mapes. University of Washington Press, Seattle, WA.

Martindale, Andrew

1997 Final Report of Year 1 of the Gitnadoiks River Survey and Excavation at Bv Th-4

Psacelay, 1996. Permit No. 1996-113. Pp. 1 - 65. Victoria, B.C., University of Toronto.

1999 The River of Mist: Change in the Tsimshian Past. Pp. 1- 476. Doctor of Philosophy, Department of Anthropology, University of Toronto.

2005 Final Report of the Excavations at the Ginakangeek Site (GbTh-2). Permit No. 2000 - 162. Pp. 1-230. Ontario, McMasters University.

2006 Tsimshian Houses and Households through the Contact Period In Household Archaeology of the Northwest Coast. pp. 140 - 158. Ed Elizabeth Sobel, Ann Trieu-Gahr, and Kenneth Ames. Ann Arbor, MI, International Monographs in Prehistory.

Maschner, Herbert D.G.

1991 The emergence of cultural complexity on the northern Northwest Coast. Antiquity 65: 924-934.

Matson, Richard Ghia 
2003 The Coast Salish house: lessons from Shingle Point, Valdes Island, British Columbia. In Emerging from the Mist, edited by Richard Ghia Matson, Gary Graham Coupland, and Quentin Mackie, pp. 76-104. UBC Press, Vancouver, British Columbia.

Matson, Richard Ghia, and Gary Graham Coupland 1994 Prehistory of the Northwest Coast. Ed. R.G. Matson and Gary Coupland. Left Coast Press, Walnut Creek, California.

Matson, Richard Ghia, Gary Graham Coupland, and Quentin Mackie 2003 Emerging from the Mist: Studies in Northwest Coast Culture History. Ed. R.G. Matson, Gary Coupland, and Quentin Mackie. UBC Press, Vancouver, British Columbia.

Matson, Richard Ghia, Joanne Green, and Eric McLay

1999 Houses and Households in the Gulf of Georgia: Archaeological Investigations of Shingle Point (DgRv 2), Valdes Island, British Columbia. Victoria.

McCartney, Peter H., and Margaret F. Glass

1990 Simulation models and the interpretation of archaeological diversity. American Antiquity 55(3): 521-536.

McKechnie, Iain Mitchell Patrick

2005 Appendix E: column sampling and the archaeology of small fish at Ts'ishaa. In Ts 'ishaa: Archaeology and Ethnography f a Nuu-chah-nulth Origin Site in Parkley Sound, Burnaby, B.C. Canada, edited by Alan D. McMillan and Denis E. St. Claire, pp. 206-223.

2007 Investigating the complexities of sustainable fishing at a prehistoric village on western Vancouver Island, British Columbia, Canada. Journal for Nature Conservation 15(3): 208-222.

2012 Appendix B: Zooarchaeological analysis of the Indigenous fishery at the Huu7ii big house and back terrace, Huu-ay-aht Territory, Southwestern Vancouver Island. In Huu7ii: Household Archaeology at ta Nuu-cha-nulth Village Site in Barkley Sound, pp. 154-186. Burnaby, B.C. Canada.

2013 An Archaeology of Food and Settlement on the Northwest Coast. Ed. Doctor of Philosophy. University of British Columbia, Vancouver, British Columbia.

McKechnie, Iain, and Madonna L. Moss 2016 Meta-analysis in zooarchaeology expands perspectives on Indigenous fisheries of the Northwest Coast of North America. Journal of Archaeological Science: Reports 8: $470-485$.

McMillan, Alan D., and Denis E. St. Claire 2005 Ts 'ishaa: Archaeology and Ethnography of a Nuu-chah-nulth Origin Site in 
Barkley Sound. Simon Frasier University, Burnaby, B.C. Canada.

2012 Huи7ii: Household Archaeology at a Nuu-chah-nulth Village Site in Barkley

Sound. Simon Frasier University, Burnaby, B.C. Canada.

McMillan, Alan D., Iain McKechnie, Denis E St. Claire, and S. Gay Frederick

2008 Exploring variability in maritime resource use on the Northwest Coast: a case study from Barkley Sound, Western Vancouver Island. Canadian Journal of Archaeology 238(32): 214-238.

Meltzer, David J., Robert D. Leonard, and Susan K. Stratton 1992 The relationship between sample size and diversity in archaeological assemblages. Journal of Archaeological Science 19(4): 375-387.

Miller, Arnold I., and Mike Foote 1996 Calibrating the Ordovician radiation of marine life : implications for Phanerozoic diversity trends. Paleobiology 22(2): 304-309.

Mitchell, D. H. 1967 Archaeological Investigations, Summer, 1966. Report to the Archaeological Sites Advisory Board (October, 1967). Report on File with the Archaeology Branch, Ministry of Small Business, Tourismn, and Culture, Victoria, BC.

Mithen, Steven J. 1990 Thoughtful Foragers: a study of prehistoric decision making. Cambridge University Press, Tinity Hall, Cambridge.

Mohlenhoff, Kathryn A., and Virginia L. Butler 2016 Tracking Fish and Human Response to Earthquakes on the Northwest Coast of Washington State, USA: A Preliminary Study at Tse-whit-zen. The Journal of Island and Coastal Archaeology 4894(September): 1-28.

Monks, Gregory G.

2000 How much is enough? An approach to sampling ichthyofaunas. Ontario Archaeology 69: 65-75.

Moss, Madonna L.

1993 Shellfish, Gender, and Status on the Northwest Coast : Reconciling Archeological , Ethnographic , and Ethnohistorical Records of the Tlingit. American Anthropologist 95(3): 631-652.

2007 The Killisnoo Picnicground MIdden (49-SIT-124) revisited: assessing archaeological recovery of vertebrate vaunal remains from Northwest Coast shell middens. Journal of Northwest Anthropology 41(1): 1-17. 
2011 Northwest Coast: arcaheology as deep history. Society for American Archaeology, Washington, D.C.

2012 Understanding variability in Northwest Coast faunal assemblages: beyond economic intensification and cultural complexity. The Journal of Island and Coastal Archaeology 7(1): 1-22.

Nagaoka, Lisa 1994 Differential Recovery of Pacific Island Fish Remains: Evidence from the Moturakau Rockshelter\} Aitutaki\} Cook Islands. Asian Perspectives 33(I): 1-17.

2005a Declining foraging efficiency and moa carcass exploitation in southern New Zealand 32: 1328-1338.

2005b Differential recovery of Pacific Island fish remains. Journal of Archaeological Science 32(6): 941-955.

Neumann, Katharina 1989 Holocene vegetation of the Eastern Sahara : charcoal from prehistoric sites. The African Archaeological Review 7: 97-116.

Neyman, Jerzy

1934 On the two different aspects of the representative method : the method of stratified sampling and the method of purposive selection. Journal of the Royal Statistical Society 97(4): 558-625.

Olson, D.L.

1993 Analysis of Faunal Remains from 35MU57. In Data Recovery Excavations at Broken Tops Site (35MU57) Portland, OR, by D.V. Ellis and J.L. Fagan, Appendix G. Archaeological Investigations Northwest Report No. 31. Report prepared for Scientific Resources, INc., Lake Oswego, Oregon.

Orton, Clive 2000 Sampling in Archaeology. Cambridge University Press, New York, NY.

Partlow, Megan A

2006 Sampling fishbones: a consideration of the importance of screen size and disposal context in the North Pacific. Arctic Anthropology 43(1): 67-79.

Payne, Sebastian

1972 Partial recovery and sample bias: the results of some sieving experiments. In Papers in Economic Prehistory, edited by E.S. Higgs, pp. 49-64. Cambridge University Press, Cambridge. 
Poteate, Aaron S., and Scott M. Fitzpatrick

2013 Testing the efficacy and reliability of common zooarchaeological sampling strategies: a case study from the Caribbean. Journal of Archaeological Science 40(10): 3693-3705.

Renouf, M.A.P.

1991 Sedentary hunter-gatherers: a case for Northern Coasts. In Bands and States:

Sedentism, Subsistence, and Interaction in Small Scale Societies, edited by Susan Gregg, pp. 89-10. Southern Illinois University Press, Carbondale.

Rootenberg, S.

1964 Archaeological field sampling. American Antiquity 30(2): 181-188.

Rosenberg, Shoshana

2015 Study of Prestige and Resource Control Using Fish Remains from Cathlapotle, a Plankhouse Village on the Lower Columbia River. Portland State University, Department of Anthropology, Master of Science.

Samuels, Stephan R

1994 OZETTE ARCHAEOLOGICAL PROJECT Research Reports: Volume II Fauna.

Vol. II. Pullman.

Sanders, Howard L.

1968 Marine benthic diversity: a comparative study. The American Naturalist 102(925): 243-282.

Shaffer, Brian S

1992 Quarter-inch screening: understanding biases in recovery of vertebrate faunal remains. American Antiquity 57(1): 129-136.

Shaffer, Brian S, and Julia L J Sanchez

1994 Comparison of 1/8 " and 1/4" mesh recovery of controlled samples of small-tomedium-sized mammals. American Antiquity 59(3): 525-530.

Shennan, Stephen

1997 Probabilistic sampling in archaeology. In Quantifying Archaeology, edited by Stephen Shennan, pp. 361-400. 2nd ed. Edinburgh University Press, Edinburgh, Great Britain.

Siegmund, David 2013 Sequential analysis: tests and confidence intervals. Springer Science \& Business Media.

Simek, J.F., and L.M. Snyder 1988 Changing assemblage diversity in Periogord archaeofaunas. In Upper Pleistocene 
Prehistory of Western Eurasia, edited by H.L. Dibble and A. Montet-White, pp. 321332. University of Pennsylvania Press, Pittsburgh.

Singer, David A.

1987 Threshold of affordability: assessing fish remains for socioeconomis. In Consumer Choice in Historical Archaeology, edited by Suzanne M. Spencerwood, pp. 85. Springer Science \& Business Media.

Smith, Cameron McPherson

2006 Formation Processes of a Lower Columbia River Plankhouse Site. In Household Archaeology on the Northwest Coast. Ed. Elizabeth A. Sobel, Ann Trieu-Gahr, and Kenneth M. Ames. pp. 233-269. International Monographs in Prehistory, Ann Arbor, MI.

Sparks, B.W.

1961 The ecological interpretation of quaternary non-marine mollusca. Proceedings of the Linnean Society of London 172: 71-80.

Stahl, Peter W.

1996 The recovery and interpretation of microvertebrate bone assemblages from archaeological contexts. Journal of Archaeological Method and Theory 3(1): 31-75.

Steadman, David W.

1995 Prehistoric extinctions of Pacific Island birds: biodiversity meets zooarchaeology. Science 267(5201): 1123-1131.

Steadman, David W., and Barry Rolett 1996 A chronostratigraphic analysis of landbird extinction on Tahuata, Marquesas Islands. Journal of Archaeological Science 23(1): 81-94.

Styles, B.W.

1981 Faunal exploitation and resource selection: early late Woodland Subsistence in the Lower Illinois Valley. Northwestern University Archeological Program, Evanston.

Thomas, David H.

1969 Great Basin hunting patterns: a quantitative method for treating faunal remains. American Antiquity 34(4): 392-401.

Tipper, John C.

1979 Rarefaction and rarefiction-the use and abuse of a method in paleoecology.

Paleontological Society 5(4): 423-434.

Vale, Deborah, and Robert H. Gargett

2002 Size matters: 3-mm sieves do not increase richness in a fishbone assemblage from Arrawarra I, an Aboriginal Australian shell midden on the Mid-north Coast of New South Wales, Australia. Journal of Archaeological Science 29(1): 57-63. 
VanDerwarker, A.M.

1999 Feasting and status at the Toqua site. Southeastern Archaeology 18(1): 1-20.

Van der Veen, M., and N. Fieller

1982 Sampling Seeds. Journal of Archaeological Science 9: 287-298.

Wolda, Henk

1981 Similarity Indices, Sample Size and Diversity. Oecologia 50(3): 296-302.

Woo, Katherine, Patrick Faulkner, and Anne Ross

2015 The effects of sampling on the analysis of archeological molluscan remains: A quantitative approach. Journal of Archaeological Science: Reports: 1-11.

Yesner, David R.

1981 Archaeological applications of optimal foraging theory: harvest strategies of Aleut hunte-gatherers. In .

1987 Life in the Garden of Eden: causes and consequences of the adoption of marine diets by human societies. In Food and Evolution, edited by M. Harris and E. Ross, pp. 285-310. Temple University Press, Philadelphia.

1998 Origins and development of maritime adaptations in the northwest pacific region of north America: A zooarchaeological perspective. Arctic Anthropology 35(1): 204-222.

Zohar, Irit, and Miriam Belmaker 2005 Size does matter: Methodological comments on sieve size and species richness in fishbone assemblages. Journal of Archaeological Science 32(4): 635-641. 


\section{Appendices}

\section{Appendix A. On the Determination of Sample Sizes in Stratified Data}

Preface:

This Appendix breaks down the mathematical reasoning developed by Cochran 1977 for both Equation 1 and Equation 2 of STR. This appendix also illustrates the mathematical factoring required to link Equation 1 in Cochran 1977 to Equation 1 as illustrated in Van der Veen and Fieller 1982.

By Cameron Yee, Portland State University

Assume a random sample $X_{1}, \ldots, X_{n}$ from a population of size N. Let $X_{i}=1 \forall i=$ $1, \ldots, n$ if a set of remains belongs to a particular species. $X_{i}=0$ if a set of remains does not. Let

$$
\begin{gathered}
N_{1}=\text { total number of positive identifications } \\
N-N_{1}=\text { total number of negative identifications }
\end{gathered}
$$

Thus, we have the following definitions:

$$
\begin{aligned}
& P(\text { positive } I D)=P=\frac{N_{1}}{N}, \\
& P(\text { negative } I D)=1-P=\frac{N-N_{1}}{N}
\end{aligned}
$$

If we let $Y=\sum_{i=1}^{n} X_{i}$, then $Y$ is the total number of successes in the sample, where successes are those cases with a positive identification. This implies that

$$
P^{*}=\frac{1}{n} \sum_{i=1}^{n} X_{i}
$$

which is the proportion of positive identifications within the given sample. This also implies that

$$
Y=\sum_{i=1}^{n} X_{i} \sim \text { Hypergeometric }
$$


We are able to fix the variance in our sample to a desired level, but first we need to determine an equation for the variance.

$$
\begin{aligned}
V[Y] & =n\left(\frac{N_{1}}{N}\right)\left(\frac{N-N_{1}}{N}\right)\left(\frac{N-n}{N-1}\right) \\
V\left[p^{*}\right] & =V\left[\frac{Y}{n}\right]=\frac{1}{n^{2}} V[Y]=\frac{1}{n^{2}} n\left(\frac{N_{1}}{N}\right)\left(\frac{N-N_{1}}{N}\right)\left(\frac{N-n}{N-1}\right) \\
& =\frac{1}{n} P(1-P)\left(\frac{N-n}{N-1}\right)
\end{aligned}
$$

Fixing $V\left[p^{*}\right]=\sigma^{2}=\left(\frac{d}{Z_{\frac{\alpha}{2}}}\right)^{2}$ where $\mathrm{d}$ is some desired level of precision (rule of thumb is $5 \%$, but is determined somewhat arbitrarily by the sampler) and $Z_{\frac{\alpha}{2}}$ is the abscissa of the normal distribution at a desired significance level $\alpha$. Plugging in this fixed quantity for variance, we have

$$
\left(\frac{d}{Z_{\frac{\alpha}{2}}}\right)^{2}=\left(\frac{P Q}{n}\right)\left(\frac{N-n}{N-1}\right)
$$

In Cochran's Sampling Techniques (1977), he solves for n where

$$
n=\frac{\left(\frac{Z_{\frac{\alpha}{2}}^{2} P Q}{d^{2}}\right)}{1+\left(\frac{1}{N}\right)\left(\frac{Z_{\frac{\alpha}{2}}^{2} P Q}{d^{2}}-1\right)}
$$

Reworking this through some algebra manipulation, we get 


$$
\begin{aligned}
& n=\frac{\left(\frac{Z_{\frac{\alpha}{2}}^{2} P Q}{d^{2}}\right)}{1+\left(\frac{Z_{\frac{\alpha}{2}}^{2} P Q}{d^{2} N}-\frac{1}{N}\right)} \\
& n=\frac{\left(\frac{Z_{\frac{\alpha}{2}}^{2} P Q}{d^{2}}\right)}{\left(\frac{d^{2} N+Z_{\frac{\alpha}{2}}^{2} P Q+d^{2}}{d^{2} N}\right)} \\
& n=\frac{\frac{Z_{\frac{\alpha}{2}}^{2} P Q N}{d^{2} N+Z_{\frac{\alpha}{2}}^{2} P Q+d^{2}}}{\frac{N}{Z_{\frac{\alpha}{2}}^{2} P Q}+1-\frac{d^{2}}{Z_{\frac{\alpha}{2}}^{2} P Q}} \\
& n=\frac{N}{1+\left(\frac{N-1}{P Q}\right)\left(\frac{d}{Z_{\frac{\alpha}{2}}}\right)^{2}} \\
& n=\frac{d}{\left.Z_{\frac{\alpha}{2}}\right)^{2}\left(\frac{N}{P Q}-\frac{1}{P Q}\right)}
\end{aligned}
$$

which matches the formula from van der Veen \& Fieller 1982.

This is maximized when we take $P=0.5$, thus we can get an upper bound on total sample size. In this particular situation, we have stratification within our data. Cochran again has a theorem which states 


$$
V\left[\bar{y}_{s t}\right]=\sum_{h=1}^{L} W_{h}^{2} V\left[\bar{y}_{h}\right]
$$

$\bar{y}_{\text {st }}:$ unbiased estimate of $\bar{Y}_{h}$, the population mean

$$
\begin{gathered}
\bar{y}_{h} \text { : sample mean of the } h^{\text {th }} \text { strata } \\
W_{h}=\frac{N_{h}}{N}, h^{\text {th }} \text { stratum weight } \\
V\left[\bar{y}_{s t}\right]=\sum_{h=1}^{L}\left(\frac{N_{h}}{N}\right)^{2} V\left[\bar{y}_{h}\right], \quad V\left[\bar{y}_{h}\right]=\frac{S_{h}^{2}\left(N_{h}-n_{h}\right)}{n_{h} N_{h}} \\
V\left[\bar{y}_{s t}\right]=\frac{1}{N^{2}} \sum_{h=1}^{L}\left(\frac{N_{h}}{n_{h}}\right)\left(N_{h}-n_{h}\right) S_{h}^{2}
\end{gathered}
$$

If $n_{h} / N_{h}$ is negligible for all strata $\mathrm{h}$, then we can ignore the finite population correction.

$$
\rightarrow V\left[\bar{y}_{s t}\right]=\frac{1}{N^{2}} \sum_{h=1}^{L} \frac{N_{h}^{2} S_{h}^{2}}{n_{h}}
$$

Given that we have stratification for every level, $n_{1}+\cdots+n_{L}=n$, we can minimize the variance by using a Lagrange multiplier. We will now use the notion that we are able to in fact neglect the finite population correction, we introduce the multiplier such that

$$
L\left(n_{1}, \ldots, n_{L}, \lambda\right)=\sum_{h=1}^{L}\left(\frac{N_{h}}{N}\right)^{2}\left(\frac{S_{h}^{2}}{n_{h}}\right)+\lambda\left(\sum_{h=1}^{L} n_{h}-n\right)
$$

For every $h=1, \ldots, L$

$$
\begin{aligned}
& \frac{\partial L}{\partial n_{h}}=-\left(\frac{N_{h}^{2}}{N^{2}} S_{h}^{2}\right)\left(\frac{1}{n_{h}^{2}}\right)+\lambda \stackrel{\text { def }}{=} 0 \\
& n_{h}=\frac{\frac{N_{h}}{N} S_{h}}{\sqrt{\lambda}}, h=1, \ldots, L
\end{aligned}
$$


To determine $\lambda$, we need to sum over $\mathrm{h}$ such that

$$
\begin{aligned}
& n=\frac{1}{\sqrt{\lambda}} \sum_{h=1}^{L} \frac{N_{h}}{N} S_{h} \\
& \frac{1}{\sqrt{\lambda}}=\frac{n}{\sum_{h=1}^{L} \frac{N_{h}}{N} S_{h}}
\end{aligned}
$$

Taking the result for $1 / \sqrt{\lambda}$ and plugging it back into the equation for $n_{h}$, we get

$$
n_{h}=n\left[\frac{\frac{N_{h}}{N} S_{h}}{\sum_{h=1}^{L} \frac{N_{h}}{N} S_{h}}\right]
$$

Cochran showed that for this case (a Bernoulli Covariate), and given the following:

$$
\begin{gathered}
\bar{Y}=\frac{\sum_{i=1}^{N} y_{i}}{N}=P, \quad \sum_{i=1}^{N} y_{i}^{2}=N P \\
S^{2}=\frac{\sum_{i=1}^{N}\left(y_{i}-\bar{Y}\right)^{2}}{N-1} \\
S^{2}=\frac{\sum_{i=1}^{N} y_{i}^{2}-N \bar{Y}^{2}}{N-1} \\
S^{2}=\frac{1}{N-1}\left(N P-N P^{2}\right) \\
S^{2}=\frac{N}{N-1} P Q
\end{gathered}
$$

Hence if we apply this to our situation, each stratum will have sample variance

$$
S_{h}^{2}=\frac{N_{h}}{N_{h}-1} P_{h} Q_{h}
$$

Taking this result and using it in our result for $n_{h}$ :

$$
n_{h}=n\left[\frac{\frac{N_{h}}{N} \sqrt{\frac{N_{h}}{N_{h}-1} \sqrt{P_{h} Q_{h}}}}{\sum_{h=1}^{L} \frac{N_{h}}{N} \sqrt{\frac{N_{h}}{N_{h}-1}} \sqrt{P_{h} Q_{h}}}\right]
$$


For sufficiently large $N_{h}$, this can be approximated by:

“ $n_{h} \cong n\left[\frac{\frac{N_{h}}{N} \sqrt{P_{h} Q_{h}}}{\sum_{h=1}^{L} \frac{N_{h}}{N} \sqrt{P_{h} Q_{h}}}\right]$ 


\section{Appendix B. Description and overview of Re-screening Process}

Working in consultation with Laura Phillips, NSF project PIs have assigned new catalog numbers to all the "C" and "S" buckets of remains that were analyzed.

The main reason for this is that project PIs realized in Summer 2012 that remains within each bag were not sorted to the screen size recorded on the bag tag/in the Burke Catalog. For example, fish remains that were supposed to be from $1 / 4$ in. mesh contained much larger specimens that should have been captured in the $1 / 2$ in mesh, as well as much smaller specimens that should have fallen through to $1 / 4 \mathrm{in}$. mesh. To mitigate this second problem, and ensure comparability with other Northwest Coast faunal assemblages, as well as the other faunal classes within this site (bird, invertebrate, mammal), I rescreened all remains that were part of the STR analysis. Only "S" bucket fish that were analyzed to redundancy were re-screened.

The process for doing this: "S" bucket fish remains from a single bucket number (one 10-liter bucket sample) divided into separate bags based on screen-size were removed from their bags and screened through nested mesh screens ( 1 in., 1/2 in., 1/4 in.). I then re-bagged the newly screened material into $1 / 2$ in., $1 / 4$ in. and $<1 / 4$ in. screen size bags, and assigned new catalog numbers. Please note too: according to LAAS records, 1/4 in. mesh was the finest screen used for " $\mathrm{S}$ " buckets, but in almost all cases for fish, some remains slipped through this mesh, were retained and bags labelled $<1 / 4$ in.. After re-screening, 19 buckets no longer had remains from greater than 1/4 in. mesh and these less than 1/4 in. remains were not included in STR analysis. As part of this rescreening, I created a new catalog numbering system, for the "sub numbers", that was more logical than was previously in place. The original cataloging 
system contained a bag \# (e.g. 7689), followed by 2 sub numbers (e.g. ".02.04”) for specific screen sizes and material types. However, these sub numbers were arbitrarily assigned for each bag, so it was impossible to tell the screen size from the catalog \# without consulting the catalog database. Given these issues, project PIs developed a plan, in collaboration with Burke Museum staff, to standardize the labelling and cataloging making it much more "user-friendly" and less susceptible to coding errors.

Example: Old system: catalog number $\underline{\mathrm{WS}}-\underline{9122} . \underline{02} . \underline{02}$

New System: WS-9122.99.04.23, where

$\underline{\text { WS }}$ (=water screen), 9122 (= $\underline{\text { Bag No }}$ same as before), 99 (=rescreened), 0.04 (=mesh size, in this case 1/4" mesh), and .23 (= animal type, in this case FISH).

Standard Sub-number values used across all Faunal Analysts

$\underline{\text { screen size } \quad \text { Material type: }}$

$.01-1$ in. $\quad .10-$ shell (all marine inverts)

$.02-1 / 2$ in. $\quad .20-$ bone (when cannot determine vertebrate class, or whether shell)

$.04-1 / 4$ in. $\quad .21-$ mammal

$.99-<1 / 4$ in. $\quad .22-$ bird

$.23-$ fish

$.24-$ herp

For fish remains, in the process of rescreening and cataloging, we created an inventory for each new catalog number, which was entered into an Excel Spreadsheet, and have included that spreadsheet in each box of returned fish remains. 
As previously stated, for each set of unit/CZs, I re-screened remains from a minimum of three buckets in the sequenced random order as part of STR with the exception of those unit/CZs where there were less than three total buckets (Chapter 3). As previously also stated, I only re-screened the buckets that were included in STR. In several cases, after re-screening, there were no longer fish remains in the $>1 / 4$ in.

screens. These $<1 / 4$ in. remains were not analyzed. Because buckets were sequenced for the equation before being re-screened, there are several cases where buckets that did not retain any fish in the $>1 / 4$ in. mesh were still included in the bucket totals (Table B-1).

Table B-1. S buckets included in STR showing which buckets have analyzed $>1 / 4$ in. fish remains

*These buckets did not retain material $>1 / 4$ in. after rescreening

\begin{tabular}{|c|c|c|c|c|c|}
\hline $\begin{array}{l}\text { Bag } \\
\text { Number }\end{array}$ & Unit & & $\mathbf{C Z}$ & $\begin{array}{l}\text { Order to } \\
\text { Analyze }\end{array}$ & $\begin{array}{l}\text { Rescreened } \\
\text { to use for } \\
\text { Analysis }\end{array}$ \\
\hline 15023 & & 2 & $\mathrm{NLR}^{1}$ & Not Analyzed & No \\
\hline 15129 & & 2 & $\mathrm{NLR}^{1}$ & Not Analyzed & No \\
\hline 15473 & & 2 & $\mathrm{NLR}^{1}$ & Not Analyzed & No \\
\hline 1335 & 2 & & Chr07 & 1 & Yes \\
\hline 1248 & 2 & & Chr07 & 2 & Yes* \\
\hline 3032 & 2 & & Chr07 & 3 & Yes \\
\hline 20630 & 2 & & Chr07 & 4 & Yes \\
\hline 21166 & 2 & & Chr07 & 5 & Yes \\
\hline 5750 & 2 & & Chr07 & 6 & Yes \\
\hline 21957 & 2 & & Chr07 & 7 & Yes \\
\hline 21500 & 2 & & Chr07 & 8 & Yes \\
\hline 1458 & 2 & & Chr07 & 9 & Yes \\
\hline 1072 & 2 & & Chr07 & 10 & Yes \\
\hline 21779 & 2 & & Chr07 & 11 & Yes \\
\hline 8309 & 2 & & Chr07 & 12 & Yes \\
\hline 5302 & 2 & & Chr07 & 13 & Yes \\
\hline 22327 & 2 & & Chr07 & 14 & Yes \\
\hline 21230 & 2 & & Chr07 & 15 & Yes \\
\hline 5657 & 2 & & Chr07 & 16 & No \\
\hline 20260 & 2 & & Chr07 & 17 & No \\
\hline 4023 & 2 & & Chr07 & 18 & No \\
\hline
\end{tabular}




\begin{tabular}{|c|c|c|c|c|}
\hline 7715 & 2 & Chr07 & 19 & No \\
\hline 2370 & 2 & Chr07 & 20 & No \\
\hline 1325 & 2 & Chr07 & 21 & No \\
\hline 1016 & 2 & Chr07 & 22 & No \\
\hline 5299 & 2 & Chr07 & 23 & No \\
\hline 5166 & 2 & Chr07 & 24 & No \\
\hline 1053 & 2 & Chr07 & 25 & No \\
\hline 946 & 2 & Chr07 & 26 & No \\
\hline 1543 & 2 & Chr07 & 27 & No \\
\hline 22372 & 2 & Chr07 & 28 & No \\
\hline 21310 & 2 & Chr07 & 29 & No \\
\hline 20257 & 2 & Chr07 & 30 & No \\
\hline 20906 & 2 & Chr07 & 31 & No \\
\hline 20826 & 2 & Chr07 & 32 & No \\
\hline 10781 & 2 & Chr07 & 33 & No \\
\hline 1296 & 2 & Chr07 & 34 & No \\
\hline 21900 & 2 & Chr07 & 35 & No \\
\hline 22605 & 2 & Chr07 & 36 & No \\
\hline 20035 & 2 & Chr07 & 37 & No \\
\hline 5014 & 2 & Chr07 & 38 & No \\
\hline 1079 & 2 & Chr07 & 39 & No \\
\hline 19937 & 2 & Chr07 & 40 & No \\
\hline 21344 & 2 & Chr07 & 41 & No \\
\hline 1087 & 2 & Chr07 & 42 & No \\
\hline 5736 & 2 & Chr07 & 43 & No \\
\hline 20445 & 2 & Chr07 & 44 & No \\
\hline 1002 & 2 & Chr07 & 45 & No \\
\hline 4553 & 2 & Chr07 & 46 & No \\
\hline 2767 & 2 & Chr07 & 47 & No \\
\hline 20528 & 2 & Chr07 & 48 & No \\
\hline 8469 & 2 & Chr07 & 49 & No \\
\hline 21164 & 2 & Chr07 & 50 & No \\
\hline 21174 & 2 & Chr07 & 51 & No \\
\hline 6243 & 2 & Chr07 & 52 & No \\
\hline 836 & 2 & Chr07 & 53 & No \\
\hline 20546 & 2 & Chr07 & 54 & No \\
\hline 19936 & 2 & Chr07 & 55 & No \\
\hline 6169 & 2 & Chr07 & 56 & No \\
\hline 20388 & 2 & Chr07 & 57 & No \\
\hline 22373 & 2 & Chr07 & 58 & No \\
\hline 21375 & 2 & Chr07 & 59 & No \\
\hline 22268 & 2 & Chr07 & 60 & No \\
\hline
\end{tabular}




\begin{tabular}{|c|c|c|c|c|c|}
\hline 2637 & 2 & & Chr07 & 61 & No \\
\hline 17805 & 2 & & Chr06 & 1 & Yes* \\
\hline 845 & 2 & & Chr06 & 2 & Yes \\
\hline 1690 & 2 & & Chr06 & 3 & Yes \\
\hline 1544 & 2 & & Chr06 & 4 & Yes \\
\hline 21382 & 2 & & Chr06 & 5 & Yes \\
\hline 21595 & 2 & & Chr06 & 6 & Yes \\
\hline 5101 & 2 & & Chr06 & 7 & Yes \\
\hline 917 & 2 & & Chr06 & 8 & Yes* \\
\hline 21423 & 2 & & Chr06 & 9 & Yes \\
\hline 19673 & 2 & & Chr06 & 10 & Yes \\
\hline 6896 & 2 & & Chr06 & 11 & Yes \\
\hline 7482 & 2 & & Chr06 & 12 & Yes \\
\hline 1042 & 2 & & Chr06 & 13 & Yes \\
\hline 20449 & 2 & & Chr06 & 14 & Yes \\
\hline 7614 & 2 & & Chr06 & 15 & Yes \\
\hline 7592 & 2 & & Chr06 & 16 & Yes \\
\hline 2136 & 2 & & Chr06 & 17 & Yes \\
\hline 21647 & 2 & & Chr06 & 18 & No \\
\hline 22267 & 2 & & Chr06 & 19 & No \\
\hline 19245 & 2 & & Chr06 & 20 & No \\
\hline 1126 & 2 & & Chr06 & 21 & No \\
\hline 14005 & & 2 & Chr01 & 1 & Yes \\
\hline 11866 & & 2 & Chr01 & 2 & Yes \\
\hline 13653 & & 2 & Chr01 & 3 & Yes \\
\hline 11840 & & 2 & Chr01 & 4 & Yes \\
\hline 13346 & & 2 & Chr01 & 5 & Yes* \\
\hline 13724 & & 2 & Chr01 & 6 & Yes \\
\hline 8993 & 2 & & Chr01 & 7 & Yes \\
\hline 7441 & 2 & & Chr01 & 8 & Yes \\
\hline 14426 & & 2 & Chr01 & 9 & Yes \\
\hline 769 & 8 & & $\mathrm{NLR}^{1}$ & Not Analyzed & No \\
\hline 1114 & 8 & & $\mathrm{NLR}^{1}$ & Not Analyzed & No \\
\hline 5938 & 8 & & $\mathrm{NLR}^{1}$ & Not Analyzed & No \\
\hline 15373 & & 8 & $\mathrm{NLR}^{1}$ & Not Analyzed & No \\
\hline 15381 & & 8 & $\mathrm{NLR}^{1}$ & Not Analyzed & No \\
\hline 19170 & 8 & & $\mathrm{NLR}^{1}$ & Not Analyzed & No \\
\hline 19881 & 8 & & $\mathrm{NLR}^{1}$ & Not Analyzed & No \\
\hline 20564 & 8 & & $\mathrm{NLR}^{1}$ & Not Analyzed & No \\
\hline 21176 & 8 & & $\mathrm{NLR}^{1}$ & Not Analyzed & No \\
\hline 21569 & 8 & & $\mathrm{NLR}^{1}$ & Not Analyzed & No \\
\hline 21931 & 8 & & $\mathrm{NLR}^{1}$ & Not Analyzed & No \\
\hline
\end{tabular}




\begin{tabular}{|c|c|c|c|c|}
\hline 7931 & 8 & Chr07 & 1 & Yes \\
\hline 20589 & 8 & Chr07 & 2 & Yes \\
\hline 7688 & 8 & Chr07 & 3 & Yes \\
\hline 5490 & 8 & Chr07 & 5 & Yes \\
\hline 1106 & 8 & Chr07 & 6 & Yes \\
\hline 1519 & 8 & Chr07 & 7 & Yes \\
\hline 7814 & 8 & Chr07 & 8 & Yes \\
\hline 7690 & 8 & Chr07 & 9 & Yes \\
\hline 940 & 8 & Chr07 & 10 & Yes \\
\hline 20478 & 8 & Chr07 & 11 & Yes \\
\hline 18821 & 8 & Chr07 & 12 & Yes \\
\hline 19384 & 8 & Chr07 & 13 & Yes \\
\hline 14211 & 8 & Chr07 & 14 & Yes \\
\hline 21190 & 8 & Chr07 & 15 & Yes \\
\hline 1195 & 8 & Chr07 & 16 & No \\
\hline 1311 & 8 & Chr07 & 17 & No \\
\hline 21872 & 8 & Chr07 & 18 & No \\
\hline 19606 & 8 & Chr07 & 19 & No \\
\hline 20627 & 8 & Chr07 & 21 & No \\
\hline 21404 & 8 & Chr07 & 22 & No \\
\hline 1120 & 8 & Chr07 & 23 & No \\
\hline 20849 & 8 & Chr07 & 24 & No \\
\hline 19809 & 8 & Chr07 & 25 & No \\
\hline 9727 & 8 & Chr07 & 26 & No \\
\hline 18826 & 8 & Chr07 & 27 & No \\
\hline 19244 & 8 & Chr07 & 28 & No \\
\hline 7901 & 8 & Chr07 & 29 & No \\
\hline 4528 & 8 & Chr07 & 30 & No \\
\hline 1546 & 8 & Chr07 & 31 & No \\
\hline 1432 & 8 & Chr07 & 32 & No \\
\hline 22050 & 8 & Chr07 & 33 & No \\
\hline 1716 & 8 & Chr07 & 34 & No \\
\hline 21947 & 8 & Chr07 & 36 & No \\
\hline 7639 & 8 & Chr06 & 1 & Yes \\
\hline 7823 & 8 & Chr06 & 2 & Yes \\
\hline 20559 & 8 & Chr06 & 3 & Yes \\
\hline 1719 & 8 & Chr06 & 4 & Yes \\
\hline 21340 & 8 & Chr06 & 5 & Yes \\
\hline 7459 & 8 & Chr06 & 6 & Yes \\
\hline 21783 & 8 & Chr06 & 8 & Yes \\
\hline 1315 & 8 & Chr06 & 9 & Yes \\
\hline 22102 & 8 & Chr06 & 10 & Yes \\
\hline
\end{tabular}




\begin{tabular}{|c|c|c|c|c|c|}
\hline 8688 & 8 & & Chr06 & 11 & Yes \\
\hline 21468 & 8 & & Chr06 & 12 & Yes \\
\hline 19210 & 8 & & Chr06 & 13 & Yes \\
\hline 7579 & 8 & & Chr06 & 14 & Yes \\
\hline 20541 & 8 & & Chr06 & 15 & Yes \\
\hline 22330 & 8 & & Chr06 & 16 & Yes \\
\hline 20558 & 8 & & Chr06 & 17 & Yes \\
\hline 4562 & 8 & & Chr06 & 19 & No \\
\hline 1319 & 8 & & Chr06 & 20 & No \\
\hline 22085 & 8 & & Chr06 & 21 & No \\
\hline 1082 & 8 & & Chr06 & 22 & No \\
\hline 1243 & 8 & & Chr02 & 1 & Yes \\
\hline 19236 & 8 & & Chr02 & 2 & Yes \\
\hline 7776 & 8 & & Chr02 & 3 & Yes \\
\hline 8342 & 8 & & Chr02 & 4 & Yes \\
\hline 1767 & 8 & & Chr02 & 5 & Yes \\
\hline 21339 & 8 & & Chr01 & 1 & Yes* \\
\hline 14885 & & 8 & Chr01 & 2 & Yes \\
\hline 15354 & & 8 & Chr01 & 3 & Yes \\
\hline 16320 & & 8 & Chr01 & 4 & Yes \\
\hline 1884 & 8 & & Chr01 & 5 & Yes \\
\hline 6095 & 8 & & Chr01 & 6 & Yes \\
\hline 14272 & & 8 & Chr01 & 7 & Yes \\
\hline 6589 & 8 & & Chr01 & 8 & Yes \\
\hline 16007 & & 8 & Chr01 & 9 & Yes \\
\hline 17338 & & 8 & Chr01 & 10 & Yes \\
\hline 16271 & & 8 & Chr01 & 11 & Yes* \\
\hline 14702 & & 8 & Chr01 & 12 & Yes \\
\hline 14793 & & 8 & Chr01 & 13 & Yes \\
\hline 15986 & & 8 & Chr01 & 15 & Yes \\
\hline 13721 & & 8 & Chr01 & 17 & Yes* \\
\hline 15284 & & 8 & Chr01 & 18 & No \\
\hline 20041 & 8 & & Chr01 & 19 & No \\
\hline 15463 & & 8 & Chr01 & 20 & No \\
\hline 14477 & 17 & & $\mathrm{NLR}^{1}$ & Not Analyzed & \\
\hline 7390 & 17 & & Chr05 & 1 & Yes \\
\hline 13949 & 17 & & Chr05 & 2 & Yes \\
\hline 17599 & 17 & & Chr05 & 4 & Yes \\
\hline 8528 & 17 & & Chr05 & 5 & Yes \\
\hline 15044 & 17 & & Chr05 & 6 & Yes \\
\hline 10577 & 17 & & Chr05 & 7 & Yes \\
\hline 9335 & 17 & & Chr05 & 8 & Yes \\
\hline
\end{tabular}




\begin{tabular}{|c|c|c|c|c|c|}
\hline 7021 & 17 & Chr05 & & 9 & Yes \\
\hline 12074 & 17 & Chr05 & & 10 & Yes \\
\hline 19967 & 17 & Chr05 & & 11 & Yes* \\
\hline 13981 & 17 & Chr05 & & 13 & Yes \\
\hline 8996 & 17 & Chr05 & & 15 & Yes* \\
\hline 14294 & 17 & Chr05 & & 16 & Yes \\
\hline 10827 & 17 & Chr05 & & 18 & Yes \\
\hline 10806 & 17 & Chr05 & & 20 & Yes \\
\hline 7395 & 17 & Chr05 & & 22 & Yes \\
\hline 7019 & 17 & Chr05 & & 23 & Yes \\
\hline 7015 & 17 & Chr05 & & 24 & No \\
\hline 6834 & 17 & Chr05 & & 26 & No \\
\hline 11584 & 17 & Chr05 & & 27 & No \\
\hline 6885 & 17 & Chr05 & & 30 & No \\
\hline 10919 & 17 & Chr05 & & 32 & No \\
\hline 11606 & 17 & Chr05 & & 33 & No \\
\hline 7802 & 17 & Chr05 & & 34 & No \\
\hline 8258 & 17 & Chr05 & & 35 & No \\
\hline 11100 & 17 & Chr05 & & 36 & No \\
\hline 6528 & 17 & Chr05 & & 40 & No \\
\hline 9302 & 17 & Chr05 & & 41 & No \\
\hline 8621 & 17 & Chr05 & & 42 & No \\
\hline 9401 & 17 & Chr04 & & 3 & Yes \\
\hline 14456 & 17 & Chr04 & & 12 & Yes \\
\hline 13238 & 17 & Chr04 & & 14 & Yes \\
\hline 12788 & 17 & Chr04 & & 17 & Yes \\
\hline 15845 & 17 & Chr04 & & 19 & Yes \\
\hline 9246 & 17 & Chr04 & & 21 & Yes \\
\hline 13469 & 17 & Chr04 & & 25 & Yes \\
\hline 15330 & 17 & Chr04 & & 28 & Yes \\
\hline 16319 & 17 & Chr04 & & 29 & No \\
\hline 9753 & 17 & Chr04 & & 31 & No \\
\hline 13677 & 17 & Chr04 & & 37 & No \\
\hline 18120 & 17 & Chr04 & & 38 & No \\
\hline 9685 & 17 & Chr04 & & 39 & No \\
\hline 9162 & 17 & Chr03 & 1 & & Yes \\
\hline 13650 & 17 & Chr03 & 2 & & Yes \\
\hline 8934 & 17 & Chr03 & 3 & & Yes \\
\hline 10038 & 17 & Chr03 & 4 & & Yes \\
\hline 14701 & 17 & Chr03 & 5 & & Yes \\
\hline 15601 & 17 & Chr03 & 6 & & Yes \\
\hline 14367 & 17 & Chr03 & 7 & & Yes \\
\hline
\end{tabular}




\begin{tabular}{|c|c|c|c|c|c|}
\hline 14021 & 17 & Chr03 & 8 & & Yes \\
\hline 8438 & 18 & Chr05 & & 1 & Yes \\
\hline 14072 & 18 & Chr05 & & 2 & Yes \\
\hline 11734 & 18 & Chr05 & & 3 & Yes \\
\hline 10683 & 18 & Chr05 & & 4 & Yes \\
\hline 8814 & 18 & Chr05 & & 6 & Yes \\
\hline 7124 & 18 & Chr05 & & 7 & Yes \\
\hline 10799 & 18 & Chr05 & & 9 & Yes \\
\hline 11633 & 18 & Chr05 & & 11 & Yes \\
\hline 14354 & 18 & Chr05 & & 13 & Yes \\
\hline 8644 & 18 & Chr05 & & 14 & Yes \\
\hline 8653 & 18 & Chr05 & & 15 & Yes \\
\hline 14490 & 18 & Chr05 & & 16 & Yes \\
\hline 12211 & 18 & Chr05 & & 19 & Yes \\
\hline 7022 & 18 & Chr05 & & 20 & No \\
\hline 6462 & 18 & Chr05 & & 21 & No \\
\hline 8446 & 18 & Chr05 & & 22 & No \\
\hline 8133 & 18 & Chr05 & & 23 & No \\
\hline 18741 & 18 & Chr05 & & 24 & No \\
\hline 11337 & 18 & Chr05 & & 26 & No \\
\hline 12066 & 18 & Chr05 & & 27 & No \\
\hline 14026 & 18 & Chr05 & & 28 & No \\
\hline 6401 & 18 & Chr05 & & 29 & No \\
\hline 20718 & 18 & Chr05 & & 30 & No \\
\hline 7410 & 18 & Chr05 & & 31 & No \\
\hline 8782 & 18 & Chr05 & & 32 & No \\
\hline 9093 & 18 & Chr05 & & 33 & No \\
\hline 18475 & 18 & Chr05 & & 34 & No \\
\hline 16394 & 18 & Chr04 & & 5 & Yes \\
\hline 15203 & 18 & Chr04 & & 8 & Yes \\
\hline 15224 & 18 & Chr04 & & 10 & Yes \\
\hline 13590 & 18 & Chr04 & & 12 & Yes \\
\hline 15059 & 18 & Chr04 & & 17 & Yes \\
\hline 9212 & 18 & Chr04 & & 18 & Yes \\
\hline 9160 & 18 & Chr04 & & 25 & Yes \\
\hline 8983 & 18 & Chr03 & 1 & & Yes \\
\hline 16089 & 18 & Chr03 & 2 & & Yes \\
\hline 11300 & 18 & Chr03 & 3 & & Yes \\
\hline 10170 & 19 & $\mathrm{NLR}^{1}$ & 2 & & No \\
\hline 8471 & 19 & Chr05 & & 3 & Yes \\
\hline 8497 & 19 & Chr05 & & 5 & Yes \\
\hline 7024 & 19 & Chr05 & & 6 & Yes \\
\hline
\end{tabular}




\begin{tabular}{|c|c|c|c|c|}
\hline 13110 & 19 & Chr05 & 8 & Yes \\
\hline 11600 & 19 & Chr05 & 10 & Yes \\
\hline 12142 & 19 & Chr05 & 11 & Yes \\
\hline 12266 & 19 & Chr05 & 12 & Yes \\
\hline 8784 & 19 & Chr05 & 13 & Yes \\
\hline 9491 & 19 & Chr05 & 14 & Yes \\
\hline 10876 & 19 & Chr05 & 15 & No \\
\hline 8252 & 19 & Chr05 & 17 & No \\
\hline 8256 & 19 & Chr05 & 18 & No \\
\hline 6394 & 19 & Chr05 & 19 & No \\
\hline 8361 & 19 & Chr05 & 20 & No \\
\hline 12675 & 19 & Chr05 & 23 & No \\
\hline 14181 & 19 & Chr05 & 24 & No \\
\hline 12118 & 19 & Chr05 & 25 & No \\
\hline 8364 & 19 & Chr05 & 26 & No \\
\hline 11971 & 19 & Chr05 & 27 & No \\
\hline 8322 & 19 & Chr05 & 31 & No \\
\hline 11566 & 19 & Chr05 & 33 & No \\
\hline 10463 & 19 & Chr05 & 36 & No \\
\hline 11229 & 19 & Chr05 & 37 & No \\
\hline 13501 & 19 & Chr04 & 1 & Yes \\
\hline 10887 & 19 & Chr04 & 2 & Yes \\
\hline 13984 & 19 & Chr04 & 4 & Yes \\
\hline 14063 & 19 & Chr04 & 7 & Yes \\
\hline 16321 & 19 & Chr04 & 9 & Yes \\
\hline 10780 & 19 & Chr04 & 16 & Yes \\
\hline 13228 & 19 & Chr04 & 21 & Yes \\
\hline 12708 & 19 & Chr04 & 22 & Yes \\
\hline 9001 & 19 & Chr04 & 28 & No \\
\hline 9462 & 19 & Chr04 & 29 & No \\
\hline 11991 & 19 & Chr04 & 30 & No \\
\hline 9482 & 19 & Chr04 & 32 & No \\
\hline 18506 & 19 & Chr04 & 34 & No \\
\hline 8141 & 19 & Chr04 & 35 & No \\
\hline 15786 & 19 & Chr04 & 38 & No \\
\hline 11141 & 19 & Chr04 & 39 & No \\
\hline 14390 & 19 & Chr04 & 40 & No \\
\hline 15249 & 19 & Chr04 & 41 & No \\
\hline 8986 & 19 & Chr03 & 1 & Yes \\
\hline 13373 & 19 & Chr03 & 2 & Yes \\
\hline 10126 & 19 & Chr03 & 3 & Yes \\
\hline 15036 & 19 & Chr03 & 4 & Yes \\
\hline
\end{tabular}




\begin{tabular}{|c|c|c|c|c|c|}
\hline 11080 & 19 & Chr03 & 5 & & Yes \\
\hline 9189 & 19 & Chr03 & 6 & & Yes \\
\hline 11215 & 19 & Chr03 & 7 & & Yes \\
\hline 14802 & 19 & Chr03 & 8 & & Yes \\
\hline 15571 & 19 & Chr03 & 9 & & Yes \\
\hline 13142 & 19 & Chr03 & 10 & & Yes \\
\hline 10243 & 19 & Chr03 & 11 & & No \\
\hline 9924 & 20 & $\mathrm{NLR}^{1}$ & Not Analyzed & & No \\
\hline 10146 & 20 & $\mathrm{NLR}^{1}$ & Not Analyzed & & No \\
\hline 10455 & 20 & $\mathrm{NLR}^{1}$ & Not Analyzed & & No \\
\hline 16550 & 20 & Chr05 & & 2 & Yes \\
\hline 10291 & 20 & Chr05 & & 4 & Yes \\
\hline 15312 & 20 & Chr05 & & 5 & Yes \\
\hline 13898 & 20 & Chr05 & & 10 & Yes \\
\hline 8816 & 20 & Chr05 & & 11 & Yes \\
\hline 6981 & 20 & Chr05 & & 14 & Yes \\
\hline 8851 & 20 & Chr05 & & 15 & Yes \\
\hline 7026 & 20 & Chr05 & & 16 & Yes \\
\hline 16242 & 20 & Chr05 & & 17 & Yes \\
\hline 12135 & 20 & Chr05 & & 19 & Yes \\
\hline 10392 & 20 & Chr05 & & 21 & No \\
\hline 9404 & 20 & Chr05 & & 22 & No \\
\hline 8476 & 20 & Chr05 & & 23 & No \\
\hline 11558 & 20 & Chr05 & & 25 & No \\
\hline 8783 & 20 & Chr05 & & 27 & No \\
\hline 10351 & 20 & Chr05 & & 28 & No \\
\hline 10593 & 20 & Chr05 & & 29 & No \\
\hline 9999 & 20 & Chr05 & & 30 & No \\
\hline 9687 & 20 & Chr05 & & 31 & No \\
\hline 22630 & 20 & Chr05 & & 32 & No \\
\hline 12974 & 20 & Chr05 & & 33 & No \\
\hline 14469 & 20 & Chr05 & & 34 & No \\
\hline 8627 & 20 & Chr05 & & 36 & No \\
\hline 14070 & 20 & Chr04 & & 1 & Yes \\
\hline 10290 & 20 & Chr04 & & 3 & Yes \\
\hline 16534 & 20 & Chr04 & & 6 & Yes \\
\hline 13516 & 20 & Chr04 & & 7 & Yes \\
\hline 14335 & 20 & Chr04 & & 8 & Yes \\
\hline 18201 & 20 & Chr04 & & 9 & Yes* \\
\hline 22609 & 20 & Chr04 & & 12 & Yes \\
\hline 15890 & 20 & Chr04 & & 13 & Yes \\
\hline 11495 & 20 & Chr04 & & 18 & Yes \\
\hline
\end{tabular}




\begin{tabular}{|c|c|c|c|c|c|}
\hline 12816 & 20 & Chr04 & & 20 & No \\
\hline 13170 & 20 & Chr04 & & 24 & No \\
\hline 16156 & 20 & Chr04 & & 26 & No \\
\hline 12442 & 20 & Chr04 & & 35 & No \\
\hline 9868 & 20 & Chr03 & 1 & & Yes* \\
\hline 9991 & 20 & Chr03 & 3 & & Yes* \\
\hline 11863 & 20 & Chr03 & 4 & & Yes \\
\hline 11704 & 20 & Chr03 & 5 & & Yes \\
\hline 9628 & 20 & Chr03 & 6 & & Yes* \\
\hline 11202 & 20 & Chr03 & 7 & & Yes \\
\hline 9520 & 20 & Chr03 & 8 & & Yes \\
\hline 12633 & 20 & Chr03 & 9 & & Yes \\
\hline 12134 & 20 & Chr03 & 10 & & Yes \\
\hline 10968 & 20 & Chr03 & 11 & & No \\
\hline 8529 & 25 & $\mathrm{NLR}^{1}$ & Not Analyzed & & No \\
\hline 8857 & 25 & $\mathrm{NLR}^{1}$ & Not Analyzed & & No \\
\hline 9864 & 25 & $\mathrm{NLR}^{1}$ & Not Analyzed & & No \\
\hline 9996 & 25 & $\mathrm{NLR}^{1}$ & Not Analyzed & & No \\
\hline 13370 & 25 & $\mathrm{NLR}^{1}$ & Not Analyzed & & No \\
\hline 14073 & 25 & $\mathrm{NLR}^{1}$ & Not Analyzed & & No \\
\hline 15423 & 25 & Chr05 & 1 & & Yes \\
\hline 13247 & 25 & Chr05 & 2 & & Yes \\
\hline 8733 & 25 & Chr05 & 3 & & Yes \\
\hline 8047 & 25 & Chr05 & 4 & & Yes \\
\hline 9379 & 25 & Chr05 & 6 & & Yes \\
\hline 9787 & 25 & Chr05 & 7 & & Yes \\
\hline 13530 & 25 & Chr05 & 8 & & Yes \\
\hline 11381 & 25 & Chr05 & 9 & & No \\
\hline 15014 & 25 & Chr04 & 1 & & Yes* \\
\hline 14483 & 25 & Chr04 & 3 & & Yes* \\
\hline 10975 & 25 & Chr04 & 4 & & Yes \\
\hline 8613 & 25 & Chr04 & 5 & & Yes \\
\hline 8519 & 25 & Chr04 & 6 & & Yes \\
\hline 8626 & 25 & Chr04 & 7 & & Yes \\
\hline 14750 & 25 & Chr04 & 8 & & Yes \\
\hline 15693 & 25 & Chr04 & 9 & & Yes \\
\hline 20696 & 25 & Chr04 & 10 & & Yes* \\
\hline 8754 & 25 & Chr04 & 11 & & Yes \\
\hline 10349 & 25 & Chr04 & 12 & & No \\
\hline 8633 & 25 & Chr04 & 13 & & No \\
\hline 15780 & 25 & Chr04 & 14 & & No \\
\hline 9820 & 25 & Chr03 & 1 & & Yes \\
\hline
\end{tabular}




\begin{tabular}{|c|c|c|c|c|}
\hline 9188 & 25 & Chr03 & 2 & Yes* \\
\hline 9563 & 25 & Chr03 & 3 & Yes \\
\hline 22572 & 25 & Chr03 & 4 & Yes \\
\hline 13234 & 31 & Chr05 & 1 & Yes \\
\hline 9770 & 31 & Chr05 & 2 & Yes \\
\hline 14899 & 31 & Chr05 & 3 & Yes \\
\hline 10465 & 31 & Chr05 & 4 & Yes \\
\hline 10216 & 31 & Chr05 & 6 & Yes \\
\hline 17860 & 31 & Chr05 & 7 & Yes \\
\hline 13723 & 31 & Chr05 & 8 & No \\
\hline 11522 & 31 & Chr05 & 9 & No \\
\hline 16224 & 31 & Chr05 & 10 & No \\
\hline 9168 & 31 & Chr04 & 1 & Yes \\
\hline 15418 & 31 & Chr04 & 2 & Yes \\
\hline 11481 & 31 & Chr04 & 3 & Yes \\
\hline 14713 & 31 & Chr04 & 4 & Yes* \\
\hline 9818 & 31 & Chr04 & 5 & Yes \\
\hline 13904 & 31 & Chr04 & 6 & Yes \\
\hline 10015 & 31 & Chr04 & 7 & Yes \\
\hline 9798 & 31 & Chr04 & 8 & Yes \\
\hline 16194 & 31 & Chr04 & 9 & Yes \\
\hline 14727 & 31 & Chr04 & 10 & Yes \\
\hline 9679 & 31 & Chr04 & 11 & Yes \\
\hline 14974 & 31 & Chr04 & 12 & Yes \\
\hline 12304 & 31 & Chr04 & 13 & Yes \\
\hline 13944 & 31 & Chr04 & 14 & Yes \\
\hline 9559 & 31 & Chr04 & 15 & Yes \\
\hline 13787 & 31 & Chr04 & 16 & No \\
\hline 9565 & 31 & Chr04 & 17 & No \\
\hline 15965 & 31 & Chr04 & 18 & No \\
\hline 10754 & 31 & Chr03 & 1 & Yes \\
\hline 11442 & 31 & Chr02 & 1 & Yes \\
\hline 8552 & 31 & Chr02 & 2 & Yes \\
\hline 13232 & 31 & Chr02 & 3 & Yes* \\
\hline 14393 & 31 & Chr02 & 4 & Yes \\
\hline 9879 & 31 & Chr02 & 5 & Yes* \\
\hline 15527 & 31 & Chr02 & 6 & Yes \\
\hline 8931 & 31 & Chr02 & 7 & Yes \\
\hline 17136 & 31 & Chr02 & 8 & Yes \\
\hline 9666 & 31 & Chr02 & 9 & Yes \\
\hline 15745 & 31 & Chr02 & 10 & Yes \\
\hline 9241 & 31 & Chr02 & 11 & Yes \\
\hline
\end{tabular}




\begin{tabular}{lllll}
\hline 15486 & 31 & Chr02 & 12 & Yes \\
14612 & 31 & Chr02 & 14 & Yes \\
11738 & 31 & Chr02 & 15 & Yes \\
\hline
\end{tabular}

${ }^{1}$ Some buckets were not given $\mathrm{CZs}$ either because an excavation record with their provenience could not be found. In such cases, buckets were instead given a designation of No Level Record (NLR). 


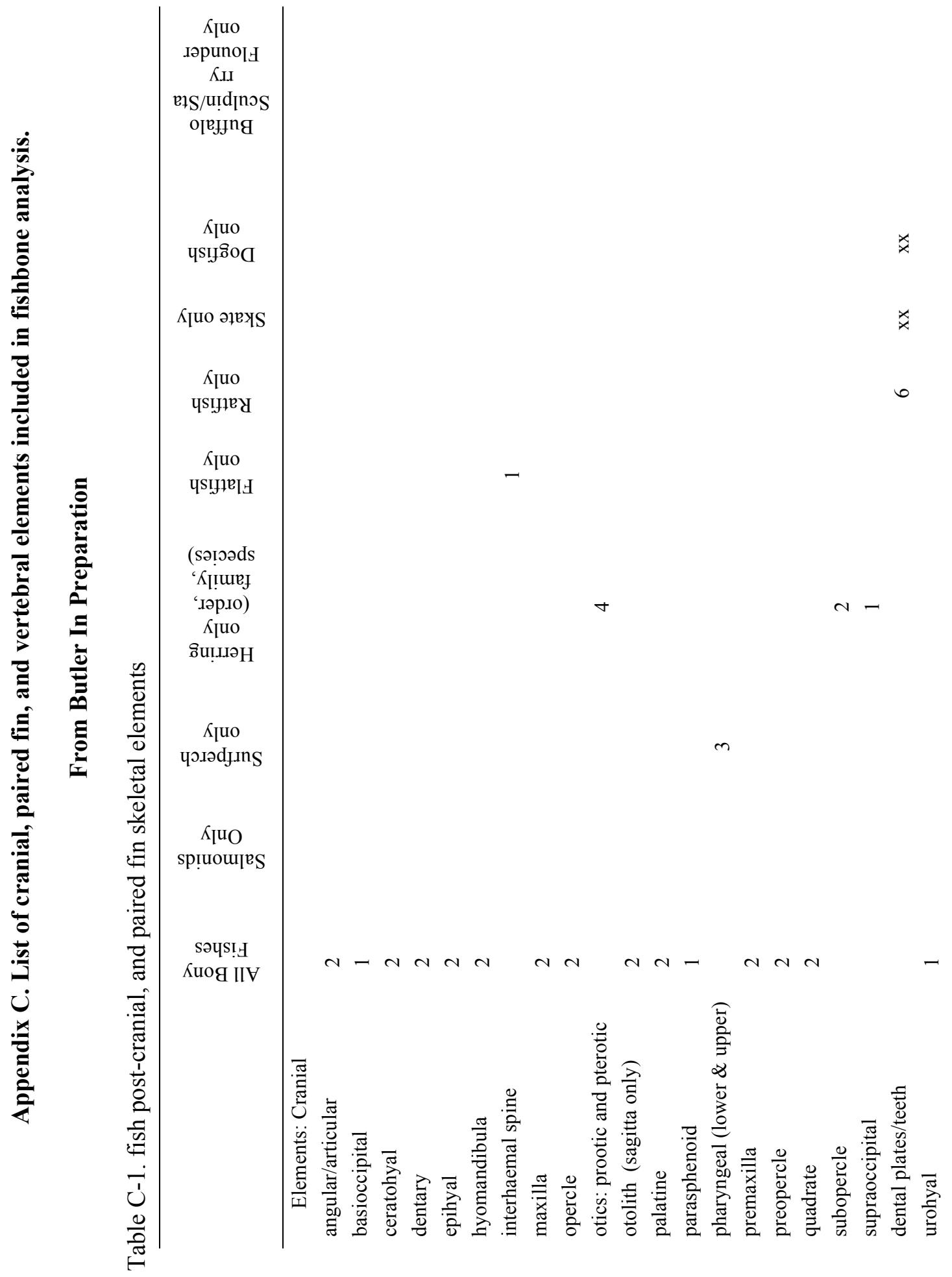




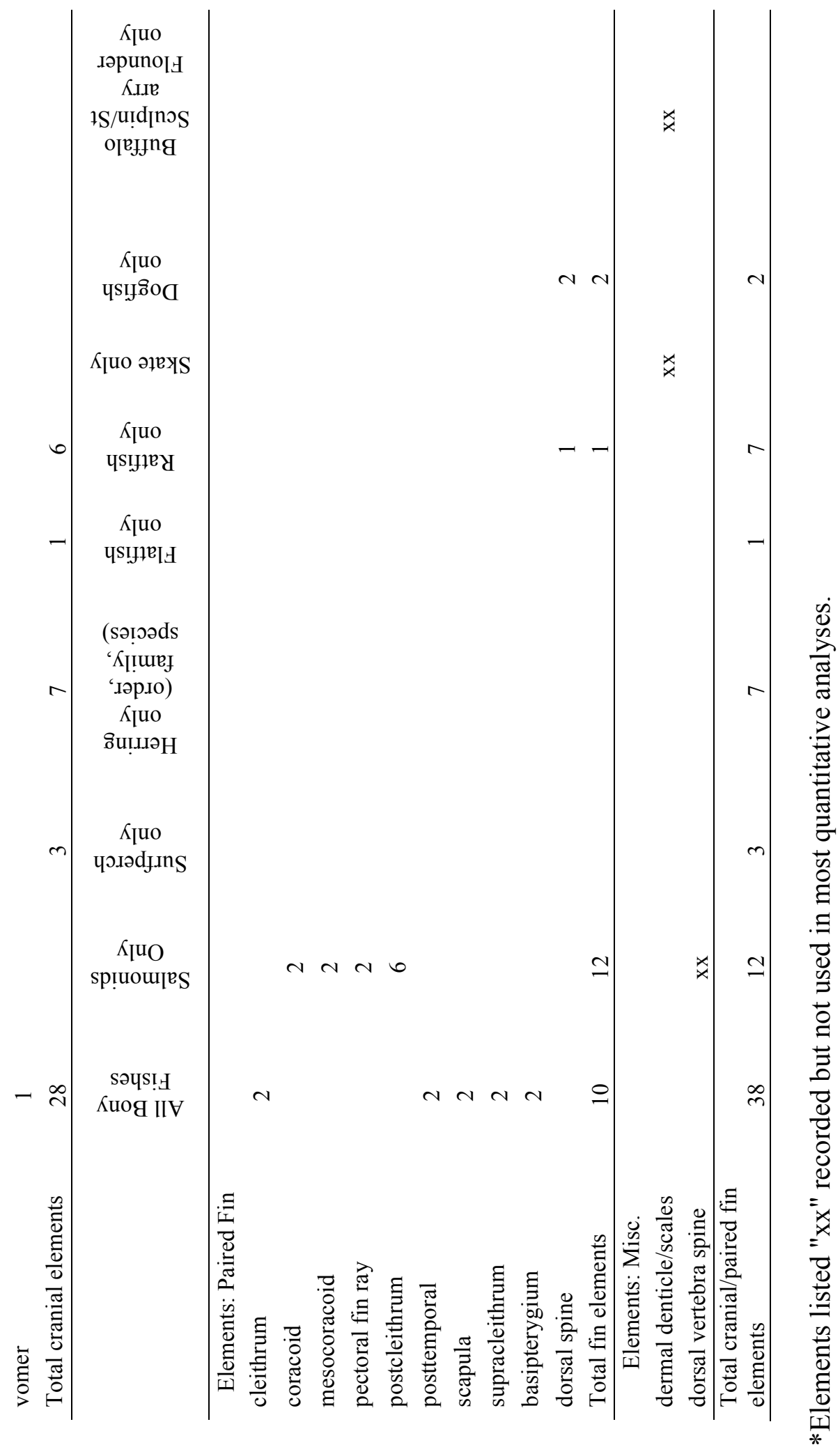




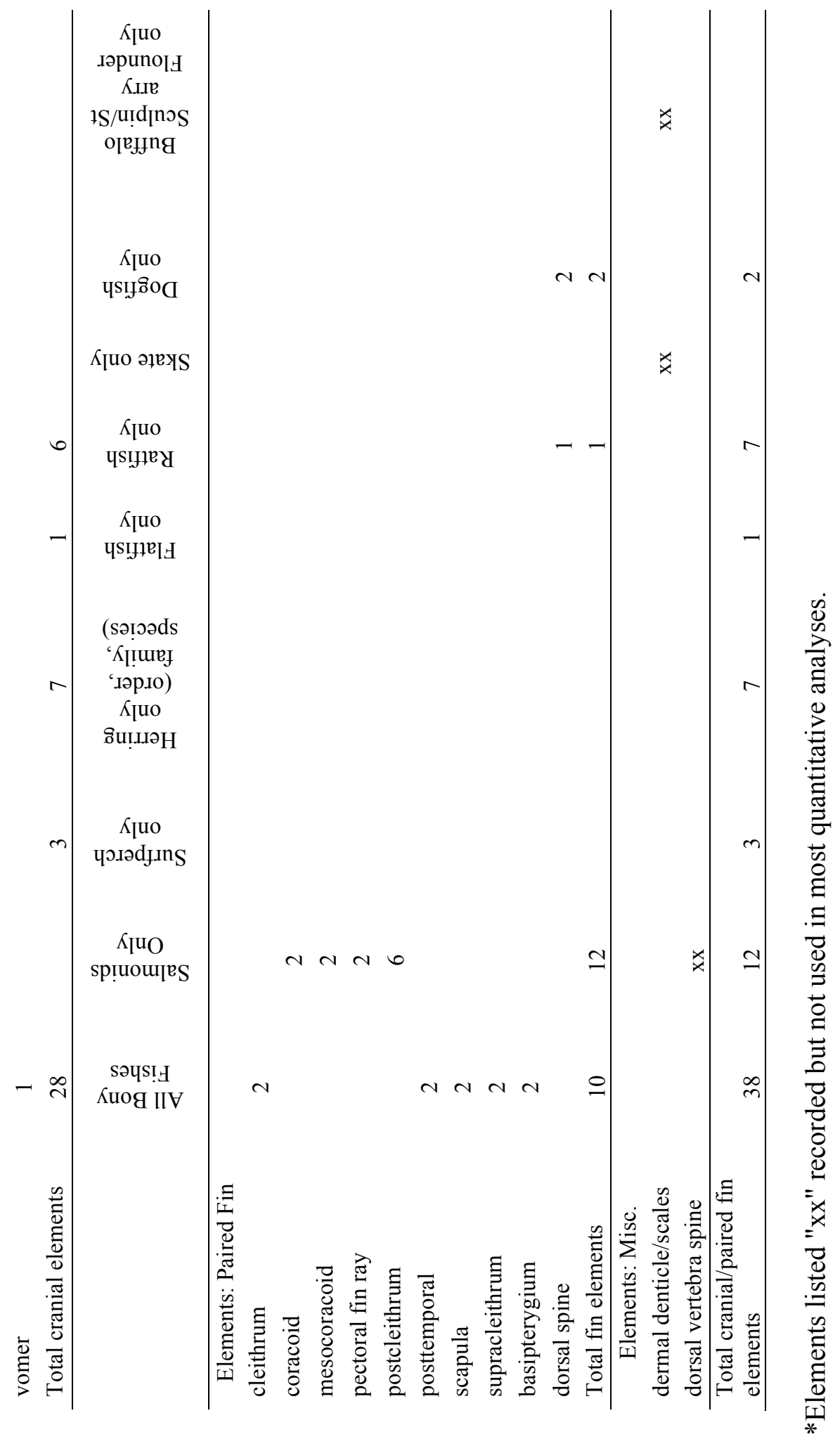


Table C-2. Number of vertebrae recorded by taxon

\begin{tabular}{lr}
\hline \multicolumn{1}{c}{ Taxon } & N Vertebrae* \\
\hline Anoplopomatidae & 55.3 \\
Clupeidae & 48.3 \\
Cottidae & 24.7 \\
$\quad$ Enophyrs bison & 21 \\
$\quad$ Hemilepidotus sp. & 21 \\
$\quad$ Hemilepidotus/Scorpaenicthys & 23.5 \\
Leptocottus armatus & 28 \\
Myoxocephalus polyacanthocephalus & 27 \\
Embiotocidae & 24.5 \\
Gadus macrocephalus & 42 \\
Microgadus proximus & 45.5 \\
Hexagrammidae & 43 \\
Hexagrammos sp. & 43 \\
Ophiodon elongatus & 43 \\
Oncorhynchus sp. & 66.3 \\
Pleuronectiformes & 26.6 \\
Sebastes sp. & 18.7 \\
Raja sp. & 86 \\
Squalus acanthias & \\
\hline
\end{tabular}

*Obtained from averaging multiple skeletons. Note the most posterior vertebrae on most bony fishes were not identified beyond fish, so $\mathrm{N}$ vertebrae is what was tallied and recorded for a given taxon, not the number of vertebrae on a given taxon. 